\title{
DETECTING SUBTLE VARIATION IN TWO CRYPTIC PRIMATE FAMILIES (TARSIIDAE \& LORISIDAE) THROUGH MORPHOLOGY AND GENETICS
}

\author{
A Dissertation \\ presented to \\ the Faculty of the Graduate School \\ at the University of Missouri-Columbia \\ In Partial Fulfillment \\ of the Requirements for the Degree \\ Doctor of Philosophy \\ by \\ RACHEL A. MUNDS \\ Dr. Gregory E. Blomquist, Dissertation Supervisor \\ JULY 2018
}


The undersigned, appointed by the dean of the College of Arts and Sciences, have examined the dissertation entitled

DETECTING SUBTLE VARIATION IN TWO CRYPTIC PRIMATE FAMILIES (TARSIIDAE \& LORISIDAE) THROUGH MORPHOLOGY AND GENETICS

presented by Rachel A. Munds

a candidate for the degree of doctor of philosophy, and hereby certify that, in their opinion, it is worthy of acceptance.

Associate Professor Gregory E. Blomquist

Associate Professor Libby W. Cowgill

Professor Lisa Sattenspiel

Associate Professor Lori S. Eggert 


\section{ACKNOWLEDGMENTS}

I have this dreaded fear I will forget someone in my acknowledgements. I prefer to sum them up with the Beatles lyric "Oh, I get by with a little help from my friends...Mm, gonna try with a little help from my friends.” So, let's get started.

Dr. Gregory Blomquist has been the perfect PhD advisor for me. He knew when I needed a push or understood when I just needed a break. He always steered me in the right direction with my research ideas, writing, or education. His patience is never ending, especially when it comes to helping me understand statistics or more specifically allometry. I am grateful he gave me a chance. I'm also glad he was down to joining his other student, Monica, and I for drinks and to unwind and talk about life. I have learned more from him then I thought possible.

Dr. Lori Eggert opened her lab to me and even hired me to teach an ecology lab under her guidance. She trusted and provided me with numerous opportunities, from general wet lab experience, to even trying my hands at ancient DNA analyses (which was a nightmare). She always takes the time to listen, even when she is almost always busy. She makes you feel important. She treats you like a colleague.

Thank you to Dr. Libby Cowgill for reading over my manuscript, making me think a bit more about skin variation, and for providing excellent seminars. Also, for keeping this process a bit less stressful. Your calmness makes this process seem a little less scary. Thank you, Dr. Lisa Sattenspiel. You weren't part of my committee for long, but I am so happy you filled the gap at the last minute. You have provided excellent advice to improve the manuscript and truly helped me out in a pinch. 
There were numerous American Zoological Association institutions that have provided tissue samples and photographs and support during this research. Dr. Helena Fitch-Snyder provided so much wisdom and advice and knowledge about the captive Lorisidae populations. Several museums granted permission for me to conduct research, and that helped this project immensely. Dr. Myron Shekelle provided his expertise and data on tarsiers. Also, the late Dr. Colin Groves helped out so much with his support, data, and knowledge of tarsiers, and I am grateful.

Monica Keith, thank you for setting aside your prejudice against me (as I did with you too) and realizing I make awful first impressions. You are an amazing advice giver, supporter, critic, and friend. I'm glad you were my one and only lab mate. Colleen Young provided pearls of wisdom with a sparkle of fun. Matthew Boulanger gave me snarky wisdom with a touch of big-brotherly advice when I needed it. Chelsea Titus, I feel like this dissertation is half yours. You put in so much time, work, patience, and drive into it. And in it all, you are a true friend who provided not only support for my dissertation, but also support for my life. There are so many other people I want to list, but to list them all would consume this whole dissertation. So, thank you to all the friends and colleagues I met while at Mizzou. You are all inspirations to me.

My parents never doubted my dreams. They might have questioned what I was doing, but they never said "don't". I am truly lucky to have them. Their love of nature and the outdoors and their constant support created this little primatologist.

Wren. She's my dog. My companion. The perfect distraction on a stressful day. The one who made me run when I needed to clear my head. She can't read, but she knows I thank her. 


\section{TABLE OF CONTENTS}

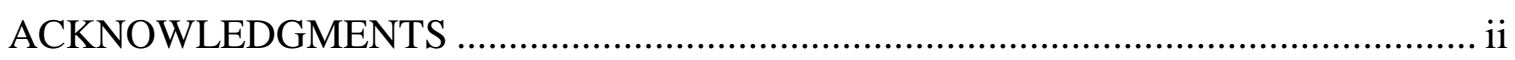

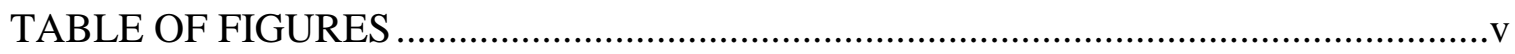

TABLE OF TABLES …................................................................................... vi

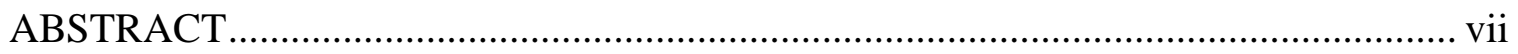

Chapters

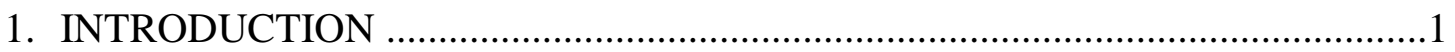

LITERATURE CITED …................................................................ 11

2. MULTIVARIATE CRANIODENTAL ALLOMETRY OF TARSIERS..............19

LITERATURE CITED ......................................................................48

3. USING A MULTI-GENE APPROACH TO INFER THE COMPLICATED HISTORY OF LORISES (ORDER PRIAMTES: FAMILY LORISIDAE)......55

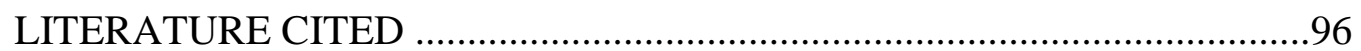

4. MOLECULAR EVOLUTION OF THE MELANOCORTIN 1 RECEPTOR (MC1R) IN LORISES (ORDER PRIMATES: FAMILY LORISDAE)...........105

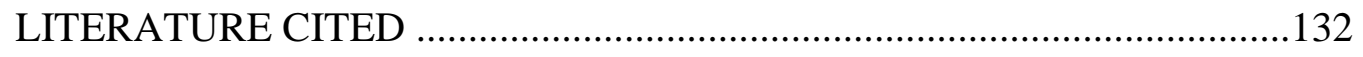

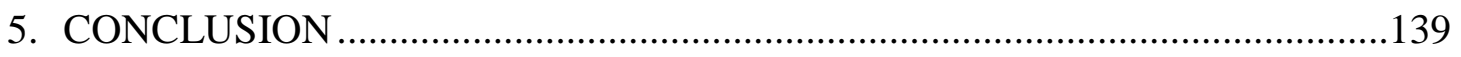

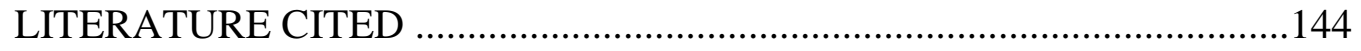

APPENDIX 1: SUPPLEMENTAL FIGURES FOR CHAPTER 3 ..............................147

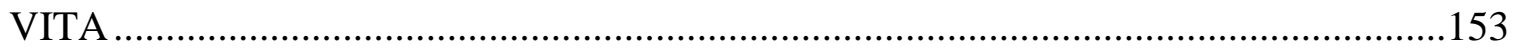




\section{TABLE OF FIGURES}

\section{Chapter 2 Figures}

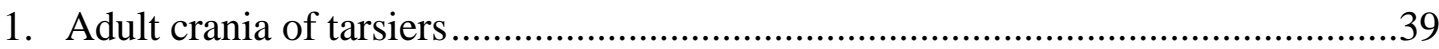

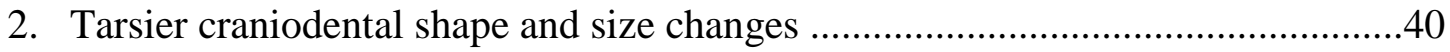

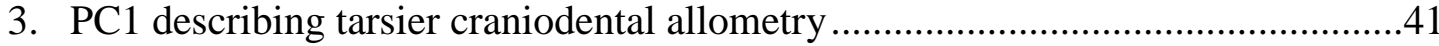

4. Scores of tarsier groups of the first two CPC of cranial measurements .................42

5. Effects of sizes and confidence intervals between Tarsius \& Cephalopachus......43

6. Unrooted neighbor joining tree \& hierarchical clustering of Euclidean distance matrix of tarsier craniodental measurements

\section{Chapter 2 Figures}

1. Proposed loris phylogenies .86

2. Monophyletic Lorisidae phylogeny from concatenated genes .............................87

3. Lorisidae phylogenies from Rag2 \& cytochrome $b$ with Arctocebus ....................88

4. Lorisidae phylogenies from Mc1r, COI, mtDNA, Rag2 .................................89

5. Coalescent-based species tree

\section{Chapter 3 Figures}

1. Coat colors and patterns of examined Lorisidae.

2. Bayesian combined cytochrome $b$ and Rag 2 tree, and Mc1r.

3. Phylogenetic tree of Lorisidae with Mc1r nonsynonymous mutations mapped on the branches 


\section{TABLE OF TABLES}

\section{Chapter 2 Tables}

1. Trait variations defining the tarsier groups

2. Sample size, means, minima, maximia of tarsier craniodental measurements ......46

3. K-means cluster analysis of tarsier craniodental measurements...........................47

\section{Chapter 3 Tables}

1. Loris samples acquired from AZA institutions.

2. GenBank sequences incorporated within this study

3. Primer sequences from this study

4. Node support, divergence times, HPD, and branch lengths from all analyses ......94

\section{Chapter 4 Tables}

1. Primer sequences for this study

2. Nonsynonymous substitutions detected in Lorisidae. 


\begin{abstract}
Cryptic species look morphologically similar but in fact are several different species lumped together. This is problematic as it hinders conservation efforts and makes it challenging to infer the evolutionary history of an organism. This dissertation research aims to improve our understanding of the evolution and variation of cryptic, nocturnal primates. Over $60 \%$ of primates are threatened with extinction, and many nocturnal species are poorly understood. Research aimed at elucidating species will help conserve them. To do so, I examined the multivariate craniodental allometry of the three genera of tarsiers. Tarsiers are small-bodied, nocturnal primates that have evolved to extremecarnivorous niche. In order to see better at night their eyes have increased dramatically in size. Such evolution has led to minimal cranial variation among the three groups, despite millions of years of separation. Yet, two distinct groups were found through allometric analyses. Genetics is another tool that can discern the evolution and variation of cryptic species. The slow moving lorises of Asia and Africa appear morphologically similar, making it a challenge to determine their evolutionary history or variation. By using a multi-gene approach, I was able to determine the family is monophyletic with four distinct genera. Furthermore, analyses of a candidate gene that impacts coat color variation, found that the darker colored African genus has more mutations along its branch that result in amino acid changes than the vibrantly colored lorises in Asia. Such a result suggests that a transition to or a maintenance of a darker phenotype is conserved or that other genes besides this one candidate gene influence coat variation. Overall, I was able to find that through a variety of methods, it is possible to detect variation and the evolutionary history of cryptic species.
\end{abstract}




\section{CHAPTER 1: INTRODUCTION}

The term "species diversity" triggers images of vibrantly colored butterflies, birds, and other organisms, or size or shape variation among species--essentially, we imagine organisms that are detectably different based on their phenotype. Historically, and even today, taxonomists and biological researchers rely on phenotypic differences to discern species (Mayr, 1977; Rose and Bown, 1993; Kimbel and Martin, 2013; Zachos, 2016). Although many species are recognizable by phenotypic differences, others are difficult to discern based on phenotype alone. These cryptic species, those that often are indistinguishable from one another, are often treated as one taxonomic unit when in fact they are two or more species misidentified as one (Baker, 1984; Bickford et al., 2007; Pfenninger and Schwenk, 2007; Dennis and Hellberg, 2010; Piggott et al., 2011; Munds et al., 2012; Mongkolsamrit et al., 2018). These species often look alike, behave similarly, may be sympatric, but they are different in other aspects that are not readily detectable such as variation in vocalization, or pheromones (Bickford et al., 2007). This is problematic as species misidentifications can have a major impact on research, as these units are used to set-up more in-depth studies of evolution and conservation: what we define as a species influences our research. Our understanding and ability to detect variation among cryptic species has improved with the use of molecular genetics, as well as various methods to interpret subtle phenotypic differences, which has led to an increase in the number of studies on them (Baker, 1984; Jones, 1997; Bearder, 1999; Glaw and Vences, 2002; Bickford et al., 2007; Munds et al., 2012). Even though there has been an increase of studies, populations of cryptic species are still poorly studied, in 
particular those that are nocturnal. Studies are lacking because nocturnal work is challenging and heavily reliant on equipment such as headlamps and radio-tracking and requires the researcher to adapt to a nocturnal life (Sterling and Radespiel, 2000). Even with better headlamps, longer-lasting batteries, and other advancements, we still have a limited understanding of nocturnal species, particularly nocturnal primates.

Non-human primates are some of the most well-studied organisms, as they are some of the few mammals with field studies that have extended beyond 50 years (Watanabe, 2008; Kappeler and Watts, 2012; Nakamura et al., 2015). Initially, the extensive body of literature on non-human primates grew out of a fascination in understanding human origins, but gradually this research has expanded to better understand the behavioral ecology, mating behaviors, diversity, and conservation of primates without an emphasis on understanding humans (Deag, 1987; McGrew, 2007; Campbell, 2011; Sussman and Hart, 2015). Yet, even though primates are well-studied, there is a clear division between the number of studies done on diurnal species versus nocturnal species, with far more studies focused on the diurnal species. Furthermore, studies on haplorhines (tarsiers, monkeys, \& apes) far exceed the number of studies done on strepsirhines (lemurs \& lorises). We have an excellent understanding of primates that are more closely related to us, but as we move away from humans our understanding diminishes; we lack research on species at the root of our evolutionary tree (Yoder, 1997; Martin, 2003; Nekaris and Nijman, 2007; Strier, 2011). The purpose of this dissertation is to provide a better understanding of cryptic, nocturnal primates, and their evolutionary history through the use of genetics and morphological analysis. 


\section{Tarsiidae: extreme adaptations lead to limited variation}

Tarsiers (family: Tarsiidae) are small-bodied, insular primates found on Borneo, Sumatra, Sulawesi, the Philippines and a few surrounding islands (Gursky, 2007; (Groves and Shekelle, 2010). All twelve species share common morphological features, such as incredibly large eyes, elongated tarsal bones, a primarily brown coat, and naked ears. They also are similar in their behavioral ecology throughout their ranges as all are faunivorous, consuming only things they kill, and using ultrasonic vocalization (Crompton and Andau, 1987; Wirdateti, 2008; Merker et al., 2010; Rosenberger, 2010; Gursky, 2015). Unlike many other nocturnal species, tarsiers lack a tapetum lucidum, a reflective eye layer that improves vision at night. Instead, to improve their night vision, tarsiers have enormous eyes, so large that they are incapable of moving them in their orbits and must move their head in order to see. Their preferred locomotion, verticalclinging and leaping also has resulted in a unique evolution of an elongated tarsal bone, which gives them an extra-spring board for their up to 3-meter leaps. The eye size and their high-speed, far distance leaps led to all tarsier skulls being highly modified, as the skull must be carefully balanced on their frame. Such constraints on their cranial morphology has led to minimal variation detected among the twelve species (Rosenberger, 2010; Rosenberger and Preuschoft, 2012). Even so, some researchers have noted a size gradient among the island groups. Musser and Dagosto (1987) proposed there could be two possible genera made up of the small Sulawesi species, and the other larger Bornean and Philippine species. Groves \& Shekelle (2010) elaborated upon this and further divided the groups as they found distinction for three genera made up of small- (Sulawesi), medium- (Philippine) and large-bodied (Borneo) tarsier groups. 
The proposed evolutionary history of Tarsiidae does not assist in aiding in understanding the taxonomic level variations of these primates, because extant and extinct tarsiers are remarkably similar. Extant and extinct tarsiers seem to share dental morphology and enlarged orbits that make it difficult to distinguish them. It appears tarsiers had evolved their large orbits and dental traits $\sim 45$ million years ago (mya), and since that time have retained these features among all the species and genera, which suggests a form of stabilizing selection (Rossie et al., 2006; Chaimanee et al., 2010; Rosenberger, 2011). The evolution to such unique adaptations and a specialized niche has resulted in minimal variation observed between modern tarsiers and their extinct relatives, or differences observed among the species. But molecular studies have assisted in demonstrating that Bornean and Philippine tarsiers are more closely related to each other than to the Sulawesi species (Brown et al., 2014; Merker et al., 2014). The divergence between the Bornean and Philippine species is dated to 10mya, whereas Sulawesi species are estimated to about 2.5mya. It is estimated the last common ancestor of crown tarsiers arose 22mya (Merker et al., 2010; Brown et al., 2014; Driller et al., 2015). These ancient dates indicate there was ample time for these island populations of tarsiers to diversify further, but from all current observations, very little variation has been noted. We tested for allometric (size and shape) differences among the three tarsier groups and hypothesized that among the groups there will be a detectable size gradient. Specifically, we expect to see tarsiers increasing in size from the small Sulwesi to the large Bornean group, but that any shape differences among the group is because of the size differences (allometric). 


\section{Lorisidae: evolution \& diversity}

The family Lorisidae is defined by quadrupedal, omnivorous, socially-solitary primates that are found in Africa and Asia. There are four commonly accepted genera (Arctocebus, Loris, Nycticebus, and Perodicticus) with over 15 species and subspecies (Nekaris \& Bearder, 2007; Munds et al., 2013; Pozzi et al., 2015). The Lorisidae family is separated into two subfamilies based on geographic origin: the African Perodictinae and the Asian Lorisinae.

Our understanding of Lorisidae phylogeny is mainly based on phenotypic and geographic distinctions. The majority of species were recognized by morphological analyses, whether from skeletal differences (Groves, 1998; Ravosa, 1998), or coat color and patterns (Stump, 2005; Nekaris \& Jaffe, 2007). These phenotype studies have yielded valuable results and improved our understanding of Lorisidae, but the findings are not conclusive. Some propose Lorisidae is monophyletic (all descended from a common ancestor) with two subfamilies (the African Perodictinae \& the Asian Lorisinae) and Galagidae as a sister taxon (Roos et al., 2004; Harrison, 2010). Historically, this was based on skeletal analyses and geographic differences. Still others suggest they are diphyletic (deriving from two separate ancestral lines) or paraphyletic (a form of grouping that excludes some of the taxonomic members). These findings suggest there is an African loris-Galagidae group with an independent Asian loris group, or vice versa (Yoder et al., 2001; Seiffert et al., 2003; Roos et al., 2004; Masters et al., 2005, 2007). Finally, some results suggest all three primates groups (African lorises, Asian lorises, and Galagidae) are equally related to each other (Pozzi et al., 2015). Within Lorisidae this is further complicated, as it is unclear how genera are related to each other. The most 
commonly accepted topology has the genera within the subfamilies (Perodictinae: Arctocebus, Perodicticus \& Lorisinae: Loris, Nycticebus) to be more closely related to each other than to the genera in the other subfamilies (Rasmussen and Nekaris, 1998; Pozzi et al., 2015). Yet, others have argued, based on morphology, that the robust Perodicticus and Nycticebus are more closely related to each other, and the gracile Arctocebus and Loris are more closely related (Schwartz \& Tattersall, 1985). There are several other topologies that have been proposed, which emphasizes how little we know and understand about the Lorisidae.

Molecular research has improved our understanding of Lorisidae phylogeny. Some of these studies support an African and Asian grouping of Lorisidae (Perelman et al., 2011; Pozzi et al., 2015), whereas others have an unresolved trichotomy between Asian \& African lorises and Galagidae (Masters et al., 2005; Pozzi et al., 2015), or other topologies (Petter and Petter-Rousseaux, 1979; Schwartz and Tattersall, 1985). Although these studies are useful, many inconsistencies remain. Part of the problem is that many of these studies rely on one gene, only use mitochondrial genes, or sample few Lorisidae species as part of comprehensive primate phylogenetics (Roos et al., 2004; Masters et al., 2005; Perelman et al., 2011; Pozzi et al., 2015). Research is needed that incorporates all genera of Lorisidae and uses multi-gene approach to provide a more robust phylogeny.

Much like the phylogeny of Lorisidae, their diversity is mainly based on phenotypes. In Africa are the less speciose Perodictinae: Arctocebus (angwantibo) and Perodicticus (potto). There are two species of Arctocebus (A. calabarensis and A. aureus). The angwantibo has a limited range of habitat in western equatorial Africa, and lacks recent detailed studies (IUCN, 2016). Conversely, the potto has a much larger 
habitat range throughout western and central Africa, but it also lacks detailed studies (IUCN, 2016). There are three species of pottos (P. potto, P. edwardsi, and $P$. ibeanus), with possible subspecies delineations within the species. Recognition of species within both these genera (Arctocebus and Perodicticus) are based on subtle morphological differences (i.e. tail length, pelage color, and size), and known geographic regions of isolation (Stump, 2005; Nekaris \& Bearder, 2007). Both these genera are poorly studied in the wild, captivity, and in museums.

The Asian Lorisinae has received more research attention, which may explain why there are more recognized species. Like Perodictinae, Lorisinae are composed of two distinct genera: Loris (slender loris) and Nycticebus (slow lorises) (Groves, 1998; Nekaris \& Bearder, 2007). Yet, studies suggest that there could be more than two genera, with N. pygmaeus being its own genus (c.f. Pozzi et al., 2015). The slender lorises (Loris spp.) are found in southern India and Sri Lanka. There are two species and six subspecies. The red slender loris (Loris tardigradus) is found only in Sri Lanka. It has two subspecies that are separated by size and geographic differences (L.t. tardigradus and L.t. nycticeboides). The gray slender loris (Loris lydekkerianus) is found in parts of southern India and northern Sri Lanka. There are four subspecies recognized by differences in coat variation, size, and geographic ranges (L.l. lydekkarianus, L.l. grandis, L.l. malabaricus, and L.l. noridcus) (Groves, 1998; Nekaris and Jayewardene, 2004; Nekaris, 2006). Slow lorises (Nycticebus spp) have an extensive range throughout South and Southeast Asia. They are found from Northern India through Indochina, and as far south as Java. They inhabit mainland Asia, and many islands in Southeast Asia. There are currently eight recognized species ( $N$. bancanus, $N$.bengalensis, $N$. borneanus, $N$. 
coucang, $N$. javanicus, $N$. kayan, $N$. menagensis, and N.pygmaeus) (Nekaris and Nijman, 2007); Munds et al., 2013). Like all Lorisidae, slow loris species are separated based on morphology; mainly coat color and patterns.

Most Lorisidae species have been demecarted based on their coat color and pattern differences. As taxonomic markers coat colors are useful in describing species, but do they correspond to evolutionary differences? To test for this candidate gene approaches are useful, as they allow one to focus on just the evolution of one gene that is associated with a specific phenotype (Hoekstra and Nachman, 2003; Hoekstra et al., 2004). The melanocortin 1 receptor (Mc1r) has been identified as a gene responsible for coat and skin color differences in a variety of organisms. Specifically, Mc1r is responsible for the production of two pigments: eumelanin (brown \& black) and pheomelanin (yellow \& red) (Barsh, 1996; Hoekstra and Nachman, 2003). Past studies have found this gene to be impacted by selection, and some studies have been able to trace its evolution onto an organism's phylogeny. For instance, studies on Mc1r variation in humans have led to a better understanding of how skin and hair color are correlated to evolutionary events in humans, such as going to areas away from intense UV radiations (Healy, 2001; Sulem et al., 2007). Yet, what impacts pigment variation in humans may not be the same in other organisms. Studies on rock pocket mice show that the phenotype of these mice are under natural selection, as different coat colors help the mice blend with the environment. Examination of the Mc1r of these mice found sequence variation corresponded to the two different morphs (Hoekstra and Nachman, 2003; Hoekstra et al., 2004). Overall, studies on humans and other organisms have found Mc1r amino acid changes are indicative of phenotypic within and between lineages. 


\section{Dissertation layout}

This dissertation focuses on detecting the subtle variation and inferring the evolutionary history of cryptic primates. In chapter 2 , I examined the multivariate craniodental allometry of Tarsiidae. Static and evolutionary allometry are excellent tools to examine allometric (size and shape) variation in closely related organisms that possess minute differences, such as within Tarsiidae. Even though little variation is noted among the living tarsiers today, some have proposed that modern tarsiers should be divided into two (Musser \& Dagosto, 1987; Groves, 1998) or three (Groves \& Shekelle, 2010) genera based on a size gradient among the island groups: Borneo (large), Philippines (medium), and Sulawesi (small). Applying allometric methods to measures of the skull and teeth we quantified size differences among groups and asked if their shape differences could be predicted by size-related change alone. Additionally, we asked if these three island groups actually separate out into "small, medium, and large" groups as proposed by Groves \& Shekelle (2010). We found support for two size groups, with the intermediate Philippine tarsiers more aligned to the Bornean tarsiers, but sometimes spanning into both groups. Tarsier group shape differences were not predictable from within group scaling patterns. Groups maintained largely the same skull shape across sizes. This further supports how adapting to a specialized niche, with unique adaptations limit the range of body size and prevent dramatic variations observed among the island groups, even when millions of years of evolution are separating species. 
As noted, the family Lorisidae have an unresolved and complicated evolutionary history. In chapter 3 I tackle this problem by using a multi-gene approach to try and infer their evolutionary history. I used two mitochondrial genes (cytochrome $\mathrm{b}$ and cytochrome c oxidase subunit 1 ), and a nuclear intron (recombination activating gene 2) and a nuclear exon (the melanocortin 1 receptor) to build our phylogeny. We used known, and well-supported fossil dates to set our clocks during for Bayesian phylogenetic analyses. This study is one of the first to incorporate a concatenated Bayesian phylogenetic analysis, using multi-genes, and sampling from all four genera of Lorisidae. Results found this family to be quite ancient, arising 40mya, and resolved the family as monophyletic.

Finally, in the last article, chapter 4, I examine how Mc1r varies among Lorisidae genera. Lorisidae present a unique opportunity to explore Mc1r variation on an interspecific level, because they are composed of two subfamilies that vary by coat color, that theoretically could be impacted by variation in Mc1r. The Mc1r sequence of the all brown Perodictinae could be functionally different from the more vibrantly colored Lorisinae. To do this I examined amino acid substitutions along the evolutionary branches of each genus to infer if Mc1r does in fact vary. Additionally, I tested to see if Lorisidae Mc1r sequence is affected by natural selection pressures. Our results found that, like most genes, the Mc1r of Lorisidae has been under purifying selection. We also found Mc1r amino acid substitutions did vary along the branches between Lorisinae and Perodictinae, indicating Mc1r could be influencing the coat color differences observed between the subfamilies 


\section{Literature Cited}

Baker RJ. 1984. A Sympatric Cryptic Species of Mammal: A New Species of Rhogeessa (Chiroptera: Vespertilionidae). Syst Zool 33:178.

Barsh RL. 1996. Indigenous Peoples and the UN Commission on Human Rights: A Case of the Immovable Object and the Irresistible Force. Hum Rights Q 18:782-813.

Bearder SK. 1999. Physical and social diversity among nocturnal primates: A new view based on long term research. Primates 40:267-282.

Bickford D, Lohman DJ, Sodhi NS, Ng PKL, Meier R, Winker K, Ingram KK, Das I. 2007. Cryptic species as a window on diversity and conservation. Trends Ecol Evol 22:148-155.

Brown RM, Weghorst JA, Olson KV, Duya MRM, Barley AJ, Duya MV, Shekelle M, Neri-Arboleda I, Esselstyn JA, Dominy NJ, Ong PS, Moritz GL, Luczon A, Diesmos MLL, Diesmos AC, Siler CD. 2014. Conservation genetics of the Philippine tarsier: cryptic genetic variation restructures conservation priorities for an island archipelago primate. PLoS One 9:e104340.

Campbell CJ. 2011. Primates in Perspective. Oxford University Press, USA.

Chaimanee Y, Lebrun R, Yamee C, Jaeger J-J. 2010. A new Middle Miocene tarsier from Thailand and the reconstruction of its orbital morphology using a geometricmorphometric method. Proceedings of the Royal Society B: Biological Sciences 278:1956-1963. 
Crompton RH, Andau PM. 1987. Ranging, activity rhythms, and sociality in freerangingTarsius bancanus: A preliminary report. Int J Primatol 8:43-71.

Deag JM. 1987. Primate evolution. Primate ontogeny, cognition and social behaviour. Primate ecology and conservation. Endeavour 11:163.

Dennis AB, Hellberg ME. 2010. Ecological partitioning among parapatric cryptic species. Mol Ecol 19:3206-3225.

Driller C, Merker S, Perwitasari-Farajallah D, Sinaga W, Anggraeni N, Zischler H. 2015. Stop and Go - Waves of Tarsier Dispersal Mirror the Genesis of Sulawesi Island. PLoS One 10:e0141212.

Glaw F, Vences M. 2002. A new cryptic frog species of the Mantidactylus boulengeri group with a divergent vocal sac structure. Amphib-reptil 23:293-304.

Groves C. 1998. Systematics of tarsiers and lorises. Primates 39:13-27.

Groves C, Shekelle M. 2010. The Genera and Species of Tarsiidae. Int J Primatol 31:1071-1082.

Gursky S. 2015. Ultrasonic Vocalizations by the Spectral Tarsier, Tarsius spectrum. Folia Primatol 86:153-163.

Harrison T. 2010. Later Tertiary Lorisiformes. In: Cenozoic Mammals of Africa. . p 333 350.

Healy E. 2001. Functional variation of MC1R alleles from red-haired individuals. Hum Mol Genet 10:2397-2402. 
Hoekstra HE. 2006. Genetics, development and evolution of adaptive pigmentation in vertebrates. Heredity 97:222-234.

Hoekstra HE, Drumm KE, Nachman MW. 2004. Ecological genetics of adaptive color polymorphism in pocket mice: geographic variation in selected and neutral genes. Evolution 58:1329-1341.

Hoekstra HE, Nachman MW. 2003. Different genes underlie adaptive melanism in different populations of rock pocket mice. Mol Ecol 12:1185-1194.

Jones G. 1997. Acoustic Signals and Speciation: The Roles of Natural and Sexual Selection in the Evolution of Cryptic Species. In: Advances in the Study of Behavior. . p 317-354.

Kappeler PM, Watts DP. 2012. Long-Term Field Studies of Primates. Springer Science \& Business Media.

Kimbel WH, Martin LB. 2013. Species, Species Concepts and Primate Evolution. Springer Science \& Business Media.

Martin RD. 2003. Primatology as an essential basis for biological anthropology. Evolutionary Anthropology: Issues, News, and Reviews 11:3-6.

Masters JC, Anthony NM, de Wit MJ, Mitchell A. 2005. Reconstructing the evolutionary history of the Lorisidae using morphological, molecular, and geological data. Am J Phys Anthropol 127:465-480. 
Masters JC, Boniotto M, Crovella S, Roos C, Pozzi L, Delpero M. 2007. Phylogenetic relationships among the Lorisoidea as indicated by craniodental morphology and mitochondrial sequence data. Am J Primatol 69:6-15.

Mayr E. 1977. Populations, Species and Evolution.

McGrew WC. 2007. Primate Behavior and Ecology Review ofPrimate Behavioral Ecologyby Karen B. Strier. 3rd edition. Allyn and Bacon, Boston. 452 pp. ISBN: 020544432-6. Paperback: US\$65.00. 2007. Primate Conserv 22:145-145.

Merker S, Driller C, Dahruddin H, Wirdateti, Sinaga W, Perwitasari-Farajallah D, Shekelle M. 2010. Tarsius wallacei: A New Tarsier Species from Central Sulawesi Occupies a Discontinuous Range. Int J Primatol 31:1107-1122.

Merker S, Thomas S, Völker E, Perwitasari-Farajallah D, Feldmeyer B, Streit B, Pfenninger M. 2014. Control region length dynamics potentially drives amino acid evolution in tarsier mitochondrial genomes. J Mol Evol 79:40-51.

Mongkolsamrit S, Noisripoom W, Thanakitpipattana D, Wutikhun T, Spatafora JW, Luangsa-Ard J. 2018. Disentangling cryptic species with isaria-like morphs in Cordycipitaceae. Mycologia 110:230-257.

Munds RA, Nekaris KAI, Ford SM. 2012. Taxonomy of the Bornean Slow Loris, With New SpeciesNycticebus kayan(Primates, Lorisidae). Am J Primatol 75:46-56.

Nakamura M, Hosaka K, Itoh N, Zamma K. 2015. Mahale Chimpanzees: 50 Years of Research. Cambridge University Press. 
Nekaris KAI. 2006. Social lives of adult Mysore slender lorises (Loris lydekkerianus lydekkerianus). Am J Primatol 68:1171-1182.

Nekaris KAI, Jayewardene J. 2004. Survey of the slender loris (Primates, Lorisidae Gray, 1821: Loris tardigradus Linnaeus, 1758 and Loris lydekkerianus Cabrera, 1908) in Sri Lanka. J Zool 262:327-338.

Nekaris KAI, Nijman V. 2007. CITES Proposal Highlights Rarity of Asian Nocturnal Primates (Lorisidae: Nycticebus). Folia Primatol 78:211-214.

Perelman P, Johnson WE, Roos C, Seuánez HN, Horvath JE, Moreira MAM, Kessing B, Pontius J, Roelke M, Rumpler Y, Schneider MPC, Silva A, O’Brien SJ, PeconSlattery J. 2011. A molecular phylogeny of living primates. PLoS Genet 7:e1001342.

Petter J-J, Petter-Rousseaux A. 1979. Classification of the Prosimians. In: The Study of Prosimian Behavior. . p 1-44.

Pfenninger M, Schwenk K. 2007. Cryptic animal species are homogeneously distributed among taxa and biogeographical regions. BMC Evol Biol 7:121.

Piggott MP, Chao NL, Beheregaray LB. 2011. Three fishes in one: cryptic species in an Amazonian floodplain forest specialist. Biol J Linn Soc Lond 102:391-403.

Pozzi L, Nekaris KA-I, Perkin A, Bearder SK, Pimley ER, Schulze H, Streicher U, Nadler T, Kitchener A, Zischler H, Zinner D, Roos C. 2015. Remarkable ancient divergences amongst neglected lorisiform primates. Zool J Linn Soc 175:661-674. 
Rasmussen DT, Nekaris KA. 1998. Evolutionary history of lorisiform primates. Folia Primatol 69 Suppl 1:250-285.

Ravosa MJ. 1998. Cranial allometry and geographic variation in slow lorises (Nycticebus). Am J Primatol 45:225-243.

Roos C, Schmitz J, Zischler H. 2004. Primate jumping genes elucidate strepsirrhine phylogeny. Proc Natl Acad Sci U S A 101:10650-10654.

Rose KD, Bown TM. 1993. Species Concepts and Species Recognition in Eocene Primates. In: Species, Species Concepts and Primate Evolution. . p 299-330.

Rosenberger AL. 2010. The Skull of Tarsius: Functional Morphology, Eyeballs, and the Nonpursuit Predatory Lifestyle. Int J Primatol 31:1032-1054.

Rosenberger AL. 2011. The Face of Strigorhysis: Implications of Another Tarsier-like, Large-Eyed Eocene North American Tarsiiform Primate. The Anatomical Record: Advances in Integrative Anatomy and Evolutionary Biology 294:797-812.

Rosenberger AL, Preuschoft H. 2012. Evolutionary morphology, cranial biomechanics and the origins of tarsiers and anthropoids. Palaeobiodiversity and Palaeoenvironments 92:507-525.

Rossie JB, Ni X, Beard KC. 2006. Cranial remains of an Eocene tarsier. Proc Natl Acad Sci U S A 103:4381-4385. 
Schwartz JH, Tattersall I. 1985. Evolutionary Relationships of Living Lemurs and Lorises (Mammalia, Primates) and Their Potential Affinities with European Eocene Adapidae.

Seiffert ER, Simons EL, Attia Y. 2003. Fossil evidence for an ancient divergence of lorises and galagos. Nature 422:421-424.

Sterling EJ, Radespiel U. 2000. Advances in studies of sociality in nocturnal prosimians. Am J Primatol 51:1-2.

Strier KB. 2011. Why Anthropology Needs Primatology. General Anthropology 18:1-8.

Sulem P, Gudbjartsson DF, Stacey SN, Helgason A, Rafnar T, Magnusson KP, Manolescu A, Karason A, Palsson A, Thorleifsson G, Jakobsdottir M, Steinberg S, Pálsson S, Jonasson F, Sigurgeirsson B, Thorisdottir K, Ragnarsson R, Benediktsdottir KR, Aben KK, Kiemeney LA, Olafsson JH, Gulcher J, Kong A, Thorsteinsdottir U, Stefansson K. 2007. Genetic determinants of hair, eye and skin pigmentation in Europeans. Nat Genet 39:1443-1452.

Sussman RW, Hart D. 2015. Primate Models for Human Evolution. In: Basics in Human Evolution. . p 73-82.

Watanabe K. 2008. A Review of 50 Years of Research on the Japanese Monkeys of Koshima: Status and Dominance. In: Primate Origins of Human Cognition and Behavior. . p 405-417. 
Wirdateti W. 2008. An exploration on the habitat, feeds and distribution of Tarsius tarsier (tarsier) in Selayar Island and Patunuang Nature Reserve, South Sulawesi. Biodiversitas, Journal of Biological Diversity 9:152-155.

Yoder AD. 1997. Back to the future: A synthesis of strepsirrhine systematics. Evolutionary Anthropology: Issues, News, and Reviews 6:11-22.

Yoder AD, Irwin JA, Payseur BA. 2001. Failure of the ILD to Determine Data Combinability for Slow Loris Phylogeny. Syst Biol 50:408-424.

Zachos FE. 2016. Species Concepts in Biology: Historical Development, Theoretical Foundations and Practical Relevance. Springer. 


\title{
CHAPTER TWO
}

\section{MULTIVARIATE CRANIODENTAL ALLOMETRY OF TARSIERS}

\author{
Rachel A. Munds ${ }^{1,2}$, Rachel H. Dunn ${ }^{3}$, and Gregory E. Blomquist ${ }^{1}$ \\ ${ }^{1}$ Department of Anthropology, University of Missouri, Columbia, MO 65211 USA \\ ${ }^{2}$ Nocturnal Primate Research Group, Oxford Brookes University, Oxford OX3 0BP UK \\ ${ }^{3}$ Department of Anatomy, Des Moines University, Des Moines, IA 50312 USA
}

\begin{abstract}
Evolutionary allometry describes size and shape differences across taxa matched for developmental stage (e.g. adulthood). Allometric studies can identify subtle differences among species, and therefore help researchers interested in small-bodied, cryptic species such as tarsiers. Recent taxonomic revision has emphasized size differences among three possible tarsier genera inhabiting different island regions: Sulawesi (genus: Tarsius), Borneo (genus: Cephalopachus), and the Philippines (genus: Carlito). We examined seven craniodental measures of 102 museum specimens of adult tarsiers representing these three regions. We found that the allometric patterns within groups do not predict the observable differences among groups. Crania of the largestbodied genus, Cephalopachus, are characterized by relatively short skulls and small orbits, with wider palates and molars than predicted by allometric increase from the smaller-bodied Tarsius. Overall, we found tarsier skulls stay the same shape as they increase in size. This may reflect shared developmental and biomechanical adaptations across tarsier groups filling an extreme leaping, faunivorous niche with hypertrophied orbits and subtle dietary differences in prey selection. These shared adaptations of tarsiers may severely limit the range of body sizes in tarsiers and impose further constraints on
\end{abstract}


cranial shape. Despite their deep divergence times in the Miocene, living tarsier groups are united by a common craniodental form across a limited size range. Adaptations to extreme niches might result in a hyper-conservatism of the cranium. Future primate allometric studies should explore cranial variation in other taxa to determine how adaptations to specific niches affect the size and shape of the cranium.

\section{Introduction}

Allometry is the study of organismal variation associated with size and shape (Cheverud, 1982; Fleagle, 1985; Jungers, et al., 1995; Klingenberg, 1996; Mitteroecker et al., 2013). There are three types of allometry: ontogenetic, static, and evolutionary. Ontogenetic allometry is the study of organismal growth stages within a species, static (intraspecific) allometry examines variation among individuals of the same age category and same species, and evolutionary (interspecific) allometry studies the covariation among different traits of different species that belong to a shared phylogeny within the same developmental stage (Cheverud, 1982; Fleagle, 1985; Klingenberg, 1996; Mitteroecker et al., 2013). Organisms can be isometric, in which shape is preserved as it increases or decreases in size. Alternatively, measurements may increase more rapidly than overall size (positive allometry) or show less increase than overall size (negative allometry), each resulting in changed proportions or shape (Jungers et al., 1995; Klingenberg, 1996; Mitteroecker et al., 2013). 
Allometry has practical applications in biology as a way to interpret limits on the size, ecology, and evolution of an organism (Fleagle, 1985; Klingenberg, 1996; Mitteroekcer et al., 2013). For example, cranial diversity among papionin primates is attributed to large size differences among the genera. Thorough ontogenetic studies found changes in size, particularly in Papio and Mandrillus, are a result of delayed adult maturation, where subadult shapes are similar to the smaller sized papionins, and the adult Papio and Mandrillus exhibit a unique phenotype (Leigh et al., 2003; Singleton, 2005). In this case, size differences drive shape differences, and influence the evolutionary and phylogenetic interpretations of papionin primates (Leigh et al., 2003; Singleton, 2005). Allometry also explains ecological and adaptive limitations on size. For example, larger primates consume more abundant plant materials, whereas smaller species consume protein rich, but less abundant insects (Fleagle, 1985), and size differences correlate with metabolic requirements (West et al., 1997). Additionally, allometric methods help clarify the relationships between within species static allometries and the evolutionary allometries observed in larger clades (Klingenberg, 2016; Mitteroecker et al., 2013). Static and evolutionary allometric analyses provide opportunities for researchers to examine allometric variation in minute differences in a closely related phylogeny (Klingenberg, 2016; Mitteroecker et al., 2013).

Tarsiers are small-bodied primates (60-120 g) (Gursky, 2007) that are found on several islands throughout Southeast Asia (Musser \& Dagosto, 1987; Shekelle \& Groves, 2010). All twelve species of tarsiers share morphological, behavioral, and ecological characteristics, and are all sit-and-wait hunting faunivores, consuming both insects and small vertebrates (Crompton \& Andau, 1987; Gursky, 2007; Nietsch, 1993; Rosenberger, 
2010). Their specialized locomotion, vertical-clinging and leaping (VCL), contributes to their hunting style, with some species being more specialized for VCL than others. The most specialized species have the longest hindlimbs and hands, and the least specialized have the shortest (Musser \& Dagosto, 1987). Morphologically, tarsiers are distinct from many nocturnal mammals as they lack a tapetum lucidum (the reflective eye tissue). Instead they have hypertrophic eyes which are larger, relative to their body size, than in any other mammal (Rosenberger, 2010; Rosenberger \& Preuschoft, 2012). These massive eyes, along with extreme VCL locomotion, influenced modifications to their crania, such as a foramen magnum placed directly below the skull case, which is typically seen in bipedal organisms, like humans. As tarsier eye size increased, the skull became lighter, permitting faster movement, and further influencing the construction of the skull, to protect the eyes during foraging and moving, including postorbital flanges and partial post orbital closure (Anemone \& Nachman, 2003; Rosenberger, 2010; Rosenberger \& Preuschoft, 2012).

Due to their similar morphologies and behavior, tarsiers are described as monophyletic, and consist of three or four species-groups (Table 2.1; Figure 2.1). Although morphological differences among the groups appear small (Gursky, 2007; Niemitz, 1984), differences in limb proportions, craniometrics, and other feature have been used to distinguish species (Groves, 1998; Gursky, 2007; Musser \& Dagosto, 1987; Niemitz, 1984; Shekelle et al., 2008). Taxonomic studies describe a size gradient among the geographic groups in which the Bornean group (Cephalopachus) is the largest, followed by the Philippine (Carlito) group, and then the Sulawesi group (Tarsius). Pygmy or montane tarsiers (Tarsius pumilus) are dramatically dwarfed. More subtle 
cranial and limb length differences show consistent size-related variation among other tarsier groups (Groves, 1998; Musser \& Dagosto, 1987). However, few studies have investigated allometric variation among or within tarsiers alone (c.f. Anemone \& Nachman, 2003).

The size gradient among the islands groups, differences in amount and type of vocalizations (i.e. the ultrasonic call of T. pumilus), and chromosomal and behavioral differences (Groves \& Shekelle, 2010; Gursky, 2007; Shekelle, 2010) have incited discussions of tarsier taxonomy. Musser and Dagosto (1987) and Groves (1998) acknowledged at least two groups of tarsiers (Bornean-Philippine and the Sulawesipygmy tarsier), and suggested genus-level differences without demarcating any genera. Groves and Shekelle (2010) divided tarsiers into three living genera (Table 1): Cephalopachus, the Bornean and Sumatran group (c.f. Tarsius bancanus spp.), Carlito (c.f. T. syrichta) the Philippine species, and Tarsius consisting of the Sulawesi species. For simplicity, we follow Groves and Shekelle's (2010) taxonomy.

Another unusual aspect of tarsiers is their morphological similarity to their identified fossil ancestors. Examining these fossil tarsiers reveal the modern-day tarsier synapomorphies. Extinct and extant tarsiers share a suite of dental traits linked to insectivory and enlarged orbits (Beard, 1998; Beard et al., 1994, Chaimanee et al., 2011; Rossie et al., 2006; Simons, 2003; Ziljstra et al., 2013). The large orbit size of extinct tarsiers is primarily inferred from geometric morphometrics based on a partial maxilla of Tarsius sirindhornae (Chaimanee et al., 2011), and a partial facial fragment of Tarsius eocaneus (Rossie et al., 2006). Based on the sparse fossil record of tarsiers (Xanthorhysis tabrumi, Tarsius eocaenus, T. thailandicus, and T. sirindhornae) for which cranial 
material exists, it is speculated extinct tarsiers possessed these large orbits by the Eocene, roughly 45 Ma (Chaimanee et al., 2011; Jablonski, 2003; Rossie et al., 2006).

The dramatically large orbits, specialized dentition, and postcranial specializations for extreme vertical clinging and leaping in tarsiers may explain the minimal variation seen among the insular groups of tarsiers today (Rosenberger, 2010; Rosenberger et al., 2016). Modern tarsiers are thought to live in forests that resemble those in which their ancestors lived (Jablonski 2003). Inhabiting roughly the same environment has contributed to the minimal morphological variation between ancestral and modern tarsiers, as well as among the modern tarsiers. This pattern, in which modern tarsiers exhibit a phenotype very similar to their distant ancestors (Chaimanee et al., 2012; Dagasto et al., 2003; Rosenberger \& Preuschoft, 2012; Rossie et al., 2006; Simons, 2003) could be explained by long-term stabilizing selection in a small-bodied nocturnal, faunivorous, extreme-vertical clinging and leaping niche.

Molecular phylogenetic studies show that Philippine and Bornean/Sumatran tarsiers are each other's closest relatives, with Sulawesi tarsiers as their sister taxon (Brown et al., 2014; Merker et al., 2009; Merker et al., 2014). The divergence between Philippine and Bornean/Sumatran tarsiers is estimated from other primate fossil calibration points to be about $10 \mathrm{Ma}$ in the late Miocene (Driller et al., 2015; Merker et al., 2009; Merker et al., 2014; Shekelle et al., 2010). The last common ancestor of crown tarsiers is estimated to have lived near the Oligocene-Miocene boundary around $22 \mathrm{Ma}$ (Driller et al., 2015; Jablonski, 2003; Merker et al., 2009). Sulawesi tarsiers are thought to be descendants of an initial wave of tarsier dispersal from mainland Asia. Once on Sulawesi, they remained isolated from other tarsier populations, though crown Sulawesi 
tarsiers only date to $2.5 \mathrm{Ma}$ (Driller et al., 2015; Merker et al., 2009). A later wave of tarsiers dispersed from mainland Asia to Sumatra, Borneo, and surrounding islands during the Miocene (Dagosto et al., 2003), with the Philippine tarsiers likely derived from migrants from Borneo (Brandon-Jones, 1998; Dagosto et al., 2003). Regardless of the biogeographic scenario of dispersal, there seems to have been ample time for morphological diversification to have taken place.

We tested for allometric differences among the three tarsier island groups (Borneo, Philippines, and Sulawesi). We hypothesize that the deep divergence and ecological differences among the tarsier groups resulted in a detectable size gradient among the island groups. Specifically, we expect that tarsiers are getting larger in size from the small Sulawesi group to the large Bornean tarsiers. Moreover, any notable shape differences among the groups are expected to be largely due to their increase in size (i.e. allometric) (Driller et al., 2015; Rychlik et al., 2006; Sebastiao \& Marroig, 2013; Wilson, 2013; Zelditch et al., 2004). If this is the case, then we predict there will be a common pattern of within-group covariance among body measurements shared by all groups of which the major axis of variation distinguishes tarsiers from different island regions (Schluter, 1996). Alternatively, group differences in shape could be largely unrelated to size, reflecting differentiation along minor axes of a common within-group covariance pattern or possibly differences in covariance patterns among groups. 


\section{Methods}

We refer to the geographic groups by their proposed genus names: Cephalopachus (Borneo/Sumatra), Carlito (Philippine), and Tarsius (Sulawesi). We do not address taxonomic distinctions among the groups in this paper. Shekelle \& Groves (2010) provide more detail regarding the possible genus level differences among the island groups.

We collected craniodental measurements from museum collections of tarsiers representing all four groups described above (Table 2.1). Due to their rarity in museum collections, sample sizes for $T$. pumilus $(\mathrm{n}=3)$ and Carlito $(\mathrm{n}=11)$ were much smaller than for non-pygmy Tarsius $(\mathrm{n}=43)$ or Cephalopachus $(\mathrm{n}=45)$. All individuals examined were adults based on tag information or skull size. We combined the sexes, as tarsiers exhibit little sexual dimorphism (Gursky, 2007). Post-crania of tarsiers are limited, and juveniles are rare in collections, so we could not collect a large sample size for post-crania comparisons or ontogenetic studies. RHD collected dental and cranial measurements from the National Museum of Natural History (USNM) to the nearest hundredth of a millimeter using dial calipers under a microscope. We took each measurement three times and recorded the mean of the three measurements. C Groves provided additional measurements from USNM, the American Museum of Natural History, British Museum of Natural History, Museum Zoologicum Bogoriense, Naturalis Leiden, and the Natural History Museum of Berlin. RHD and Groves followed collection methods from Musser and Dagosto (1987). The data from this study are available from the corresponding author on request. 


\section{Analysis}

We log-transformed all measurements prior to analysis to reduce differences in variances among measurements and render them interpretable on proportionate scales, as is traditional in allometric studies (Klingenberg, 1996). We visually inspected density plots and z-scores for each single measurement and for all possible measurement pairs in bivariate scatterplots to detect egregious outliers indicative of possible measurement error (z-scores $>3$ or visual inspection of bivariate plots). We tested inter-observer agreement using 20 skulls and limited our analyses to the seven variables with good agreement between the two observers (Pearson's $r>0.8$ for $\mathrm{M}^{1}$ length and $\mathrm{r}>0.9$ for all others). These seven measurements are skull length (SkullL), Biorbital breadth (BiOrbB), upper palate width at the third molar (M3tPalW), maxillary canine to the third molar length (C.M3L), mandibular canine to third molar length (c.m3L), mesiodistal length of the upper first molar (M1), buccolingual width of the upper first molar (M1W). We conducted all analysis in R (v 3.3.1) (R Core Team 2016).

We used Bayesian methods implemented in the MCMCglmm package (Hadfield, 2010) for most of the analysis. There are distinct advantages to this approach compared to simpler alternatives. First, it allowed flexible modeling of the tarsier group means and within-group covariances despite the imbalance in sample sizes. Second, the separation into groups roughly accounts for phylogenetic covariance and ensures within-group covariance matrices are estimated rather than a hybrid of within- and between covariance (McCoy et al. 2006). Third, Bayesian methods allow propagation of error throughout the analysis from imputation of any missing data through the inference of allometric coefficients. In small datasets this is particularly advantageous because it prevents the 
false precision of step-wise analysis (Ovaskainen et al. 2008; Gelman \& Weakliem 2009). The primary output from MCMCglmm was posterior distributions of mean vectors for each of the four tarsier groups and covariance matrices among measurements.

Because we had very small samples of $T$. pumilus and Carlito we pooled T. pumilus with Tarsius and Carlito with Cephalopachus in these models for estimation of covariance matrices. In other words, each model posterior sample includes an estimate of the mean vector for each of the four groups but only two covariance matrices (all Tarsius v. Cephalopachus + Carlito). We used block diagonal (i.e. a pair of 7x7 blocks) inverse Wishart priors with low variance and degree of belief $(\mathrm{V}=0.02, \mathrm{nu}=8)$ on the residual covariance, and normal priors with mean of zero and very large variance $\left(10^{8}\right)$ for the mean vectors. We ran each model for 150,000 iterations, discarded 50,000 as burn-in and retained every 100th thereafter, yielding 1000 samples of the posterior distributions for later analysis. Autocorrelation between successive retained samples was low enough to achieve effective sample sizes close to 1000 (minimum 815). We also extracted posterior means for any missing data points for use in later graphical exploration or analysis where a complete data set was desirable. This amounts to averaging the 1000 imputations of trait-group means.

We applied common principal components analysis implemented in the cpca package (Ziyatdinov et al., 2014) to each of the paired posterior covariance matrices. The resulting common principal component posterior distribution describes shared orientation (eigenvectors or principal components) of covariation in multivariate space but allows for group differences in variance/hypervolume (eigenvalues) (Flury, 1998; McCoy et al., 2006; Phillips \& Arnold, 1999). Multivariate allometry is described by the principal 
components (PCs) of the common eigenvector matrix, with the first principal component (PC1) regarded as a metric of overall size and size-related shape variation (Klingenberg, 2016). We used the $95 \%$ credible interval of the posterior distribution of PC1 and to test against isometry. Isometric $\mathrm{PC} 1$ scores are expected to be $\sqrt{ } 7$ (i.e., 0.378) (Klingenberg 1996). If the credible intervals did not include the isometric value, then the measurement would either be negatively or positively allometric, indicating relative decrease or increase of the measurement, respectively, with increasing overall size.

While necessary to describe common allometric patterns among groups, there is no assurance the common principal components model accurately describes the withingroup covariance matrices. We used a pair of matrix comparison methods to test this assumption using only the data from non-pygmy Tarsius and Cephalopachus because we had insufficient sample sizes for the other groups. First, we used the Flury hierarchy, which describes a series of comparisons from equal matrices, through common principal components to completely unrelated matrices. We used Phillips CPC program for this test (Bolker \& Phillips, n.d., Phillips, 1999). Different CPC models in the hierarchy are compared to the best model using AIC or $\Delta_{\text {AIC }}$ from (Phillips and Arnold, 1999). Because of concerns over the biological interpretation of the CPC hierarchy, we also used random skewers, which tests for overall matrix similarity by computing hypothetical response vectors to directional selection (Cheverud \& Marroig, 2007). This test relies on randomization for significance testing, for which we used 5000 randomizations with 500 skewers per cycle as implemented in R scripts (Roff et al., 2012). 
To supplement these numerical results, we plotted the first two common PC scores and compared these with plots of individual craniodental measurements or a ratio of a measurement to the geometric mean against the geometric mean. Discriminant analysis and other clustering statistics were inappropriate given our small sample sizes particularly of T. pumilus and Carlito. We also calculated a CPC1-adjusted dataset for graphical exploration and t-tests comparing non-pygmy Tarsius and Cephalopachus after this adjustment (Klingenberg 1996, Burnaby 1966). To supplement the allometric analysis, we also built neighbor-joining and hierarchical clustering trees from the Euclidean distance matrix of all tarsiers. We generated neighbor-joining trees with the nj function in the ape package (Paradis, 2010). We used the hclust function with Ward's (1963) minimum variance criterion for agglomerative hierarchical clustering. We use these methods to show information from the distance matrix and do not to attempt to interpret the resulting trees as phylogenies. We used a robust k-means clustering procedure of the pamk function in the fpc package (Hennig, 2015) on the logged or logged and z-scored data to identify any additional non-hierarchical patterns. To test for any clustering we used the Duda-Hart test $\left(\mathrm{H}_{0} \mathrm{k}=1\right)$. To test for further clustering $(\mathrm{k}>1)$ we used the average silhouette criterion. We found no difference in results with alternative criteria. 


\section{Results}

Although tarsier crania are not dramatically different in overall size, we found clear differences in quantitative comparisons (Figure 2.2, Table 2.2). Tarsier crania are not isometrically or allometrically scaled variants; they have different shapes at different sizes and the shape changes are not predicted by within group covariance patterns. The departure from isometry is apparent in bivariate plots of ratios of skull dimensions to the geometric mean (Figure 2.2). Skulls become relatively shorter with increasing size and palates get relatively wider. Biorbital breadth and canine-third molar lengths have more complex patterns that appear more isometric in aggregate across the tarsier groups. First molars become relatively wider and perhaps shorter across the groups. While the pygmy tarsier sample is very limited, they do not appear to have unusual shapes for any of these variables. With the exception of skull length, biorbital breadth and first molar length pygmy tarsiers are isometrically shrunken versions of any tarsier group. They have relatively long skulls such as those in non-pygmy Tarsius, while their biorbital breadths are most similar to the relatively large eyed Cephalopachus. Their molar lengths are unusually short with two of the three points outside the shape range of any other tarsier group. Carlito are largely intermediate between Tarsius and Cephalopachus in both size and shape. While the sample of this group is also small they fall on the margin of Tarsius and are often subsumed in or overlap heavily with Cephalopachus.

Eigenvalues from the separate matrices show the first common principal component (CPC1), a general size and size-related shape metric, accounts for $25.99 \%$ (CI: $19.00-36.38 \%$, Tarsius) or $38.60 \%$ (CI: 29.99-48.65\%, Cephalopachus+Carlito) of the variance. Negatively allometric patterns are strongest in skull length and biorbital 
breadth, while positive allometry is weaker but most notable in the molar dimensions (Figure 2.3). Although other variables are less distinguishable from isometry their values still imply potentially important size-related shape changes. For example, the weak negative allometry of palate width coupled with strong allometry of skull length implies tarsier skulls within groups should have an increasing ratio of palate width to skull length. This pattern appears to carry over across groups as well in the ratios to the geometric mean described above (Figure 2.2). Plots of the first two CPCs show the tarsier groups arrayed in along a size gradient, with the small-bodied pygmy tarsiers well separated from the larger-bodied cluster of Tarsius, Carlito, and Cephalopachus (Figure 2.4). There is limited overlap between Tarsius and Cephalopachus in these plots, and Carlito is often subsumed within Cephalopachus.

T-tests on the raw and CPC1-adjusted data highlight allometric and nonallometric differences between Cephalopachus and Tarsius (Figure 2.5). Cephalopachus is greater than Tarsius in all measurements in the raw data and $\mathrm{CPC} 1$ adjustment either reduces the difference or changes the sign for all variables except maxillary palate length (C.M3L). For $\mathrm{M}^{1}$ length and especially skull length, adjustment turns a small difference into a very large difference, with Tarsius larger than Cephalopachus. The skull and $\mathrm{M}^{1}$ are shorter than expected in Cephalopachus than if they were allometrically scaled versions of Tarsius. In the case of skull length, this implies further shape change beyond negative within-group allometry to maintain essentially indistinguishable raw lengths across tarsier groups. Similarly, the positive allometry of molar length implies Cephalopachus molars are shorter than expected from within-group allometry. For other measures large raw differences are greatly reduced by CPC1-adjustment. While 
Cephalopachus biorbital breadths are much greater than in Tarsius, negative withingroup allometry would predict them to be even larger. Mandibular canine- $\mathrm{M}_{3}$ length is also smaller than expected in Cephalopachus despite its approximately isometric scaling. Palate width, molar width and maxillary canine- $\mathrm{M}^{3}$ length all remain larger in Cephalopachus, indicating relative size increase beyond that predicted by their static allometry. In particular, molar width remains larger in Cephalopachus after CPC1 adjustment. Although molar widths scale with positive allometry within groups, Cephalopachus molars are larger than predicted from this scaling relationship. This result identifies the wide molars of Cephalopachus as an important non-allometric group difference.

Matrix comparisons support the CPC model and reveal only subtle differences between Tarsius and Cephalopachus covariance matrices. Random skewers correlations are high and not significantly different from one $\left(\mathrm{r}=0.827, \mathrm{p}=0.999 \mathrm{H}_{0}: \mathrm{r}=1\right)$ suggesting very little difference in response to directional selection for the two groups. AICs for common principal component models in the Flury hierarchy indicate CPC (5) as the best fitting model, but the full CPC model with all eigenvectors shared is nearly as good a model and much better than unrelated matrices $\left(\Delta_{\text {AIC }} 0.36\right.$ v. 7.060$)$. In summary, there are subtle differences between the two genera in covariance matrices, but they should not complicate the common principal components analysis presented above.

Neighbor-joining and hierarchical clustering trees show overall craniodental similarity among the tarsiers that capture the size and shape differences described in the allometric analysis and taxonomic descriptions (Figure 2.6). In the neighbor-joining tree, pygmy tarsiers are distant outliers on long branches emanating from a cluster of Tarsius. 
The largest crania, from Cephalopachus, are the most distant tips from either Tarsius group. The intermediate-sized Carlito are in the middle of the tree with Cephalopachus as their nearest neighbors. The hierarchical clustering tree has essentially the same pattern, with Tarsius and Cephalopachus well sorted into two major clades. Carlito are scattered within the Cephalopachus clade, while pygmy tarsiers form a distinct subclade among Tarsius. k-means clustering consistently identifies two groups. The first group contains pygmy tarsiers and nearly all Tarsius. The second is Carlito and nearly all of Cephalopachus. The results are almost identical if measurements are logged or logged and z-scored which eliminates size differences among measurements that would weight them differently in the clustering (Table 2.3, only non-z-scored results shown). DudaHart test rejects a single cluster $(\mathrm{p}<0.001)$ and average silhouette width is maximized by $\mathrm{k}=2$.

\section{Discussion}

Our findings do not support the hypothesis that tarsier groups are distinguished primarily by within-group allometric size and shape differences (Schluter, 1996). The most recognizable inter-group differences in tarsier crania are not predicted by withingroup covariance patterns. Previous descriptions have emphasized the relatively shorter skull with wider, flaring orbits and more robust dentition of Cephalopachus and Carlito (Musser \& Dagosto, 1987; Shekelle \& Groves, 2010). Static within-group allometries do not account for these characterizations. For example, the negative allometry of skull length is far exceeded by the nearly indistinguishable mean lengths of the three groups, and the wide molars of Cephalopachus are wider than expected after allometric 
adjustment. The wide, flaring orbits of Cephalopachus are partially accounted for by allometric patterns, but they should be even larger if Cephalopachus were a scaled up version of Tarsius. These results suggest factors beyond static allometry to explain cranial differences among the groups.

Due to our limited sample, we did not focus on the taxonomic significance of cranial variation, but did offer some description of their multivariate clustering. In general, we found two readily distinguishable groups of tarsiers: a Tarsius group (Sulawesi) and a Cephalopachus/Carlito (Borneo/Philippines) group. Carlito was between Tarsius and Cephalopachus, but was usually subsumed by Cephalopachus. Pygmy tarsiers are most similar to non-pygmy Tarsius but are distinct in neighbor-joining and hierarchical cluster analysis. In general, they are most similar to Tarsius, but usually have shapes seen in any tarsier group. We hypothesized the limited craniodental variation among tarsiers is maintained because of their unusual adaptations to nocturnal foraging as visually and acoustically reliant predators and extreme vertical clingers and leapers. The observed dental and masticatory differences among groups may reflect specialization on different prey types.

Additionally, our allometric results support the hypothesis that hyperconservation of the crania balances and protects the eyes. In particular, this can be seen in the biorbital breadth and skull length; two features that cannot change greatly as tarsiers increase or decrease in size. Both are negatively allometric within groups, reflecting the familiar negative allometry of neural tissues (Howland et al. 2004), but the group differences depart from the within-group CPC1. We hypothesize these group differences reflect shifts either toward maintaining similar shapes at all sizes (biorbital breadth) or 
enhancing shape change (skull length) with increasing size to reduce antero-posterior forces during leaping or landing. Furthermore, these features are useful in distinguishing among the groups when allometric influences are removed.

Craniodental variation among tarsiers may reflect prey selection differences. It is expected that faunivorous mammals, such as tarsiers, have increased molar size to improve grinding capabilities (Gingerich et al., 1982; Gould, 1975; Gursky, 2007; Jablonski \& Crompton, 1994; Strait, 1993). Yet, insectivores often have narrower molars to effectively break up insects, as the narrower teeth increase bite force to fracture exoskeletons (Evans \& Sanson, 1998; Strait, 1993). These findings may explain why the more insectivorous Tarsius (Gursky, 2007) has a smaller average molar width than the other two tarsiers, a difference which persists in the maxillary molars even when adjusted for allometry. Field observations indicate Cephalopachus favors larger prey, such as small reptiles, amphibians, birds, and occasionally small mammals such as bats (Crompton \& Andau 1987; Niemitz 1984), which may explain their absolutely and relatively wider palate and maxillary molars. Carlito is thought to be insectivorous, but there are no detailed field studies of this genus (Dagosto et al., 2003). Carlito may have an intermediate diet which is not as faunivorous as Cephalopachus, or as insectivorous as Tarsius. This would be consistent with their intermediate craniodental anatomy, and these dietary differences may explain some of the subtle differences between the groups.

The small-bodied, Neotropical Callitrichidae (Callitrhix, Mico, Cebuella, Callibella, and Callimico) exhibit allometric patterns over a narrow size range that may be related to ecological, behavioral, and dietary differences among taxa. It is speculated that pre-natal miniaturization Callitrichidae's is the primary contributor to the observed, 
predominantly conserved-allometric patterns in Callitrichidae. However, dietary preferences, like gummivory, and their vertical locomotion may also influence cranial development (Ford, 1980; Marroig \& Cheverud, 2009; Vinyard et al., 2009). Additionally, similar to tarsiers, Callitrichidae has a pygmy form, the pygmy marmoset (Cebeulla). Similar to Cebeulla, which is a scaled-down variant of Callithrix (Marroig \& Cheverud, 2009), we found Tarsius pumilus ( $\mathrm{n}==3$ ) to be an allometrically scaled-down variant of Tarsius.

In summary, tarsier craniodental variation reflects their extreme locomotor and dietary specialization. Given our limited sample size, we cannot confidently address tarsier taxonomy, but they suggest there are at least two groups: a Western tarsier group (Cephalopachus/Carlito) and an Eastern tarsier (Tarsius) group that, while united by a common craniodental form, can be readily distinguished. Although there are important size and shape differences between these groups, they are not simply extensions of the allometric patterns seen within groups. Future studies should investigate how these differences emerge through ontogeny and their relationship with postcranial morphology. 


\section{Acknowledgements}

We thank R. Thorington, L. Gordon (National Museum of Natural History) for allowing us to access the collections. We also want to thank Dr. Yao for providing the photograph of the tarsier skulls, as well as E. Westig and N. Duncan (American Museum of Natural History) for granting permission for us to use this photograph. Thank you Dr. M. Shekelle for your advice, feedback and willingness to share your data. We must thank the editor of IJP, as well as several anonymous reviewers who provided excellent suggestions for the improvement of this article. Finally, this research would not have been accomplished if it were not for the late Dr. C. Groves who not only provided his data, but also his expertise on the subject. 

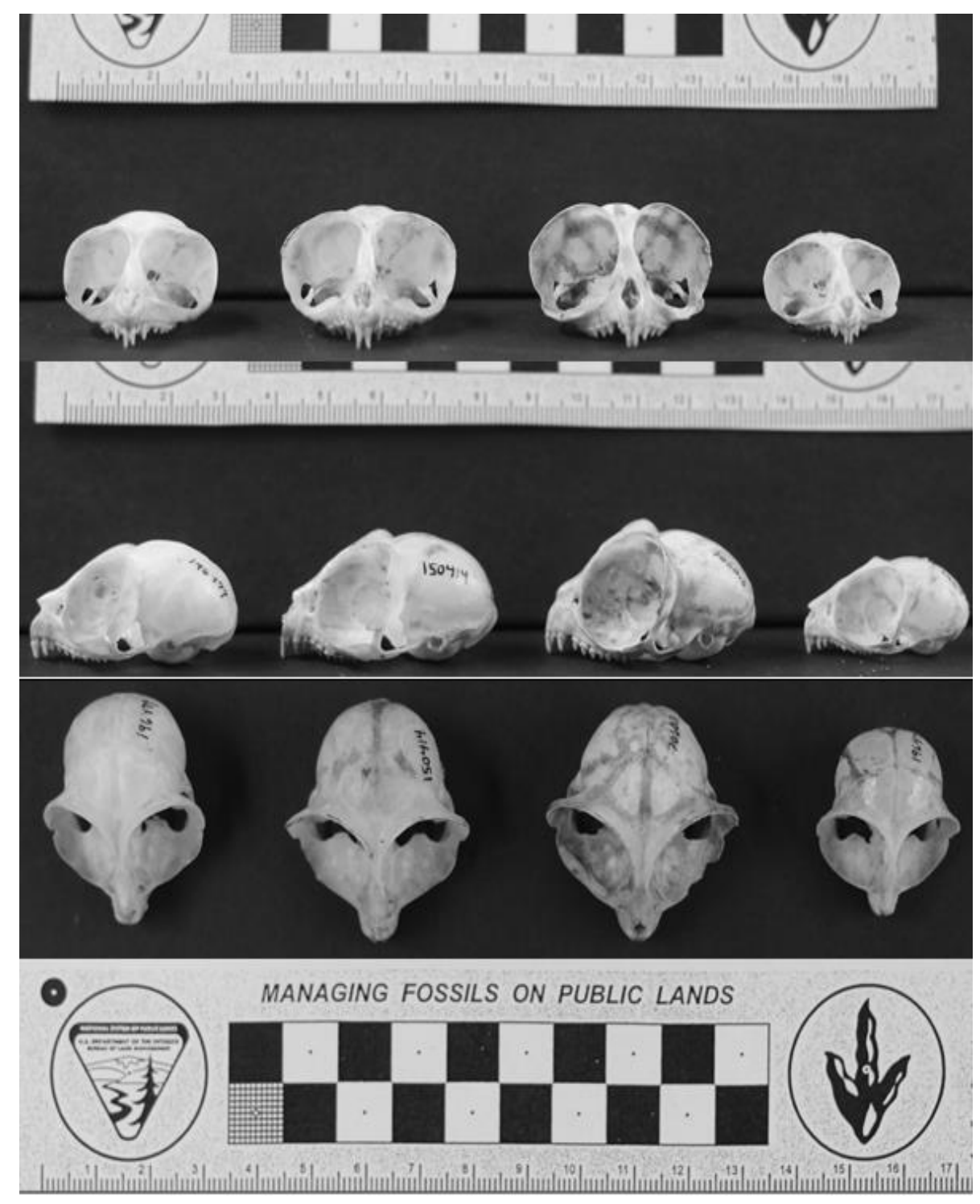

Figure 2.1: Adult crania of tarsiers from left to right: Tarsius, Carlito,

Cephalopachus, and T. pumilus (pygmy tarsier). Photography credit Dr. L. Yao. Specimens from American Museum of Natural History. 


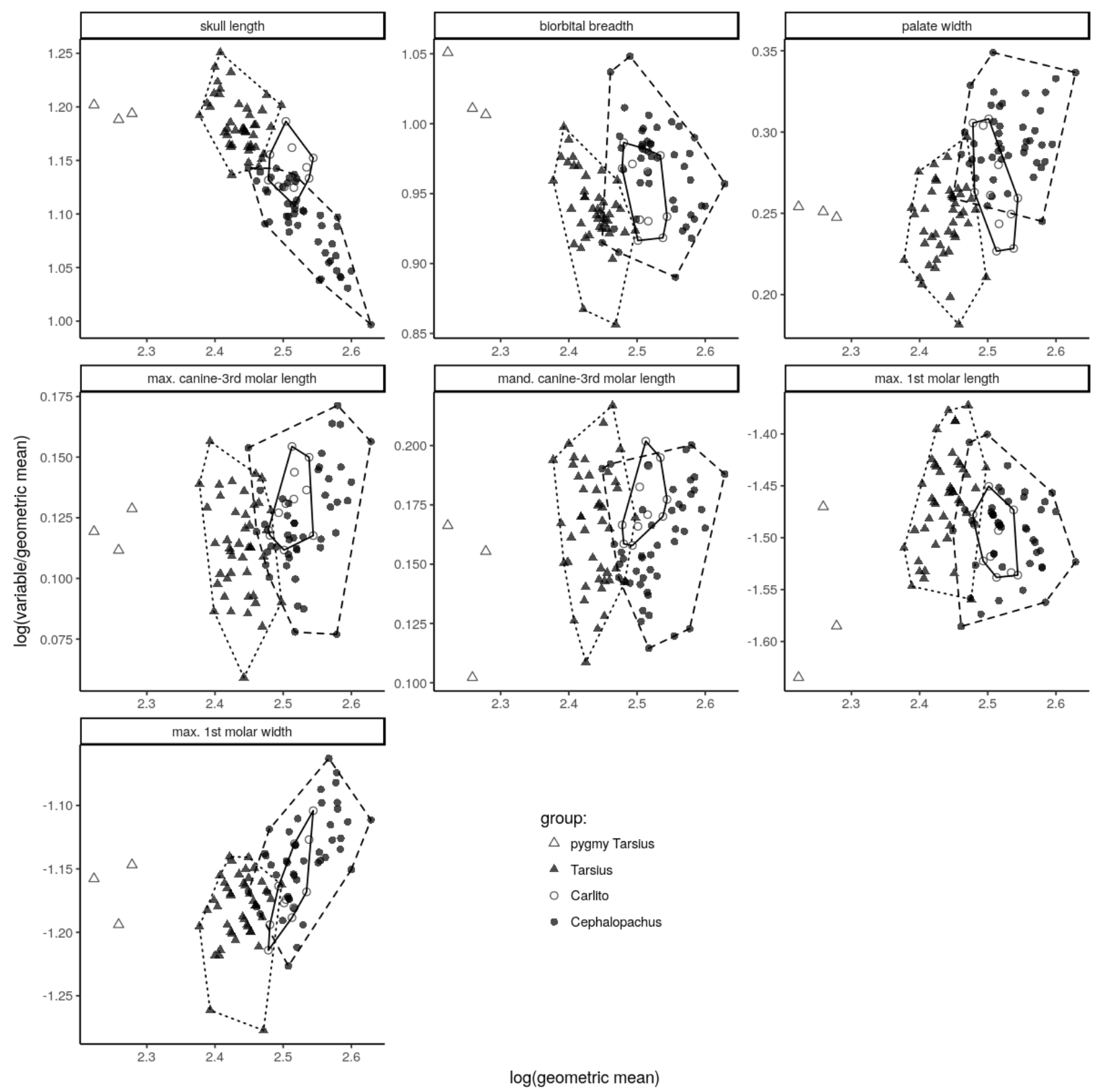

Figure 2.2: Departure from isometry in shape change (y-axis) versus overall size (xaxis) in tarsier craniodental measures from museum specimens. Pygmy tarsiers (N=3) are open triangles, non-pygmy Tarsius $(\mathrm{N}=43)$ are filled triangles, Carlito ( $\mathrm{N}=11)$ are open circles, and Cephalopachus $(\mathrm{N}=45)$ are filled circles. 


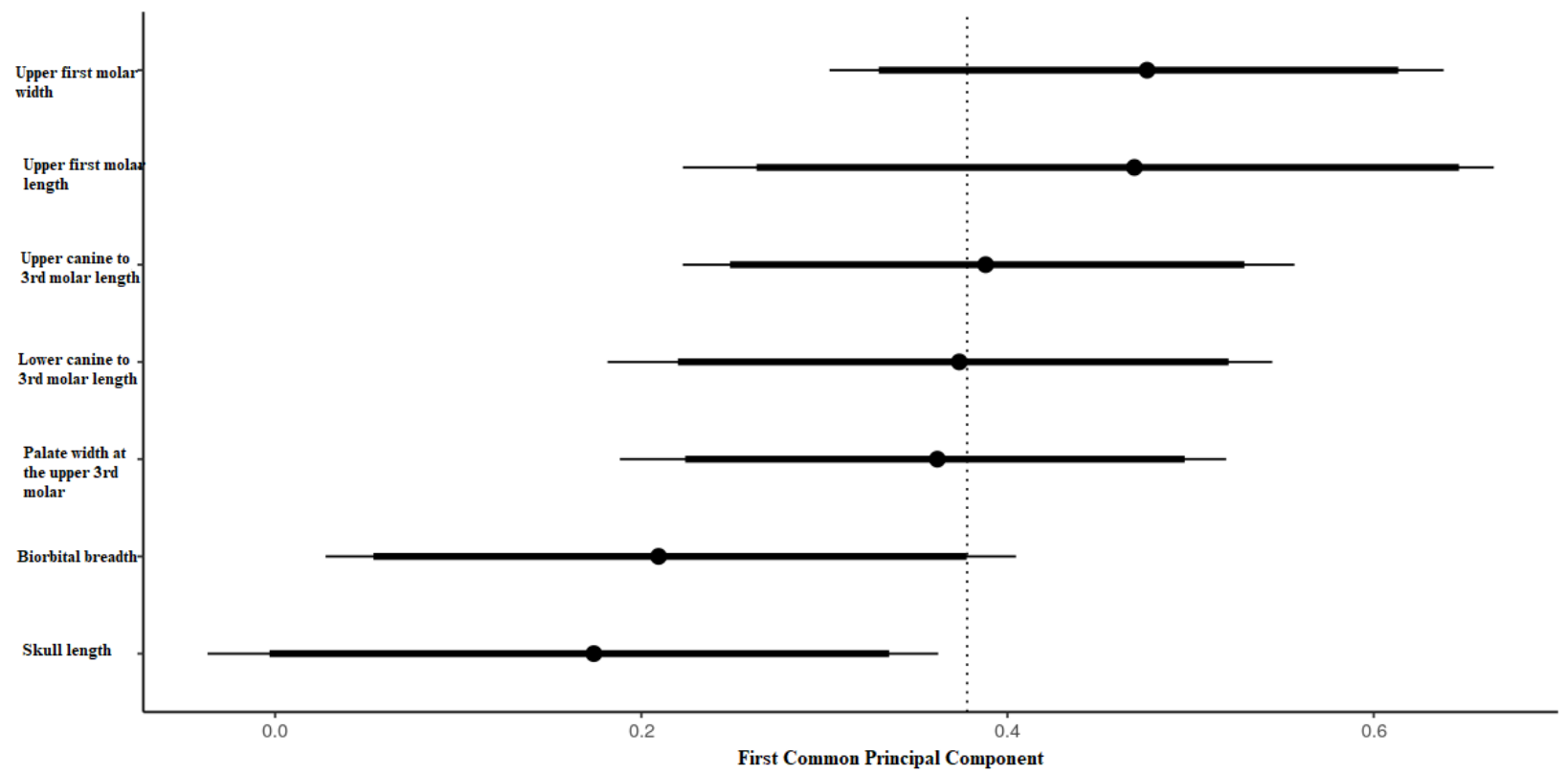

Figure 2.3: The first common principal component describing tarsier craniodental allometry, based on log transformed craniodental measures. Dots indicate posterior modes with $90 \%$ (thick) and $95 \%$ (thin) credible intervals. The vertical dashed line shows the isometric value. 


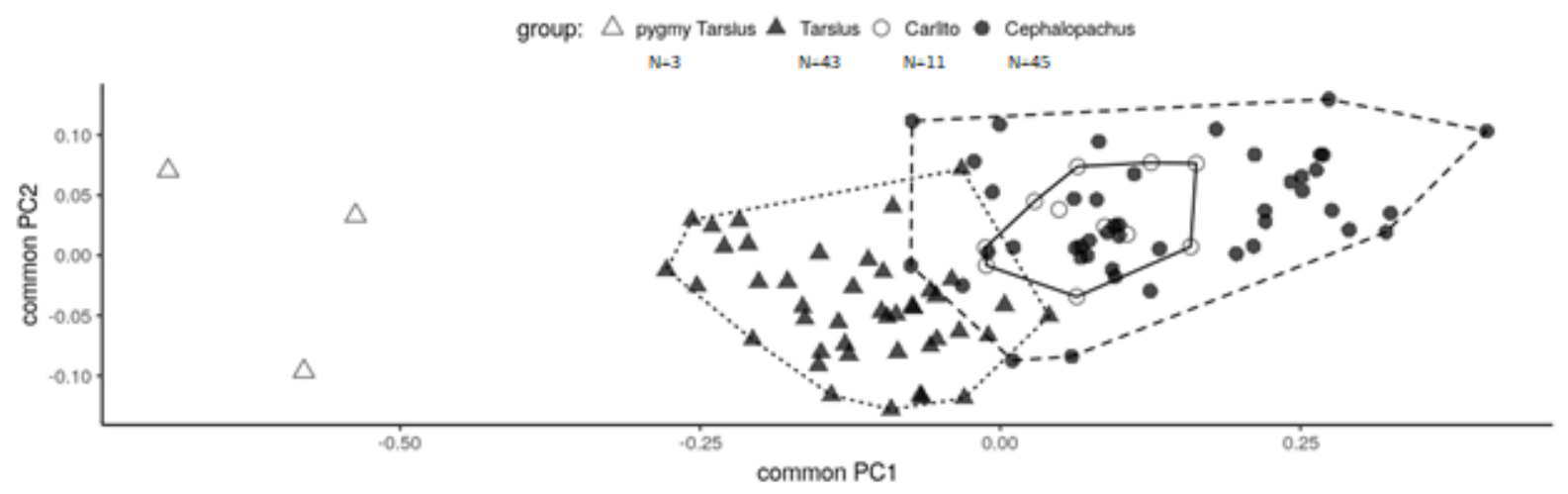

Figure 2.4: Scores for four tarsier groups on the first two common principal components of their craniodental measurements. 


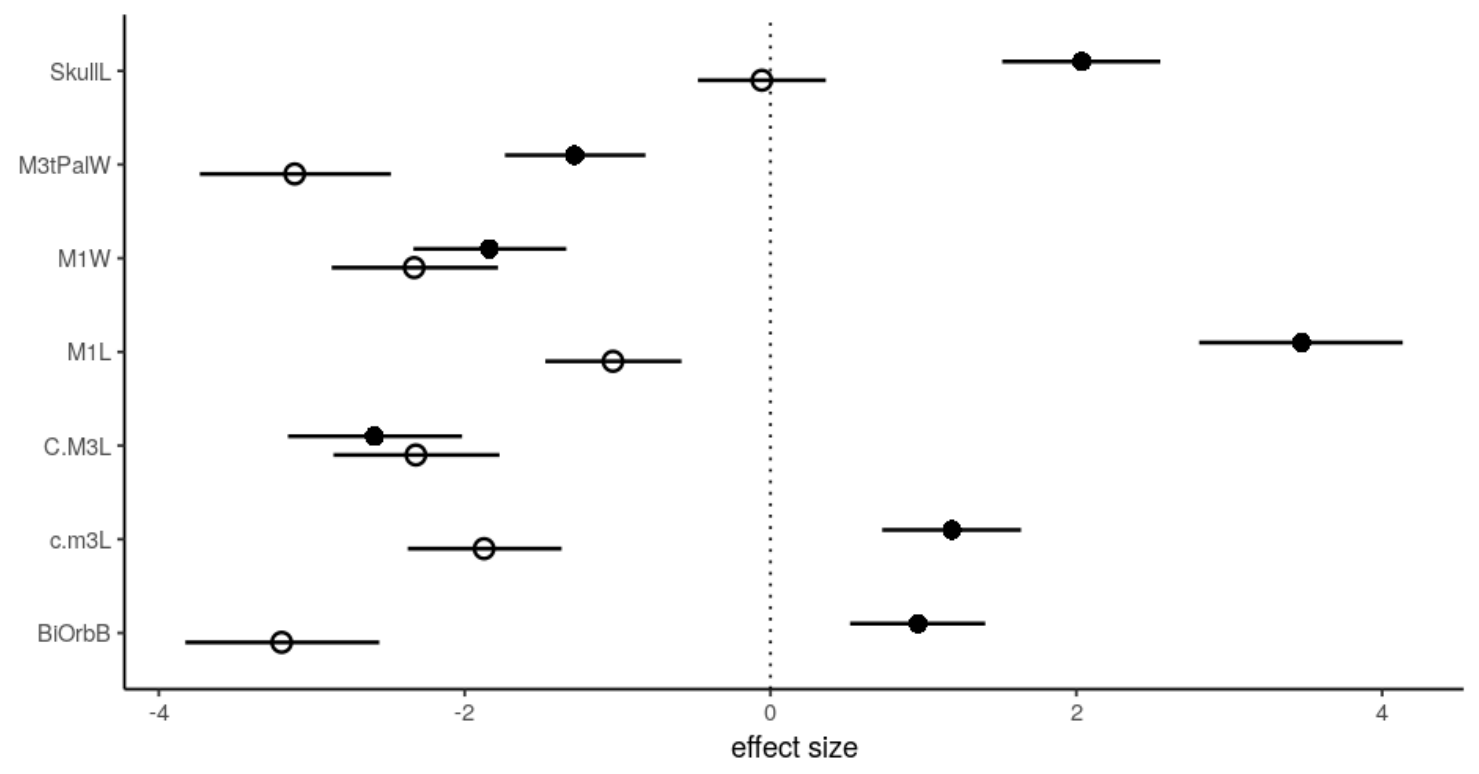

Figure 5. Effect sizes and confidence intervals from raw data (open circles) and sizeadjusted t-tests (filled circles) for differences between Tarsius and Cephalopachus in craniodental measures. Negative values indicate larger measurements in Cephalopachus and positive larger measurements in Tarsius. 

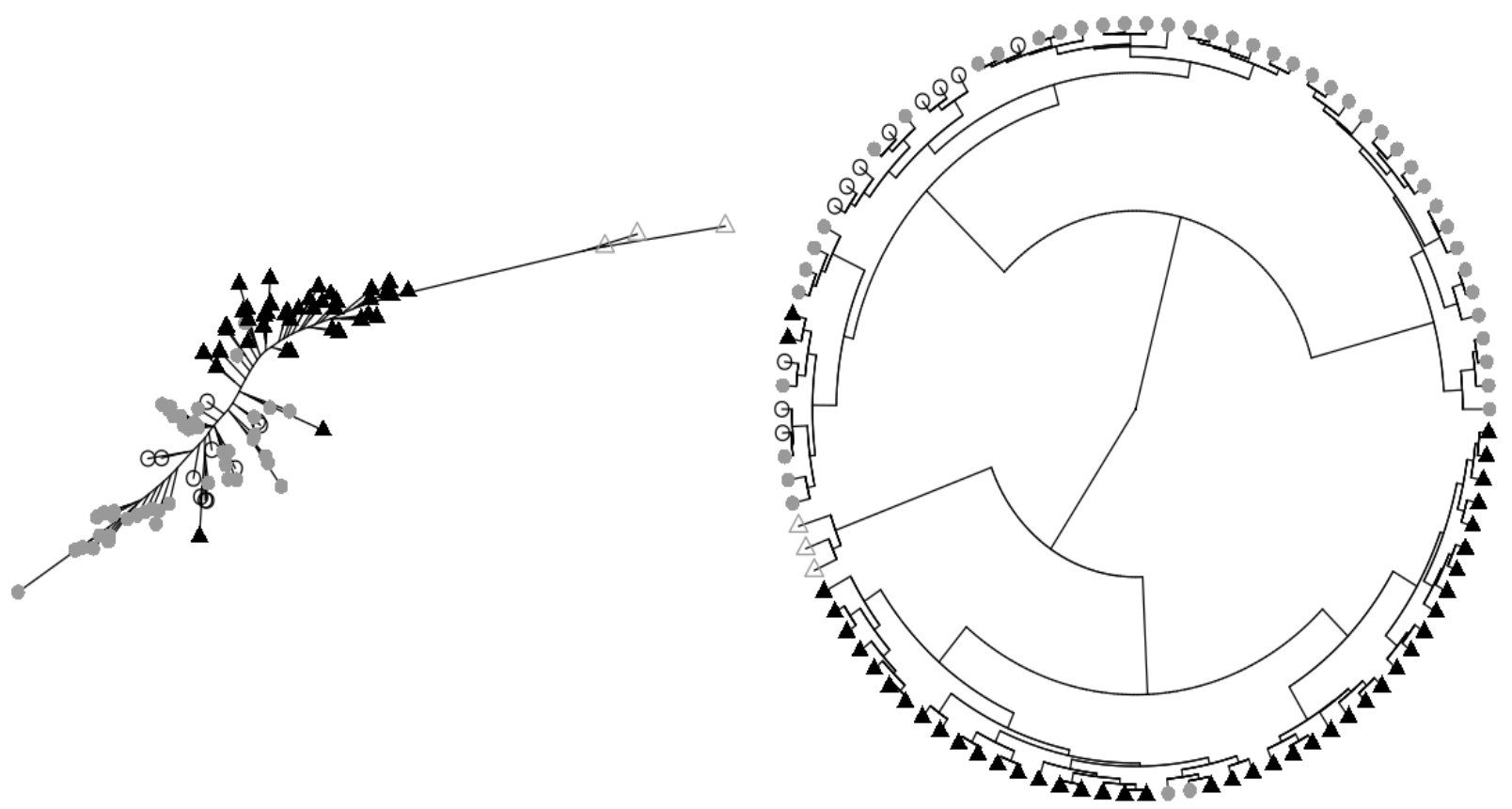

Figure 6: Unrooted neighbor joining tree (left) \& hierarchical clustering (right) of a Euclidean distance matrix of tarsier craniodental measurements. Pygmy tarsiers $(\mathrm{N}=3)$ are grey, open triangles, other Tarsius $(\mathrm{N}=43)$ are black, filled triangles, Carlito $(\mathrm{N}=11)$ are black, open circles, and Cephalopachus $(\mathrm{N}=45)$ are grey, filled dots. 
Table 2.1: Trait variations defining the three tarsier groups and pygmy tarsiers

\begin{tabular}{|c|c|c|}
\hline Group/Genus & Species & Traits \\
\hline $\begin{array}{l}\text { Borneo, Sumatra, and adjacent } \\
\text { islands: Cephalopachus }\end{array}$ & Ce. bancanus & $\begin{array}{l}\text {-Largest body mass }(123 \mathrm{~g})^{*} \\
\text {-Solitary sleepers } \\
\text {-Most faunivorous } \\
\text {-Little vocalization } \\
\text {-Most specialized VCL }\end{array}$ \\
\hline Philippine islands: Carlito & Ca. syrichta & $\begin{array}{l}\text {-Intermediate body mass } \\
(132 \mathrm{~g})^{*} \\
\text {-Solitary sleeper } \\
\text {-Intermediate VCL }\end{array}$ \\
\hline $\begin{array}{l}\text { Sulawesi and adjacent islands: } \\
\text { Tarsius }\end{array}$ & $\begin{array}{l}\text { T. dentatus, } T . \text { lariang, } T . \\
\text { pelengensis, } T \text {. sangirensis, } T \text {. } \\
\text { tarsius, } T . \text { tumpara, } T . \\
\text { wallacei }\end{array}$ & $\begin{array}{l}\text {-Small body mass }(112 \mathrm{~g})^{*} \\
\text {-Social sleepers } \\
\text {-Mainly insectivorous } \\
\text {-Highly vocal } \\
\text {-Duet calls with mates } \\
\text {-Least specialized VCL }\end{array}$ \\
\hline $\begin{array}{l}\text { Sulawesi highlands: } \\
\text { T. pumilus }\end{array}$ & T. pumilus & $\begin{array}{l}\text {-Very small body mass }(58 \mathrm{~g}) * \\
\text {-Ultrasonic vocalizations } \\
\text {-Ultrasonic duet calls }\end{array}$ \\
\hline
\end{tabular}


Table 2: Sample sizes, means, minima, and maxima of tarsier craniodental measurements from museum specimens in millimeters (mm).

\begin{tabular}{|c|c|c|c|c|c|c|c|c|c|c|c|c|c|c|c|c|c|c|c|c|}
\hline & \multicolumn{4}{|c|}{ total } & \multicolumn{4}{|c|}{ T. pumilus } & \multicolumn{4}{|c|}{ non-pygmy Tarsius } & \multicolumn{4}{|c|}{ Carlito } & \multicolumn{4}{|c|}{ Cephalopachus } \\
\hline Measurement & $\mathbf{N}$ & mean & $\min$ & $\max$ & $\mathbf{N}$ & mean & $\min$ & $\max$ & $\mathbf{N}$ & mean & $\min$ & $\max$ & $\mathbf{N}$ & mean & $\min$ & $\max$ & $\mathbf{N}$ & mean & $\min$ & $\max$ \\
\hline Skull length & 91 & 37.33 & 30.7 & 40.40 & 3 & 31.43 & 30.7 & 32.2 & 40 & 37.38 & 35.20 & 40.4 & 11 & 38.55 & 36.96 & 40.30 & 37 & 37.40 & 35.3 & 39.52 \\
\hline readth & 95 & 31.04 & 26.3 & 36.08 & 3 & 26.47 & 26.3 & 26.7 & 42 & 29.23 & 26.80 & 30.9 & 10 & 31.94 & 30.50 & 33.50 & 40 & 33.07 & 28.9 & 36.08 \\
\hline palat & 101 & 15.68 & 11.9 & 19.40 & 3 & 12.23 & 11.9 & 12.5 & 43 & 14.60 & 13.44 & 15.9 & 11 & 16.08 & 15.48 & 16.60 & 44 & 16.87 & 15.0 & 19.40 \\
\hline$-\mathrm{M}^{3}$ length & 98 & 13.52 & 10.4 & 16.20 & 3 & 10.73 & 10.4 & 11.1 & 40 & 12.80 & 12.00 & 13.6 & 11 & 14.05 & 13.44 & 14.70 & 44 & 14.22 & 13.2 & 16.20 \\
\hline ength & 100 & 14.11 & 10.6 & 16.72 & 3 & 10.97 & 10.6 & 11.4 & 41 & 13.50 & 12.60 & 14.6 & 11 & 14.69 & 14.00 & 15.32 & 45 & 14.74 & 13.7 & 16.72 \\
\hline esi & 101 & 2.72 & 1.8 & 3.12 & 3 & 2.00 & 1.8 & 2.2 & 43 & 2.65 & 2.32 & 3.0 & 11 & 2.74 & 2.64 & 2.90 & 44 & 2.82 & 2.4 & 3.12 \\
\hline buccolingual width of $\mathrm{M}^{1}$ & 101 & 3.75 & 2.9 & 4.56 & 3 & 2.97 & 2.9 & 3.1 & 43 & 3.51 & 3.10 & 3.8 & 11 & 3.84 & 3.54 & 4.22 & 44 & 4.02 & 3.6 & 4.56 \\
\hline
\end{tabular}


Table 2.3: K-means cluster analysis of tarsier craniodental measurements. Presence of more than 1 cluster is confirmed by the Duda-Hart test, while the average silhouette criterion is maximized with two clusters. Assignment of tarsier groups to the two clusters primarily divides Tarsius and T. pumilus (cluster A) from Carlito and Cephalopachus (cluster B).

\begin{tabular}{|c|c|c|c|c|c|c|c|c|c|}
\hline \multicolumn{5}{|c|}{ Clustering criteria: } & \multicolumn{5}{|c|}{$\mathrm{K}$-means clustering with $\mathrm{k}=\mathbf{2}$ : } \\
\hline \multicolumn{10}{|c|}{ Duda-Hart $\mathrm{H}_{0}: \mathrm{k}=1, \mathrm{p}<0.001$} \\
\hline \multicolumn{5}{|c|}{ Average silhouette criteria } & cluster & T. pumilus & Tarsius & Carlito & Cephalopachus \\
\hline $\mathrm{k}=2$ & $\mathrm{k}=3$ & $\mathrm{k}=4$ & $\mathrm{k}=5$ & $\mathrm{k}=6$ & $\mathbf{A}$ & 3 & 43 & 0 & 4 \\
\hline 0.430 & 0.350 & 0.349 & 0.321 & 0.272 & B & 0 & 0 & 11 & 41 \\
\hline
\end{tabular}




\section{Literature Cited}

Anemone, R.L., \& Nachman, B.A. (2003). Morphometrics, functional anatomy, and the biomechanics of locomotion among tarsiers. In P.C. Wright, E.L. Simons, \& S. Gursky (Eds.), Tarsiers: Past, Present and Future (pp. 97-120) New Brunswick, N.J: Rutgers University Press.

Beard, K.C., Qi, T., Dawson, M.R., Wang, B., \& Li, C.K. (1994). A diverse new primate fauna from middle Eocene fissure-fillings in southeaster China. Nature, 368, 604609.

Beard, K.C. (1998). A new genus of Tarsiidae (Mammalia: Primates) from the Middle Eocene of Shanxi Province, China, with notes on the historical biogeography of tarsiers. Bulletin of Carnegie Museum of Natural History. 34, 260-277.

Bolker, B., \& Phillips, P.C. (n.d.). Common principal components/back-projections analysis. cpcbp package $\mathrm{v}$ 0.3.3.

Brandon-Jones, D. (1998). Pre-glacial Bornean primate impoverishment and Wallace's line. In R. Hall \& J.D. Holloway (Ed.s), Biogeography and geological evolution of SE Asia (pp. 393-404). Leiden: Backhuys Publisher.

Brown, R.M., Weghorst, J.A., Olson, K.V., Duya, M.R.M., Barley, A.J., Duya, M.V., Shekelle, M., Neri-Arboleda, I., Esselstyn, J.A., Dominy, N.J., Ong, P.S., Moritz, G.L., Luczon, A., Diesmos, M.L.L., Diesmos, A.C., \& Siler, C.D. (2014). Conservation genetics of the Philippine tarsier: Cryptic genetic variation restructures conservation priorities for an island archipelago primate. PLOS ONE, 9(8),e104340.

Burnaby, T.P. (1966). Growth-invariant discrimination functions and generalized distances. Biometrics, 22, 96-110.

Chaimanee, Y., Lebrun, R., Yamee, C., \& Jaeger, J.J. (2011). A new Middle Miocene tarsier from Thailand and the reconstruction of its orbital morphology using a geometric-morphometric method. Proceedings of the Royal Society of London B: Biological Sciences, rspb20102062. 
Chaimanee, Y., Chavasseau, O., Beard, K.C., Kyaw, A.A., Soe, A.N., Sein, C., Lazzari, V., Marivaux, L., Marandat, B., Swe, M., Rugbumrung, M., Lwin, T., Valentin, X., Maung-Thein, Zin-Maung, Jaeger, J. (2012). Late Middle Eocene primates from the Myanmar and the initial anthropoid colonization of Africa. Proceedings of the National Academy of Sciences, 109, 10293-10297.

Cheverud, J.M. (1982). Relationships among ontogenetic, static, and evolutionary allometry. American Journal of Physical Anthropology, 59, 139-149.

Cheverud, J.M., \& Marroig, G. (2007). Comparing covariance matrices: random skewers method compared to the common principal components model. Genetics and Molecular Biology, 30(2), 461-469.

Crompton, R.H., \& Andau, P.M. (1987). Ranging, activity rhythms, and sociality in freeranging Tarsius bancanus: A preliminary report. International Journal of Primatology, 8(1), 43-71.

Dagosto, M., Gebo, D.L., \& Dolino, C.N. (2003). The natural history of the Philippine tarsier (Tarsius syrichta). In P.C. Wright, E.L. Simons, \& S. Gursky (Eds.), Tarsiers: Past, Present and Future (pp. 237-259) New Brunswick, N.J: Rutgers University Press.

Driller, C., Merker, S., Perwitasari-Farajallah, D., Sinaga, W., Anggraeni, N., \& Zischler, H. (2015). Stop and Go-Waves of tarsier dispersal mirror the genesis of Sulawesi island. PloS one, 10(11), e0141212.

Evans, A.R., \& Sanson, G.D. (1998). The effect of tooth shape on the breakdown of insects. Journal of Zoology London, 246, 391-400.

Fleagle, J.G. (1985). Size and Adaptations in Primates. In W.L. Jungers (Ed.), Size and Scaling in Primate Biology (pp. 1-19). New York: Plenum Press.

Flury, B. (1988). Common principal components and related multivariate models. Wiley, New York.

Ford, S.M. (1980). Callitrichids as phyletic dwarfs, and the place of the Callitrichidae in Platyrrhini. Primates 21:31-43. 
Gelman, A., \& Weakliem, D. (2009). Of beauty, sex and power: Too little attention has been paid to the statistical challenges in estimating small effects. American Scientist 97: 310-316.

Gingerich, P.D., Smith, B.H., \& Rosenberg, K. (1982). Allometric scaling in the dentition of primates and prediction of body weight from tooth size in fossils. American Journal of Physical Anthropology, 58, 81-100.

Gould, S.J. (1975). On the scaling of tooth size in mammals. American Zoologist, 15, $353-362$.

Groves, C. (1998). Systematics of tarsiers and lorises. Primates, 39, 13-27.

Groves, C., \& Shekelle, M. (2010). The genera and species of Tarsiidae. International Journal of Primatology, 31, 1071-1082.

Gursky, S. (2007). Tarsiiformes. In: C. Campbell, A. Fuentes, K. MacKinnon, M. Panger, S.K. Bearder (Eds.), Primates in Perspective (pp. 73-85) Oxford: Oxford University Press.

Hadfield, J.D. (2010). MCMC methods for multi-response generalized linear mixed models: the MCMCglmm R package. Journal of Statistical Software, 33(2), 1-22.

Hennig, C. (2015). Package 'fpc'.

Howland, H.C., Merola, S., \& Basarab, J.B. (2004). The allometry and scaling of the size of vertebrate eyes. Vision Research, 44(17), 2043-2065.

Jablonski, N.G. (2003). The evolution of the Tarsiid niche. In P.C. Wright, E.L. Simons, \& S. Gursky (Eds.), Tarsiers: Past, Present and Future (pp. 35-49) New Brunswick, N.J: Rutgers University Press.

Jablonski, N.G., \& Crompton, R.H. (1994). Feeding behavior, mastication, and tooth wear in the Western tarsier (Tarsius bancanus). International Journal of Primatology, 5(1), 29-59. 
Joffe, B., Peichl, L., Hendrickson, A., Leonhardt, H., \& Solovei, I. (2014). Diurnality and nocturnality in primates: an analysis from the rod photoreceptor nuclei perspective. Evolutionary Biology, 41(1), 1-11.

Jungers, W.L., Falsetti, A.B., \& Wall, C.E. (1995). Shape, relative size, and sizeadjustments in morphometrics. Yearbook of Physical Anthropology, 38, 137-161.

Klingenberg, C.P. (1996). Multivariate allometry. L.F. Marcus, M. Corti, A. Loy, G.J.P. Naylor, \& D.E. Slice (Eds.), Advances in Morphometrics (pp. 23-49) US: Springer.

Klingenberg, C.P. (2016). Size, shape, and form: Concepts of allometry in geometric morphometrics. Development Genes and Evolution, 226, 113-137.

Leigh, S.R., Shah, N.F., Buchanan, L.S. (2003). Ontogeny and phylogeny in papionin primates. Journal of Human Evolution, 45, 285-316.

Marroig, G., \& Cheverud, J.M. (2009). Size and shape in callimico and marmoset skulls: allometry and heterochrony in the morphological evolution of small Anthropoids. S.M. Ford, L.M. Porter, \& L.C. Davis (Eds.), The Marmoset/Callimico Radiation (pp. 331-354) US: Springer.

Martin, D., \& Ross, C.F. (2005). The evolutionary and ecological context of primate vision. In J. Kremers (Ed). The primate Visual System: A Comparative Approach (pp. 1-36) West Sussex: John Wiley \& Sons Ltd.

McCoy, M.W., Bolker, B.M., Osenberg, C.W., Miner, B.G., \& Vonesh, J.R. (2006). Size correction: comparing morphological traits among populations and environments. Oecolog, 148, 547-544.

Merker, S., Driller, C., Perwitasari-Farajallah, D., Pamungkas, J., Zischler, H. (2009). Elucidating geological and biological processes underlying the diversification of Sulawesi tarsiers. Proceedings of the National Academy of Sciences, 106, 84598464. 
Merker, S., Thomas, S., Volker, E., Perwitasari-Farajallah, D., Feldmeyer, B., Streit, B., \& Pfenniger, M. (2014). Control region length dynamics potentially drives amino acid evolution in tarsier mitochondrial genomes. Journal of Molecular Evolution, 79(1-2), 40-51.

Mitteroecker, P., Gunz, P., Windhager, S., \& Schaefer, K. (2013). A brief review of shape, form, and allometry in geometric morphometrics, with applications to human facial morphology. Hystrix, 24, 59-66

Musser, G.G., Dagosto, M. (1987). The identity of Tarsius pumilus, a pygmy species endemic to the montane mossy forests of central Sulawesi. American Museum Novitates, 2867, 1-53.

Niemitz, C. (1984). The Biology of Tarsiers. New York: Gustav Fischer Verlag.

Nietsch, A. (1993). Beitrage zur Biologie von Tarsius spectrum in Sulawesis-Zur morphometric, Entwicklung sowie zum Verhalten unter halbfreien und unter Freilandbedingungne, PhD Thesis, Freie Universitat Berlin.

Ovaskainen, O., Cano, J.M., \& Merilä, J. (2008). A Bayesian framework for comparative quantitative genetics. Proceedings of the Royal Society of London B 275: 669-678.

Paradis, E. (2010). pegas: an R packaged for population genetics with an integratedmodular approach. Bioinformatics, 26, 419-420.

Phillips, P.C., \& Arnold, S.J. (1999). Hierarchical comparison of genetics variancecovariance matrices. I. Using the Flury hierarchy. Evolution, 1506-1515.

R Development Core Team. (2013). R: A language and environment for statistical computing. R Foundation for Statistical Computing, Vienna, Austria. ISBN 390051-07-0.

Roff, D.A., Prokkola, J.M., Krams, I., \& Rantala, M.J. (2012). There is more than one way to skin a G matrix. Journal of evolutionary biology, 25(6), 1113-1126. 
Rosenberger, A.L. (2010). The skull of Tarsius: Functional morphology, eyeballs, and the nonpursuit of predatory lifestyle. International Journal of Primatology, 31, 1031-1054.

Rosenberger, A.L., \& Preuschoft, H. (2012). Evolutionary morphology, cranial biomechanics and the origins of tarsiers and anthropoids. Palaeobiodiversity and Palaeoenvironments, 92(4), 507-525.

Rosenberger, A.L., Smith, T.D., DeLeon, V.B., Burrows, A.M., Schenck, R., \& Halenar, L.B. (2016). Eye size and set in small-bodied fossil primates: A threedimensional method. The Anatomical Record, 299, 1671-1689.

Rossie, J.B., Xijun N., \& Beard, K.C. (2006). Cranial remains of an Eocene tarsier. Proceedings of the National Academy of Sciences of the United States of America, 103(12), 4381-4385.

Rychlik, L., Ramalhinho, G., \& Polly, P.D. (2006). Response to environmental factors and competition: skull, mandible and tooth shapes in Polish water shrews (Neomys, Soricidae, Mammalia). Journal of Zoological Systematics and Evolutionary Research, 44(4), 339-351.

Schluter, D. (1996). Adaptive radiation along genetic lines of least resistance. Evolution, 1766-1774.

Sebastiao, H., \& Marroig, G. (2013). Size and shape in cranial evolution of 2 marsupial genera: Didelphis and Philander (Didelphimorphia, Didelphidae). Journal of Mammalogy, 94(6), 1424-1437.

Simons, E.L. (2003). The evolution of the Tarsiid niche. In P.C. Wright, E.L. Simons, \& S. Gursky (Eds.), Tarsiers: Past, Present and Future (pp. 9-34) New Brunswick, N.J: Rutgers University Press.

Shekelle, M., Groves, C., Gursky, S., Neri-Arboleda, I. \& Nietsch, A. (2008). A method for multivariate analysis and classification of tarsier tail tufts. Primates of the oriental night, 71-84. 
Shekelle, M., Meier, R., Wahyu, Wirdateti I. \& Ting, N. (2010). Molecular phylogenetics and chronometrics of Tarsiidae based on 12S mtDNA haplotypes: Evidence for Miocene origins of crown tarsiers and numerous species within the Sulawesian Clade. International Journal of Primatology, 31, 1083-1106.

Singleton, M. (2002). Patterns of cranial shape variation in the Papionini (Primates: Cercopithecinae). Journal of Human Evolution, 42(5), 547-578.

Strait, S.G. (1993). Differences in occlusal morphology and molar size in frugivores and faunivores. Journal of Human Evolution, 25(6), 471-484.

Vinyard, C.J., Wall, C.E., Williams, S.H., Mork, A.L., Armfield, B.A., Melo, L.C.D., Valenca-Montengero, M.M., Valle, Y.B.M., de Oliveira, M.A.B., Lucas, P.W., Schmitt, D., Taylor, A.B. \& Hylander, W.L. (2009). The evolutionary morphology of tree gouging in marmosets. S.M. Ford, L.M. Porter, \& L.C. Davis (Eds.), The Marmoset/Callimico Radiation (pp. 395-409) US: Springer.

Ward Jr, J.H. (1963). Hierarchical grouping to optimize an objective function. Journal of the American statistical association, 58(301), 236-244.

West, G.B., Brown, J.H., \& Enquist, B.J. (1997). A general model for the origin of allometric scaling laws in biology. Science, 276, 122-126.

Wilson, L.A.B. (2013). Allometric disparity in rodent evolution. Ecology and Evolution, 3(4), 971-984.

Zelditch, M.L., Lundrigan, B.L., \& Garland, T. (2004). Developmental regulation of skull morphology. I. Ontogenetic dynamics of variance. Evolution \& Development, 6(3), 194-206.

Zijlstra, J.S., Lawerence, J.F., \& Wessels, W. (2013). The westernmost tarsier: A new genus and species from the Miocene of Pakistan. Journal of Human Evolution, $65,544-550$.

Ziyatdinov, A., Kanaan-Izquierdo, S., Trendafilov, N.T., Perera-Lluna, A. (2014). cpca: Methods to perform Common Principal Component Analysis (CPCA). R package vers. 0.1.2. 


\title{
CHAPTER 3:
}

\section{USING A MULTI-GENE APPROACH TO INFER THE}

\section{COMPLICATED PHYLOGENY AND EVOLUTIONARY HISTORY OF LORISES (ORDER PRIMATES: FAMILY LORISIDAE).}

\author{
Rachel A. Munds ${ }^{1,2}$, Chelsea L. Titus ${ }^{3}$, Lori S. Eggert ${ }^{3}$, and Gregory E. Blomquist ${ }^{1}$ \\ ${ }^{1}$ Department of Anthropology, University of Missouri, Columbia, MO 65211 \\ ${ }^{2}$ Nocturnal Primate Research Group, Oxford Brookes University, Oxford OX3 0BP, UK \\ ${ }^{3}$ Division of Biological Sciences, University of Missouri, Columbia, MO 65211
}

\begin{abstract}
Extensive phylogenetic studies have found robust phylogenies are modeled by using a multi-gene approach and sampling from the majority of the taxa of interest. Yet, molecular studies focused on the lorises, a cryptic primate family, have often relied on one gene, or just mitochondrial DNA, and many were unable to include all four genera in the analyses, resulting in inconclusive phylogenies. Past phylogenetic loris studies resulted in lorises being monophyletic, paraphyletic, or an unresolvable trichotomy with the closely related galagos. The purpose of our study is to improve our understanding of loris phylogeny and evolutionary history by using a multi-gene approach. We used the mitochondrial genes cytochrome $b$, and cytochrome c oxidase subunit 1 , along with a nuclear intron (recombination activating gene 2) and nuclear exon (the melanocortin 1 receptor). Maximum Likelihood and Bayesian phylogenetic analyses were conducted based on data from each locus, as well as on the concatenated sequences. The robust,
\end{abstract}


concatenated results found lorises to be a monophyletic family (Lorisidae) ( $\mathrm{PP} \geq 0.99$ ) with two distinct subfamilies: the African Perodictinae $(\mathrm{PP} \geq 0.99)$ and the Asian Lorisinae ( $P P \geq 0.99)$. Additionally, from these analyses all four genera were all recovered as monophyletic $(\mathrm{PP} \geq 0.99)$. Some of our single-gene analyses recovered monophyly, but many had discordances, with some showing paraphyly or a deep-trichotomy. Bayesian partitioned analyses inferred the most recent common ancestors of lorises emerged $\sim 42 \pm 6$ million years ago (mya), the Asian Lorisinae separated $~ 30 \pm 9$ mya, and Perodictinae arose $\sim 26 \pm 10$ mya. These times fit well with known historical tectonic shifts of the area, as well as with the sparse loris fossil record. Additionally, our results agree with previous multi-gene studies on Lorisidae which found lorises to be monophyletic and arising 40mya (Pereleman et al., 2011; Pozzi et al., 2014). By taking a multi-gene approach, we were able to recover a well-supported, monophyletic loris phylogeny and inferred the evolutionary history of this cryptic family.

\section{Introduction}

Inferring phylogenetic relatedness in deeply-diverged and cryptic organisms is a major challenge for biologists. Methods that rely on morphology to ascertain differences are useful but limited in scope as many cryptic species closely resemble each other (Bickford, 2007; Munds et al., 2013; Pozzi et al., 2015). Our understanding of cryptic species improved with the advent of genetics as many taxa were found to contain distinct genetic lineages. Early phylogenetic studies relied on single genes, often mitochondrial (mtDNA) genes, to analyze relationships (Lavergne et al., 1996; Porter et al., 1996; Rasmussen et al., 1998; Arnason et al., 1999), but more thorough research revealed 
dissonance in evolutionary rates among genes, emphasizing the need to use more than one gene and one type of gene for phylogenetic reconstructions (Springer et al., 2001; Rokas et al., 2003; Hedtke et al., 2006). What is known is that the incorporation of multiple genes from both the mitochondrial and nuclear genomes are helping researchers gain a clearer picture of the genetic relationships among cryptic species and their evolutionary histories, yet many taxa remain unexamined. Here, we adopt the use of multi-gene analyses to provide better insight to a primate family with an unresolved phylogeny, the lorises.

In addition, phylogenetic analyses are being improved by concatenating genes or through the use of a partitioned analysis which allows for the ideal model of molecular evolution for each individual locus (Springer et al., 2001; Rokas et al., 2003; Hedtke et al., 2006; Drummond et al., 2012). But studies have found that concatenation and partitioned analyses can be biased towards a single locus that overwhelms the phylogeny. Often these methods result in discordance between the designed gene-trees and the accepted species-tree (Pamilo \& Nei, 1988; Kubatko, 2007; Heled \& Drummond, 2009). To overcome for these incongruences, gene-tree species-tree analyses were developed. Unlike concatenation analyses that can be influenced strongly by one locus, the use of a multispecies coalescent or gene-tree species-tree reconciliation model has been demonstrated to provide a more robust phylogeny (Heled \& Drummond, 2009; Larget et al., 2010; Pozzi et al., 2014). Specifically, reconciliation analyses do not average all gene trees together to create a species tree, but instead recognize the gene trees are rooted in the species tree and work back in time from the present to the past (whereas concatenation analyses work from the past to the present) (Heled \& Drummond, 2009). 
Gene-tree species-tree reconciliation analyses are still new and not widely used, as concatenation and partitioned analyses still can produce well supported trees (Rokas et al., 2003; Heled \& Drummond, 2009; Pozzi et al., 2014). To attempt to infer the most robust phylogeny for lorises we will employ both a partitioned analysis and a gene-tree species-tree reconciliation analysis. This type of methodology has been used on Lorisiformes (galagos and lorises) (Pozzi et al., 2014).

Galagos and lorises are the non-Malagasy radiation of strepsirrhine primates. There are five genera of galagos (family: Galagidae): Galago, Galagoides, Euoticus, Otolemur, and Sciurocheirus. All galagos are nocturnal, primarily vertical clingers and leapers or arboreal quadrupeds, omnivorous, and are only found in Africa (Nash et al., 1989; Bearder, 1999; Nekaris \& Bearder, 2007; Pozzi et al., 2015; Svensson et al., 2016). Within lorises (family: Lorisidae) there are two genera in Africa (Arctocebus and Perodicticus) and two genera in Asia (Loris and Nycticebus). Lorises are nocturnal, omnivorous, arboreal quadrupeds that cannot leap (Nekaris \& Bearder, 2007). All lorises share a suite of traits, such as cryptic locomotion in which they move steadily and quietly throughout the forest making them difficult to detect (Charles-Dominique, 1977; Nekaris \& Bearder,2007), and some are similarly built: robust (Nycticebus and Perodicticus) or gracile (Loris and Arctocebus). All lorises possess a strong grasp facilitated by a highlyextended hallux and pollex and a reduced second digit on their hands and feet (Rasmussen \& Nekaris, 1998; Yoder et al., 2001; Harrison, 2010). This grasp can be kept tight for an extraordinarily long amount of time because of their unique circulation system (Harrison, 2010). Their crania are highly similar, with all genera having a diastema, and raised temporal lines. They also share specialized features in their post- 
crania, such as an elongated lumbar, a reduced tail, and practically equal lengths of their fore- and hind limbs (Cartmill, 1975; Schwartz \& Tattersall, 1985; Masters et al., 2005). In general, this shared loris morphology is a common argument for their proposed monophyly.

It is widely accepted that galagos and lorises (African and Asian) comprise a monophyletic infraorder (Lorisiformes) distinct from the Malagasy lemurs (Pozzi et al., 2014; Pozzi et al., 2015), but it is not as widely accepted that galago and loris families are monophyletic. Phylogenetic studies routinely distinguished the galagos, the African lorises, and the Asian lorises as three monophyletic groups, but the relationship among these groups remains a subject of debate due to differing interpretations of molecular, morphological, and biogeographic data (Yoder et al., 2001; Masters et al., 2005; Seiffert, 2007; Pozzi et al., 2014; Pozzi et al., 2015). A multi-gene approach clarified genus-level and species differences, and confirmed the monophyly of galagos (Pozzi et al., 2014; Pozzi et al., 2015). Such work has underscored the importance of using multiple genes for phylogenetic reconstruction, and the value of such research in interpreting the evolutionary histories of cryptic species. Although our understanding of galagos has improved, the same is not true for lorises. Much of the issue in interpreting loris phylogeny is due to a poor understanding of the relationship between the African and Asian lorises; without an improved understanding of their phylogeny we cannot adequately interpret their evolutionary history or dispersal events. 
Currently, there are several commonly proposed phylogenies for the loris family, with the first being loris monophyly (Fig 3.1A; Schwartz \& Tattersall, 1985; Roos et al., 2004; Harrison, 2010). It has also been suggested they are paraphyletic/diphyletic with an African loris-galago clade with an independent Asian loris group, or vice versa, an Asian loris-galago clade with the African lorises forming their own clade (Fig 3.1B; Yoder et al., 2000; Seiffert, 2003; Roos et al., 2004; Masters et al., 2005; Masters et al., 2007; Seiffert, 2007). Additionally, some propose all three primate groups (galagos, African lorises, and Asian lorises) are equally related to each other, forming an unresolvable trichotomy (Fig 3.1C; Pickford, 2012; Pozzi et al., 2015). In addition, there is debate on how the genera are related to each other. Commonly, it is accepted that there are African (subfamily Perodictinae: Arctocebus, and Perodicticus) and Asian (subfamily Lorisinae: Loris and Nycticebus) subfamilies (Rasmussen \& Nekaris, 1998), but other topologies have been put forth. Based on morphology, it has been suggested that robust lorises (Perodicticus and Nycticebus), and gracile lorises (Arctocebus and Loris) form different groups (Schwartz \& Tattersall, 1985). Karyotype studies have found Nycticebus and Arctocebus to be more closely related, with Loris and Perodicticus excluded (de Boer, 1973; Petter et al., 1979). Lastly, some have found Perodicticus to be an outgroup of the other lorises, based on cranial differences (Yoder, 1994). These various phylogenies are mainly based on morphological, fossil, and historical biogeographic analyses, although some have used molecular analyses too (de Boer, 1973; Petter et al., 1979; Yoder, 1994; Roos et al., 2004; Masters et al., 2007). 
The geographic separation of the African (Arctocebus and Perodicticus) and Asian (Loris and Nycticebus) lorises, in which the African lorises share a continent with the closely-related galagos, suggest a complicated evolutionary history that is poorly represented in the fossil record. There are three, well-confirmed loris and galago fossils that have been discovered: the galagos Saharagalago misrensis and Wadilemur elegans and the loris Karanisia. All three are North African and have been dated to the Eocene ( 35-41 million years ago (mya)) (Seiffert et al., 2005; Seiffert, 2007; Harrison, 2010; Seiffert, 2012). Additionally, there are three younger loris fossils dated to the Miocene ( 6-10mya). From Pakistan, a partial skeleton was attributed to Nyticeboides simposoni, and dental remains were attributed to Microloris pilbeami (Harrison, 2010). Finally, a 6mya snout from Kenya was attributed to a primate related to Arctocebus (Pickford, 2012). Based on the fossil record, some researchers have suggested that lorises have an Afro-Arabian origin (Roos et al., 2004; Masters et al., 2007; Seiffert, 2012; Pozzi et al., 2015). Others suggest that galagos evolved in Africa and lorises in Southeast (SE) Asia, and from there Perodicticus and Arctocebus spread to Africa during the late Miocene (Pickford, 2012). Such a proposal would explain why galagos are not present in SE Asia, but this proposal is not well supported by the Eocene fossil record (Seiffert, 2007; Seiffert, 2012).

Additionally, tectonic events inform our understanding of loris dispersal and evolution. During the Eocene ( 40mya), a land bridge formed connecting Africa to Asia, and opening a possible route of dispersal to Asia. During this time, the Indian plate was moving away from Africa and towards Asia, which could have facilitated loris movement to Asia. The land bridge and movement of the Indian plate to Asia are estimated to have 
occurred from 29-55mya (Chatterjee \& Scotese, 1999; Ali \& Aitchison, 2008). This timeline matches well with galago-loris and African-Asian loris divergences, which are estimated to 40mya and 38 mya, respectively (Roos et al., 2005; Masters et al., 2007; Seiffert, 2007; Pozzi et al., 2015). Yet, it remains unclear as to the manner in which the African and Asian lorises split. Some have suggested lorises are exhibiting an amazing form of parallel evolution. This hypothesis is supported by past molecular studies that found lorises to be either paraphyletic or polyphyletic, even though morphologically they appear very similar. Through parallel evolution these cryptic primates could have evolved similar morphologies, even similar robust (Perodicticus and Nycticebus) and gracile (Arctocebus and Loris) morphs between the two African and Asian groups (Yoder et al., 2001; Masters et al., 2007). But, it is not unreasonable to propose that these primates are monophyletic, and that they rapidly evolved from each other after separating from galagos ( 40mya), and before the African-Asian split ( 38mya). In fact, a monophyletic family would be the most parsimonious explanation and is well supported by morphological and molecular-phenotype studies (Schwartz \& Tattersall, 1985; Yoder et al., 2001; Roos et al., 2004; Pozzi et al., 2015). But without a resolved phylogeny, there is no way to infer their unique evolution, where they originated, and what traits would be considered ancestral or derived.

This study is one of the few studies to incorporate a multi-locus approach to infer the evolutionary history and relatedness within Lorisidae. There have been studies that have incorporated just a few mitochondrial DNA genes (mtDNA) or a few short interspersed nuclear elements (SINEs). Such research is important, but limited in scope, as mtDNA evolves faster than nuclear loci, and SINEs can be informative but 
incorporating different loci such as nuclear and mtDNA genes can provide a better understanding of the phylogenetic history of an organism. To date Pozzi et al., (2014) and Perelman et al., (2011) have provided the most detailed phylogenetic history of Lorisidae. Through the incorporation of 54 nuclear genes, Perelman et al., (2011) resolved a monophyletic Lorisidae family. Similarly, Pozzi et al., (2014) used 27 nuclear genes to recover a monophyletic Lorisidae phylogeny through maximum likelihood and Bayesian approaches, but gene tree species tree analyses found Galagidae to be paraphyletic with Asian lorises to the exclusion of African lorises. Besides these two studies only Roos et al., (2004) found Lorisidae to be monophyletic based on molecular evidence. Unlike these previous studies, our research will use both mtDNA and nuclear DNA to resolve the Lorisidae phylogeny. In addition, we will incorporate multiple individuals from most genera to provide a more robust estimate of their evolutionary history.

It is clear that more work is needed to provide a well-resolved and reliably dated loris phylogeny. Our research was conducted to improve our understanding of the evolutionary history of the Lorisidae and will help assess the plausibility of proposed dispersal events and the amount of morphological homoplasy or stasis involved. We used two mitochondrial genes (cytochrome $b$ (cytb) and cytochrome c oxidase subunit 1 (COI)) along with one intron of a nuclear (recombination activating gene $2(\operatorname{Rag} 2))$ and one exon of a nuclear gene (the melanocortin 1 receptor (Mc1r)). This study was focused only on interpreting the phylogenetic relationship of the lorises (not galagos), and the relationships among the loris genera. Furthermore, once phylogenies were established we inferred the divergence time of lorises, and the possible two subfamilies. This research will help determine the best scenarios of loris evolutionary history. 


\section{Methods}

Samples

We obtained samples (DNA, hair, tissue) from captive specimens housed at AZA approved institutions (Table 3.1). The majority of our samples were hair follicles. Our collection protocol for hair follicles required little to no handling of the animal and adhered to humane animal handling guidelines (Animal Behavior, 2008). Keepers were instructed to wear sterile gloves and use a piece of tape to pluck hair and follicles from individual lorises. The tape was then wrapped over the $\sim 20$ hair follicles and stored in a clean, dry coin envelope. Each sample was stored separately in its own sterile envelope. Two Nycticebus pygmaeus samples were from deceased individuals from the Duke Lemur Center. Several of our samples were from the Frozen Zoo ${ }^{\circledR}$ Collection at the San Diego Institute for Conservation Research and were provided as extracted DNA. The use of captive individuals is not considered problematic as our research interests are assessing the phylogenetic relationship among, rather than within genera. Additionally, these species and genera are easily recognizable (Nekaris \& Bearder, 2007) and hybridization due to living together in zoos is unlikely. Beyond their phenotype, there are isolating mechanisms that would prevent hybridization, such as differences in chromosome numbers, with Nycticebus having $2 \mathrm{n}=50$ and Arctocebus having $2 \mathrm{n}=52$. Although Perodicticus and Loris have the same number of chromosomes $(2 \mathrm{n}=62)$, they are phenotypically distinct from each other (deBoer, 1973; Chen et al., 1993). 
We acknowledge that using captive individuals would be problematic if this study addressed within species diversity (Lacy, 1987; Bailey et al., 2007; Pastorini et al., 2015). Obtaining samples from wild populations can be costly, and most lorises are difficult to humanely capture (Wiens, 2002; Pozzi et al., 2015). While it is possible to use museum specimens, ancient DNA methods are time consuming, and can be costly (Mason et al., 2011). We found it most effective to use captive individuals, although doing so meant that we were unable to include Arctocebus in parts of our study, as there are none in captivity. Fortunately, past studies have sequenced some Arctocebus samples and made those sequences (Rag2 and cyt $b$ ) available on GenBank, along with our outgroup sequences (Table 3.2).

Genomic DNA was extracted from hair follicles using the protocols of Eggert et al. (2005). For tissue samples, we extracted DNA using the DNeasy Blood and Tissue kit (Qiagen, Valencia, CA) with the manufacturer's protocols. For samples that were received as extracted DNA, we determined DNA concentrations using a Nano-drop spectrophotometer (Thermo Fisher Scientific, Waltham, M. A.) and diluted to a standard concentration $(15 \mathrm{ng} / \mu \mathrm{L})$ for amplification using the polymerase chain reaction (PCR).

\section{Sequencing}

We sequenced fragments of two mitochondrial and two nuclear loci respectively: cytochrome oxidase subunit 1 (COI), cytochrome $b$ (cyt $b)$, and recombinant activation gene 2 intron (Rag2) and the melanocortin 1 receptor (Mc1r) (Table 3.3). Previous studies have sequenced cyt $b$ and Rag2 for most, if not all genera of lorises, and made 
those sequences publicly available on GenBank (Perelman et al., 2011; Pozzi et al., 2015). The use of COI was based on the Barcode of Life project, in which part of COI has been designated as the standard genetic locus for species identification (Hebert et al., 2003; Hajibabaei et al., 2007). This particular gene is considered quite good at discriminating closely related species, but it is not always reliable (Hebert et al., 2003; Waugh, 2007). The criteria for using Mc1r is based on some genera of lorises (Loris and Nycticebus) possessing vibrant face masks that have been used to distinguish species within the genus (Nekaris \& Munds, 2010; Munds et al., 2013). The Mc1r is known to influence coat color in a variety of mammals suggesting that variation in this gene might be useful for demarcation in lorises (Hoekstra, 2006; Bradley \& Mundy, 2008).

Amplifications were performed in $25 \mu \mathrm{L}$ volumes containing $1 \mathrm{X}$ PCR Gold Buffer (50 mM KCL, 8 mM Tris-HCL), $0.2 \mathrm{mM}$ dNTPs, $0.4 \mu \mathrm{M}$ each forward and reverse primers, $2 \mathrm{mM} \mathrm{MgCl} 2$, 1 X BSA, $0.5 \mathrm{U}$ Amplitaq Gold DNA Polymerase (Thermo Fisher Scientific, Waltham, MA), and $1 \mu \mathrm{L}(\sim 15 \mathrm{ng})$ of DNA template. The PCR was performed under the following conditions: pre-denaturation at $95^{\circ}$ for 10 minutes; 40 - 45 cycles of denaturation at $95^{\circ} \mathrm{C}$ for 1 minute, primer annealing at $55^{\circ}-$ $60^{\circ} \mathrm{C}$ for 1 minute, and primer extension at $72^{\circ}$ for 1 minute; and a final elongation step at $72^{\circ} \mathrm{C}$ for 10 minutes. Amplification products were visualized in a $2 \%$ agarose gel and prepared for sequencing with either a Qiaquick PCR Purification Kit (Qiagen, Valencia, CA) or an EXO-AP protocol. The QIAquick PCR Purification followed the standard protocol, except for incubation of the elution step for 5 minutes and elution in $20 \mu \mathrm{L}$ of Buffer EB. Exo-AP Clean-up was run in $23.5 \mu \mathrm{L}$ volume reactions containing $2.75 \mu \mathrm{L}$ of 10x FastAP buffer (Thermo Fisher Scientific, Waltham, M. A.), $0.50 \mu \mathrm{L}$ of $1 \mathrm{U} / \mu \mathrm{L}$ 
FastAP (Thermo Fisher Scientific, Waltham, M. A.), $0.25 \mu \mathrm{L}$ of $20 \mathrm{U} / \mu \mathrm{L}$ Exonuclease I (New England Biolabs Inc., Ipswich, M. A.), and $20 \mu \mathrm{L}$ of PCR product. The profile included incubation at $37^{\circ} \mathrm{C}$ for 30 minutes followed by enzyme inactivation at $80^{\circ} \mathrm{C}$ for 15 minutes. Purified PCR products were sequenced in both directions at the University of Missouri DNA Core Facility on a 3730x1 96-capillary DNA Analyzer with Applied Biosystems Big Dye Terminator cycle sequencing chemistry (Thermo Fisher Scientific, Waltham, M. A.)

Analyses

Forward and reverse sequences were aligned and edited using GENEIOUS software v. 8.0.5 (Biomatters, Ltd.). All sequences were tested for saturation effects using DAMBE (Xia, 2017). If there is saturation, particularly at the third codon, we would expect twice as many transversions as transitions in our sequences. Both our nuclear and mitochondrial genes had a higher number of transitions than transversions, indicating low saturation (Xia, 2017). Sequences were trimmed to remove primers and to uniform lengths and translated to test for the presence of pseudogenes (numts). Numts are quite common in mammals and even more so in primates. These mtDNA sequences in the nuclear genome are problematic, as they can provide unreliable, often slower, interpretations of evolution. We used universal primers to reduce the chance of amplifying numts, as well as by checking for numts after amplification (Thalmann et al., 2004; Hazkani-Covo et al., 2010). For phylogenetic reconstruction, it is recommended to use outgroup species that are closely related, but not too closely related to the organisms of interest (Sanderson \& Shaffer, 2002; Puslednik \& Serb, 2008). Our interest was 
focused on the phyletic relationships within the family of lorises, and therefore Galago and Eulemur were outgroups for the analyses. Outgroups Eulemur and Galago, and available Arctocebus sequences were added to alignments. Eulemur is a distant relative, but still in the same suborder (Strepsirrhines) as lorises. Galagos share the same infraorder with lorises (Lorisiformes), which makes them closely related, but it is commonly accepted they form their own family separate from lorises (Phillips \& Walker, 2002; Nekaris \& Bearder, 2007). Sequences were then aligned with outgroup and Arctocebus sequences and then trimmed. Basepair (bp) lengths and number of polymorphic sites for each gene were: 205bp and 58 polymorphic sites for COI, $331 \mathrm{bp}$ and 107 polymorphic sites for cytb, 716bp and 34 polymorphic sites for Rag2, and 731bp and 45 polymorphic sites for Mc1r.

We used Bayesian and ML analyses as both frameworks have known limitations, but by using both we can provide a robust model of loris phylogeny. Bayesian posterior probability (PP) results are sensitive to long branch lengths, as well as closely related taxa, and small sample sizes (Susko, 2008); our study is susceptible to all these factors. Yet, bootstrap probabilities (BP) from Maximum Likelihood (ML) analyses can be too conservative and result in a ML that may not properly reflect the topology (Douady et al., 2003; Susko et al., 2008). Theoretically, if our sample sizes are sufficient then our final tree results from both sets of analyses should be similar (Douday et al., 2003; Brooks et al., 2007; Susko et al., 2008). For Bayesian analyses, a sample size is considered sufficient when the ESS exceeds 200 (Susko, 2008; Drummond et al., 2012). For ML, running bootstraps more than 250 times is acceptable, but given our small sample size of 
individuals, we increased our bootstrap runs to 1000 (Douady et al., 2003; Susko et al., 2008).

In total, we analyzed eight datasets: each gene was analyzed separately and were titled by their gene name (COI, cytb, Rag2, and Mc1r). Additionally, there were two sets of Rag2 and cytb analyses: one set that included Arctocebus and one set that did not include them. A Bayesian partitioned analysis was run on the combined mitochondrial genes (concatenated mtDNA), as well as all four genes that were analyzed (concatenated genes). Aligned sequences were uploaded to jModeltest ver. 2.1.7. The optimal model of nucleotide substitution was selected using the AICc criterion which is preferred with small datasets. An additional check was performed using the BIC criterion for our Bayesian analyses. Results from the BIC supported the nucleotide substitution model selected by the AICc. COI, Rag2 and Mc1r were analyzed with the HKY model, whereas for cyt $b$ we used the GTR model. For the Bayesian analyses, concatenated analyses used each individual gene's substitution rate inferred from jModeltest. The ML analyses required determining the concatenated substitution model which was HKY for both analyses. Program MEGA7 was used for ML phylogenies (Kumar et al., 2015). Node supports less than $0.5 \mathrm{BP}$ were discarded. A total of 1000 bootstrap replications were run for each Maximum Likelihood set of analyses performed.

A Bayesian approach was used to estimate phylogeny and divergence times using BEAST ver.2.4.5 (Drummond et al., 2012). Analyses incorporated the gene dataset generated from this research, as well as the two outgroup genera (Eulemur and Galago) and Arctocebus when available. 
A total of eight Bayesian analyses were run (Rag2 with and without Arctocebus, COI, cytb with and without Arctocebus, Mc1r, concatenated mtDNA, and concatenated genes). Based on our results from $j$ Modeltest we implemented a $G T R+G$ substitution model for cyt $b$ with the shape parameter of the gamma distribution fixed to 0.295. An HKY substitution model was used for COI with kappa set to 21.4686. The substitution model for Rag2 was an HKY+I with proportion of invariable sites fixed to 0.681 and a kappa of 4.8769. An HKY+G substitution model was used for Mc1r, with a gamma shape parameter of 0.1970 and a kappa set to 10.2679 . The concatenated models used Bayesian partitioned analyses so that each locus used the ideal model of molecular evolution in the analysis. All analyses used an uncorrelated lognormal relaxed-clock (ucld) model. There was variation on some of the priors for each gene due to the difference in models. For all models, we used a Yule process of speciation on the tree prior, with birth rate as a gamma distribution $(\alpha=0.001, \beta=1000)$ for cyt $b$ and all the genes, and a uniform distribution for the remainder of the analyses. Gamma shape was exponential with a mean of 1 . Both the ucld mean and ucld standard deviation varied depending on the genes being analyzed. Two calibration points with normal distributions were used to obtain the estimated divergence times of the Lorisidae genera. A mean of 58 mya, with a standard deviation of 3.0 was used for the time to most recent common ancestor (TMRCA) for Lemuriformes and Lorisiformes. The TMRCA for galagos and lorises was 40 mya with a standard deviation of 3.0. The dates used are based on wellsupported fossil dates and other phylogenetic studies (Yoder et al., 2001; Seiffert, 2007; Harrison, 2010; Perelemann et al., 2010; Pickford 2012). 
Four independent Markov chain Monte Carlo (MCMC) runs were used for each set of analyses. Each run was 40 million generations with an initial 50000 burn-in and sampled every 1000 for both log and tree files. Log files were imported into Tracer ver 1.4.1, where we checked to make sure the estimated sample size (ESS) was sufficient. Our sampling was more than enough as all ESSs exceeded 200 (most exceeded 1000) and trace plots all appeared as expected. TreeAnnotater ver. 2.4.5 was used to prepare each tree file for examination. Parameters for TreeAnnotater files were: 25\% burn-in, target tree type was Maximum clade credibility, and node heights were established by mean heights. Each tree file was independently inspected before combining all tree files for each set of analyses with LogCombiner ver. 1.5.3. Final combined trees were viewed in FigTree ver. 1.3.1. Consensus trees detailing the Bayesian Posterior Probability (PP) and ML Bootstrap Probability (BP) from analyses were designed using TreeGraph2 (Stover \& Muller, 2010), unless there were major discrepancies between analyses. Minimum displayed node support for Bayesian was $75 \%$.

In addition to Bayesian and ML analyses, we ran a Bayesian framework for a species-tree multispecies coalescent using *BEAST (Heled \& Drummond, 2009). Our primary purpose for this analysis was to account for uncertainty in the individual gene trees. Often results from concatenated gene trees can be heavily influenced by a single gene, and instead of accurately depicting a species tree they end up showing a gene-tree. The multi-species coalescent circumnavigates this problem by allowing each gene tree to influence each other (Heled \& Drummond, 2009; Liu \& Edwards, 2009; Pozzi et al., 2014). 
We used *BEAST a template within BEAST ver. 2.4.5 (Drummond et al., 2012) to run our multispecies coalescent species tree. All four loci (cytb, COI, Rag2, and Mc1r) were used for these analyses, as well as all individual Lorisidae analyzed in the study. Parameters for each locus were maintained from the above partitioned Bayesian analyses. Substitution models and tree models were independent for each locus, but the clock model for COI and cyt $b$ were not separated, as they are both mtDNA and expected to share similar clock rates (Heled \& Drummond, 2009; Drummond et al., 2012). All individual lorises were kept in the model, but Arctocebus was excluded as we did not have this genus for all genes analyzed. We used a Yule model for the species tree and a gamma distribution for the birthrate. Our model was run for 400 million generations, with an initial burn-in of 500 thousand, and we stored every 4000 generations for log and tree files. Log files were imported into Tracer ver. 1.4.1, where we checked to make sure the ESS was sufficient. All parameters exceeded the minimum ESS threshold of 200. TreeAnnotater ver. 2.4.5 was used to prepare the tree file for examination. Parameters used were $10 \%$ burn in, with 0.5 posterior probability, target tree was Maximum clade credibility and node heights were established at the median heights. A total of 90001 trees were viewed in FigTree ver. 1.3.1, with minimum node support set to 50\%. 


\section{Results}

Phylogeny

Based on our concatenated genes analyses (Fig 3.2; Fig Appendix (A)3.1) and our complete taxa analyses (Rag2 and cytb) (Fig 3.3) we found lorises to be monophyletic $(\mathrm{PP} \geq 0.99, \mathrm{BP} \geq 0.89)$ and with one distinct subfamily, the Asian lorises (Lorisinae) $(\mathrm{PP} \geq 0.99, \mathrm{BP} \geq 0.93$ ) (Fig 3.2). We could not confirm an African subfamily (Perodictinae) from the concatenated analyses as Arctocebus was not included in the analyses. But based on our Rag2 (Fig 3.3A; Fig A3.6A) and cytb (Fig 3.3B; Fig 3.3A) analyses that included Arctocebus, Perodictinae was significantly supported ( $\mathrm{PP} \geq 0.99$, $\mathrm{BP} \geq 0.97$ ). From all three (concatenated, Rag2 with Arctocebus, and cyt $b$ with Arctocebus) analyses, all genera were well-supported and distinct.

Our concatenated mtDNA tree and single gene trees were inconsistent with the concatenated and complete taxa topologies (Fig. 3.4). Only Mc1r results support loris monophyly ( $\mathrm{PP} \geq 0.99, \mathrm{BP} \geq 0.91$ ) with an Asian loris subfamily ( $\mathrm{PP} \geq 0.99, \mathrm{BP} \geq 0.91)$ (Fig. 3.4A; Fig A3.5). But Mc1r ML and Bayesian results differed, as ML supported a galagoPerodicticus clade. Mc1r was the only gene tree to fail in resolving species within Nycticebus, intermingling N. coucang and N. pygmaeus. Most of our single gene trees have polytomies, with no clear resolution to the loris phylogeny. The weak BP and PP results of COI (Fig 3.4B; Fig A3.4) suggest that Galago, Perodicticus, Loris, and Nycticebus are all equally related. Each genus is well-supported, but based on Bayesian analyses, $N$. coucang does not form its own species group ( $\mathrm{PP} \geq 0.46, \mathrm{BP} \geq 0.85)$. Similarly, the concatenated mtDNA (Fig 3.4C; Fig A3.2) analyses resulted in a polytomy among Galago and the loris genera, but $N$. coucang remained a distinct species $(\mathrm{PP} \geq 0.99$, 
$\mathrm{BP} \geq 0.99$ ). Finally, the exclusion of Arctocebus from cytb and Rag2 analyses failed to recover loris monophyly. Cyt $b$ without Arctocebus resulted in loris polytomy. Rag2 without Arctocebus (Fig 3.4D; Fig A3.6B) found lorises to be paraphyletic, as it had weak support for a monophyletic loris family ( $\mathrm{PP} \geq 0.36, \mathrm{BP} \geq 0.72$ ), thus pushing back the Perodicticus branch and making them equally related to galagos as they are to the distinct Asian loris subfamily ( $\mathrm{PP} \geq 0.99, \mathrm{BP} \geq 0.94)$.

Our discordances between the results of our single-gene and mtDNA analyses prompted us to run a multispecies coalescent model. Results regarding the relationships among the five genera analyzed were different from our concatenated analyses. There was weak support for loris monophyly ( $\mathrm{PP} \geq 0.48$ ). Instead, we found Perodicticus to be equally related to galagos as they are to the Asian lorises ( $P P \geq 0.99$ ) (Fig. 3.5).

\section{Evolutionary History}

Based on our concatenated gene results we found the loris family's (Lorisidae) most recent common ancestor (MRCA) emerged roughly 42mya. Even though we are cautious of our single gene results, we are confident of our concatenated gene analysis because all our results (single and combined gene analyses) indicated the MRCA of Lorisidae was present within the $95 \%$ confidence intervals (CI) of the concatenated gene's results (36-47mya), with a minimum age of 38mya (Rag2 without Arctocebus) and a maximum of 42mya (concatenated genes). Lorisinae was dated to 30mya (CI: 2239 mya), with Loris having a relatively young emergence of 4 mya (0.5-9mya) and an older Nycticebus date of 18mya (10-27mya). Once again, results from other analyses that had a Lorisinae subfamily fell within the $95 \%$ CI of our concatenated results, with Rag2 
without Arctocebus being on the lower cusp at 23my and cyt $b$ having the oldest estimated age at 34my. Similarly, results for Loris were comparable too, except COI and mtDNA dated the genus as much older (12 and 13my, respectively). Nycticebus results fell within the concatenated genes $\mathrm{CI}$ range, with $\mathrm{COI}$ and $\mathrm{mtDNA}$ results skirting the upper $\mathrm{CI}$ range (25.5 and 26my, respectively). As previously stated, we were only able to acquire Arctocebus sequences for cyt $b$ and Rag2, therefore Perodictinae age inferences were based on those results. Based on both analyses we estimated the MRCA of Perodictinae emerged 26mya (CI: 13-38mya). We only had multiple sequences of Arctocebus with our cyt $b$ analyses, which resulted in an estimated age of 6mya (CI: 1-11.43mya). Based on concatenated genes Perodicticus was younger than the other genera, with its MRCA dated to 3.5my (CI:0.4-8). Yet, COI, Rag2 with Arctocebus, and mtDNA all found the MRCA of Perodicticus to be older (14.5, 8.2, 16my, respectively). Finally, we were able to determine the emergence of $N$. coucang and $N$. pygmaeus. It is estimated $N$. coucang arose 7 mya (CI: $2-12.5 \mathrm{mya})$ and $N$. pygmaeus is dated to 5 mya (CI: $0.94-10.27 \mathrm{mya})$. Once again, COI and mtDNA analyses found these species to be relatively older, with $N$. coucang dated to $17 \mathrm{my}$, and $N$. pygmaeus dated to $15 \mathrm{my}$ (COI) or 17my (mtDNA). Even though there is variation among our results, the majority of our results fall within the $95 \%$ $\mathrm{CI}$ of the concatenated genes, adding further support to our conclusions. 


\section{Discussion}

Loris Phylogeny

By using multiple genes from both the mitochondrial and nuclear genomes we found lorises to be an ancient, monophyletic group (Lorisidae) with African and Asian lorises as distinct monophyletic subclades (Perodictinae and Lorisinae, respectively). Moreover, results from all analyses found each recognized loris genus to be monophyletic (Table 3.4). Prior confusion surrounding loris phylogeny resulted from immunological, karyotype, and genetics studies that relied on a single gene, often a mitochondrial gene. These past molecular studies were limited in scope or excluded some of the genera in the analyses. Additionally, many of these molecular studies failed to agree with the extensive studies on morphology that found a monophyletic Lorisidae (Rasmussen \& Nekaris, 1998; Yoder et al., 2001; Masters et al., 2005). As previously stated, the four Lorisidae genera share numerous traits that unite them as a family, such as a reduced index finger, a unique vascular system that enhances their ability to grasp, cryptic locomotion, extended hallux and pollex, a diastema, as well as many more features (Rasmussen \& Nekaris, 1998; Harrison, 2010), which are unlikely to have evolved in parallel. Like the morphology studies that incorporated a variety of analyses to conclude monophyly, and a few molecular studies that also resolved a monophyletic Lorisidae, our research demonstrates the importance of multiple genes from both the nuclear and mitochondrial genomes to interpret family relationships (Kullnig-Gradinger et al., 2002; Hedtke et al., 2006; Perelmann et al., 2011; Pozzi et al., 2014). 
We have discordance between our results based on concatenated sequences and those based on single genes, and our multispecies coalescence gene-tree species-tree model, which highlights the challenges researchers have faced in trying to interpret a molecular loris phylogeny. Although our concatenated and complete-taxa analyses resulted in a monophyletic Lorisidae with two distinct subfamilies (Fig. 3.2 \& 3.3), many of our single-gene analyses and the coalescence analysis resulted in either loris paraphyly (Fig. 3.4D, Fig. 3.5), or a polytomy of equally related groups among Galago, Perodicticus, Loris, and Nycticebus group (Fig 3.4 A, B, \& C). These varying results are unsurprising, as past Lorisidae phylogenies built using a single gene or only mtDNA have similar conclusions. Both Porter et al., (1997) and Yoder et al., (2001) noted Lorisinae to be more closely related to galagos than to Perodictinae. These results were based solely on genetic analyses that used one or two genes, mainly mtDNA; a monophyletic Lorisidae was recovered when morphology was also included in the analyses (Yoder et al., 2001). Masters et al., (2005) had similar incongruences with their own study, as they could not recover a monophyletic Lorisidae with their genetic results based on $12 \mathrm{~S}, 16 \mathrm{~S}$, and a combined $12 \mathrm{~S}$ and $16 \mathrm{~S}$ rRNA gene analysis. Instead they found Lorisidae to be paraphyletic with Lorisinae linked to galagos, like past studies (Porter et al., 1997; Yoder et al., 2001), or with Perodictinae as a sister taxon to galago, similar to our results from Rag2 that excluded Arctocebus. Yet, Masters et al., (2005) recovered a monophyletic Lorisidae when they excluded Microcebus as their outgroup, and instead used galagos.

As for the different results based on analysis methods, Pozzi et al., (2014) also ran a gene-tree species-tree analysis to infer the relationships among galagos and lorises. Similar to our results, they found Lorisinae to be monophyletic, but they could not 
conclude Lorisidae monophyly. Instead, their results found Lorisinae and galagos to form a sister relationship to the exclusion of Perodictinae (Pozzi et al., 2014). Although our results were not in complete agreement with their findings, we both found Lorisidae was not monophyletic with gene-tree species-tree coalescence analyses. Unlike Pozzi et al., (2014), we found Perodictinae to form a sister-taxa with galago. This could be a result of missing taxa, as we were unable to include Arctocebus in these analyses. No other studies have done such analyses on Lorisidae phylogeny, so although we find this approach useful, we will base our conclusions of Lorisidae phylogeny on the Bayesian partitioned analyses.

Pozzi et al., (2014; 2015) has provided the most recent, and possibly most comprehensive investigation into Lorisidae phylogeny. Their 2015 analyses used one gene for their interpretation (cyt $b$ ). While cyt $b$ is a well-conserved gene and has been used by many to recover phylogenies (Zardoya \& Meyer, 1996) studies have found that it is not always reliable (Springer et al., 2001). Using cytb, Pozzi et al., (2015) could not confirm the monophyly of Lorisidae, and instead found it to be paraphyletic, with Perodictinae more related to galagos than to Lorisinae. Roos et al. (2004) also used whole cyt $b$ sequences, as well as sequences from two strepsirrhine-specific short interspersed nuclear elements (SINEs). Similarly, their cyt $b$ results did not confirm a monophyletic Lorisidae, and instead showed a deep trichotomy between the galagos, the Asian, and the African lorises (Roos et al., 2004). Our own cyt $b$ results provide weak support for monophyly, particularly when Arctocebus is not included in the analyses; in this case we find Lorisidae to form a trichotomy with the galagos, Asian, and African lorises. Yet, based on three SINE loci, Roos et al., (2004) support monophyly with three 
integrations, and further support a common ancestor for Perodictinae and Lorisinae. Pereleman et al. (2011) examined loris phylogeny in the context of examining the whole Primates Order. Unlike most past studies, they used multiple introns and exons of nuclear genes for phylogenetic reconstruction, providing a more robust interpretation, but they had a small number of samples from each genus, often only one individual. Pozzi et al., (2014) used 27 nuclear genes to specifically determine the evolutionary history of Galagidae, but also incorporated Lorisidae to provide a more detailed history. Both their ML and Bayesian analyses found Lorisidae to be monophyletic, but the coalescent results determined them to be paraphyletic with Asian lorises more closely related to Galagidae than to the African lorises. Like Roos et al. (2004), and our concatenated results, Perelemann et al., (2011) found Lorisidae to be monophyletic (ML 71-80\%). The monophyly of Lorisidae is well-supported when multiple nuclear genes are considered, but not when the analysis is based on single genes, particularly mitochondrial genes (Roos et al., 2004; Perleman et al., 2011).

The use of multiple genes, and different types of genes to recover a robust phylogeny is not a new concept, but this method has rarely been used for phylogenetic analyses with the Lorisidae. Although, some have proposed that at least 20 genes should be used for phylogenetic analyses (Rokas et al., 2003), others have demonstrated that as few as three genes can suffice as long as taxon sampling is sufficient (Hedtke et al., 2006; Heath et al., 2008). Robust phylogenies are inferred by using a variety of genes, and not just mitochondrial genes (Kullnig-Gradinger et al., 2002; Hedtke et al., 2006).

Additionally, complete or near-complete taxon sampling improves phylogenetic accuracy (Pollock et al., 2002; Zwickl \& Hillis, 2002; Hillis et al., 2003). This was demonstrated 
quite well with our own study, as the only monophyletic single-gene trees were from those that include all the Lorisidae genera (Fig. 3.3), and Mc1r. Cytochrome $b$ with Arctocebus is a polytomy within Lorisidae, but Galago is not a part of that polytomy, unlike the other single-gene trees in which Galago is part of the polytomy. By using a variety of genes, and sampling from all the taxa, researchers can avoid common pitfalls, such as nuclear mitochondrial pseudogenes (Numts), high measures of repeatability, and errors in alignment and interpretation of insertions and deletions (Sorenson \& Quinn, 1998; Bensasson et al., 2001; Zwickl \& Hillis, 2002; Heath et al., 2008; Loytynoja \& Goldman, 2008; Song et al., 2008; Fletcher \& Yang, 2010). Similarly, our study circumvents these issues as we used four genes, both mitochondrial and nuclear, sampled from all the genera, and used more than one individual to represent each genus. By incorporating all these methods, we have a well-supported loris phylogeny.

\section{Evolutionary History}

Based on our analyses, and other evolutionary studies, we estimate Lorisidae emerged during the Eocene around 41 mya (HPD 95\%: 36-47.1mya) (Perelemann et al., 2011; Pozzi et al., 2015). Once Lorisidae split from galagos (Galagidae), we predict a subfamily division occurred, resulting in Lorisinae and Perodictinae arising during the Oligocene ( 30mya). Because we do not have Arctocebus sequences for all analyses we can only confidently provide Perodictinae divergence estimates from Rag2 and cyt $b$ (26 mya and 27 mya, respectively). Alternatively, we were able to acquire sequences from all the genes of interest for Loris and Nycticebus to provide a robust Lorisinae estimate. On average, Lorisinae's most recent common ancestor (MRCA) is dated to 29mya, with 
an early divergence of 36.5 mya (cyt $b$ without Arctocebus) and the youngest dating to 22.6mya (Rag2 without Arctocebus). Similarly, Perelemann et al., (2011) and Pozzi et al., (2014; 2015) found deep divergences between the Lorisidae subfamilies with Lorisinae emerging $\sim 29$ mya and Perodictinae $~ 23$ mya. Such a deep divergence, roughly 30mya of independent evolution, implies that Lorisidae diversified rapidly, resulting in two distinct morphologies for each subfamily: robust (Perodicticus and Nycticebus) and gracile (Arctocebus and Loris). Our study reaffirms the extraordinarily deep-divergences within Lorisidae, emphasizing the complicated evolutionary history these primates present in comparison to other primates (Perelman et al., 2011).

Some researchers have suggested that Lorisidae arose in Asia and then moved to Africa (Masters et al., 2005), with some adding that from the African group galagos emerged (Pickford, 2012). This suggestion would provide an easy explanation as to the absence of galagos from Asia, but it is not in agreement with the current fossil record or our concatenated results. Our concatenated results suggest that Lorisidae arose $\sim 41$ mya and are monophyletic. This is in accordance with the dating of Karanisia which is dated to 35-51mya and found in Egypt (Seiffert, et al., 2005; Seiffert, 2007; Harrison, 2010; Seiffert, 2012). A North African point of origin is in contradiction to the loris Asian origin proposal, but a North African dispersal of Lorisidae is supported by well-accepted biogeographic changes - although it does not explain why galagos are not present in Asia. Their absence on Asia could have been due to competition with tarsiers (Tarsius), another vertical-clinging, small-bodied primate, that shares a similar diet with galagos. It could also be attributed to a lack of resources, or the tectonic shifts that aided Lorisidae dispersal was not favorable to galagos (Fleagle, 2013). Biogeographically, it is 
understood that India began to separate from Seychelles and Gondwana around 65mya but remained intermittently connected to North Africa for around 20my afterwards, thus remaining connected to this region until about 45mya (de Wit, 2003; Ali \& Aitchison, 2008), and then eventually it collided with Tibet $~ 35$ mya (Ali \& Aitchison, 2008). The 35mya collision of India to Tibet correlates to our MRCA of Lorisinae which is dated to 22.6-36.5mya. It also supports the over 30my of separation between Lorisinae and Perodictinae. From our analyses, not only is a monophyletic Lorisidae supported, but our dates are corroborated from well-documented geographic and fossil dates.

We are confident with our genus-level results as they are comparable to past molecular studies, but the species and possible genus level differences that Pozzi et al., (2015) suggested between $N$. coucang and N. pygmaeus are tentatively proposed as we have insignificant posterior support for $N$. coucang when using Rag2 and COI. Like other studies, Nycticebus is the oldest genus with its MRCA dated to 12.9-26.7mya, or 18.4mya based on results when using the concatenated genes. The species divergence within this genus are quite deep too, with the MRCA for $N$. coucang at 6.49 and $N$. pygmaeus at 4.87 mya. This seemingly long-term separation between species has caused some to propose that $N$. pygmaeus should be its own genus (Pozzi et al., 2015), as few primate species exhibit such distinct morphological difference and millions of years of separation from each other (Goodman et al., 1998; Yoder \& Yang, 2000; Perelemann et al., 2011; Fleagle, 2013). In general, our results support Pozzi et al. (2015), who claim that $N$. pygmaeus should be its own genus but given our weak support for phylogenetic distinction based on some of the genes, we suggest more analyses be done. In comparison to Nycticebus, the other Lorisidae genera are relatively younger with Loris 
emerging 4.08 mya and Perodicticus at only 3.53 mya. We are not reporting Arctocebus results, as they are only based on one gene (cytb). The relatively young MRCA dates for these latter two genera, in comparison to Nycticebus, could be used to further support the genus level distinction of $N$. pygmaeus.

The evolutionary history of Lorisidae is difficult to interpret, as our understanding is based on a handful of fossils, and a reasonable comprehension of the biogeographic history. The dearth of fossils is a major hindrance in interpreting their evolution. There are three well-supported Lorisiformes fossils (Saharagalago, Wadilemur, and Karanisia) from North Africa that are dated to the Eocene (35-41mya) (Seiffert et al., 2005; Seiffert, 2007; Harrison, 2010; Seiffert, 2012). After these fossils, there is an almost 35my gap before the next dated fossils. Of three Miocene (6-10mya) fossils, two are from Pakistan for the possible ancestral Lorisinae, and one is from Kenya for the ancient Arctocebus (Harrison, 2010; Pickford, 2012). The Eocene and Miocene fossil dates are what are used when calibrating Bayesian analyses to infer Lorisidae evolution (Masters et al., 2007; Perelman et al., 2011; Pozzi et al., 2015), and could possibly be contributing to the difficulty of interpreting them. Ideally, more fossils will be found that are dated between the Eocene and Miocene, which will provide a better idea of Lorisidae evolution, but at this time researchers must rely on other methods, such as molecular analyses to understand Lorisidae. By combining the fossil evidence with what we know of the biogeographic history of North Africa and Asia, we can provide a reasonable reconstruction of Lorisinae's dispersal to Asia. 


\section{Conclusion}

Our research emphasizes the importance of incorporating several genes, of varying types, for phylogenetic reconstruction, and the importance of sampling from all members of the taxa (Rokas et al., 2003; Hedtke et al., 2006). Research on other ancient $(40 \mathrm{my}+)$ taxa have demonstrated a single gene tree is not reflective of a species tree, with single gene trees producing different phylogenetic reconstructions and inconsistencies. By using a variety genes misinterpretation can be avoided (Hedtke et al., 2006). We provide one of the most comprehensive loris molecular phylogenies by using several types of genes and sampling from all members of the taxa. Our results found lorises to be a monophyletic family, Lorisidae, with two subfamilies: the Asian Lorisinae and the African Perodictinae. The distinctiveness of these subfamilies has elicited suggestions that they be up-listed to family status (Pozzi et al., 2015), and future research should investigate that proposal. We anticipate increases in the genetic data and sample sizes may reveal significant separation between the two subfamilies. Additionally, future work should examine the possible genus level separation of $N$. pygmaeus from $N$. coucang, as our concatenated results support such a division along with Pozzi et al., (2015).

The evolutionary history of Lorisidae is mired because of the lack of fossils, and the difficulty in interpreting the dispersal of these primates from North Africa to Asia. Until more fossils are unearthed, we can only speculate when and how they arrived in Asia, and why galagos are not present in Asia. What our study demonstrates is that Lorisidae has a deep-evolutionary history, emerging during the Eocene roughly 40mya. From there the two subfamilies quickly diverged around the Oligocene/Miocene, with each subfamily retaining similar gracile and robust forms. An improved understanding of 
Lorisidae evolution will only be found with more molecular studies that incorporate a multitude of sequences, a larger taxa set (Rokas et al., 2003; Hedtke et al., 2006), and of course more fossils.

\section{Acknowledgements}

We thank the American Zoological Association for their assistance with this project, and the participatory zoos and institutions. Dr. Helena Fitch-Snyder for her advice, information on the AZA captive lorises, and her time. Drs Elena Less and Mike Dulaney for studbook information. Finally, we thank financial support from Sigma Xi. Also, we thank two anonymous reviewers who greatly improved the quality of this manuscript. 


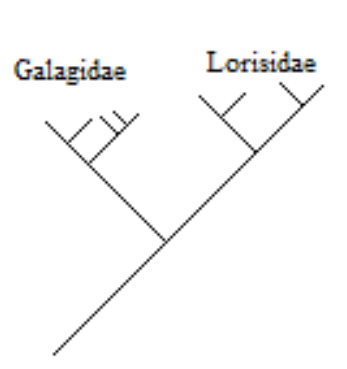

A

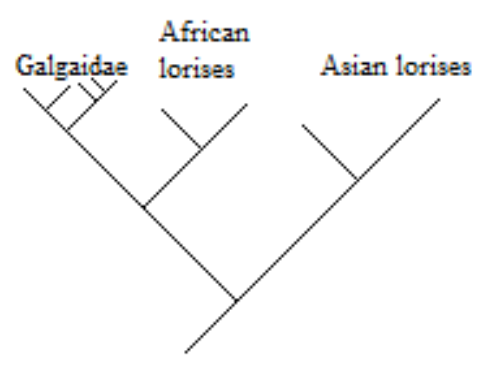

B

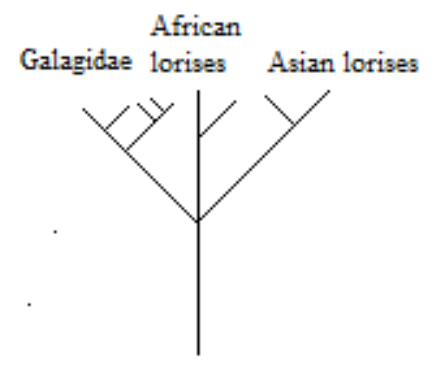

C

Figure 3.1: Commonly proposed loris phylogenies: (A) shows a monophyletic loris (Lorisidae) grouping, (B) shows a geographically parsimonious African and Asian grouping (a less parsimonious alternative is Asian lorises are more closely related to galagos-not shown), (C) indicates that Galagidae, the African, and the Asian lorises are all equally related. 


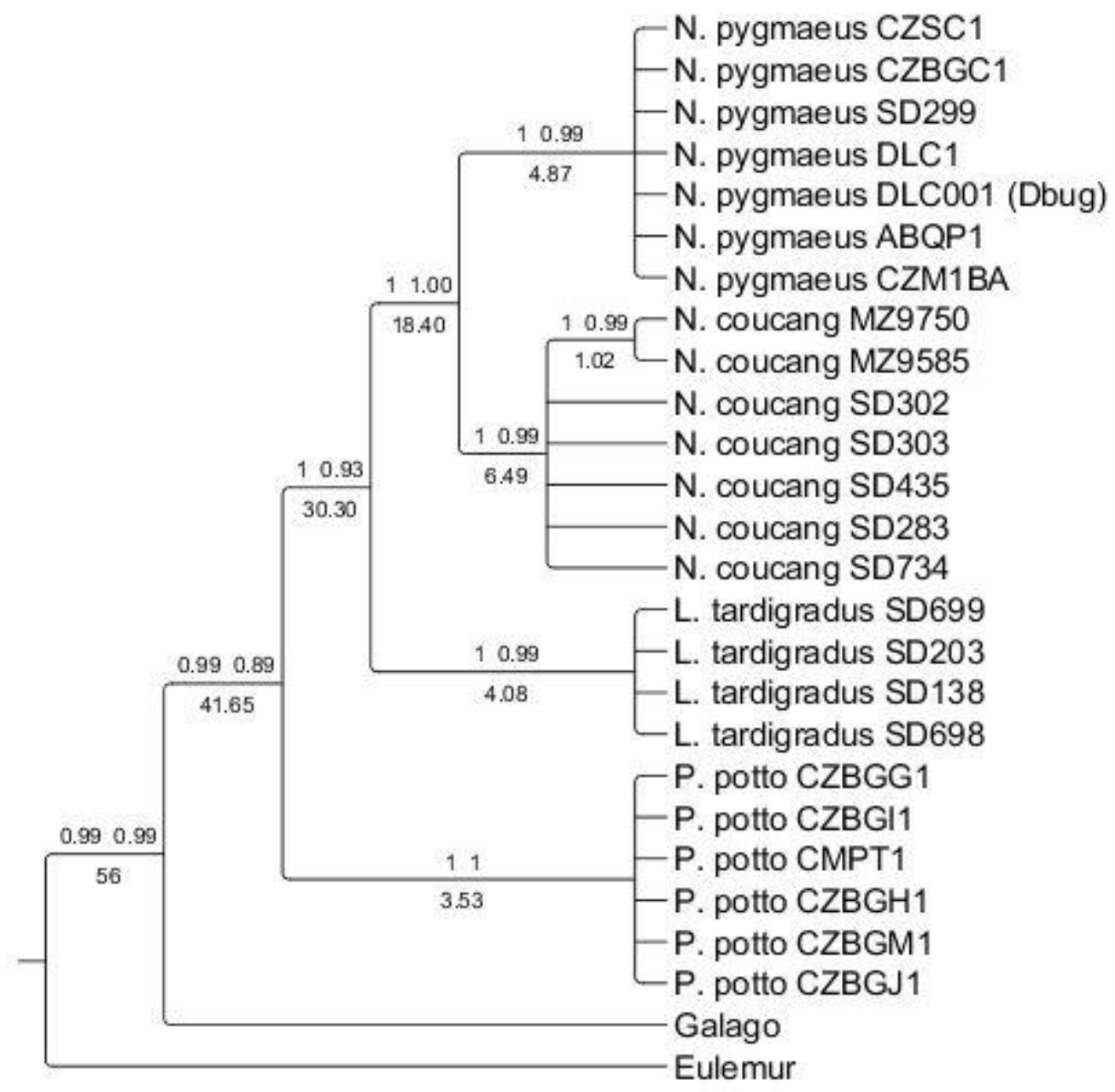

Figure 3.2: Monophyletic Lorisidae phylogeny based on concatenated genes.

Numbers below branches are the divergence date in million years of the node.

Numbers on top of the branches to the left are the Bayesian posterior probability, and numbers to the right are the Maximum Likelihood bootstrap probability for the node. 

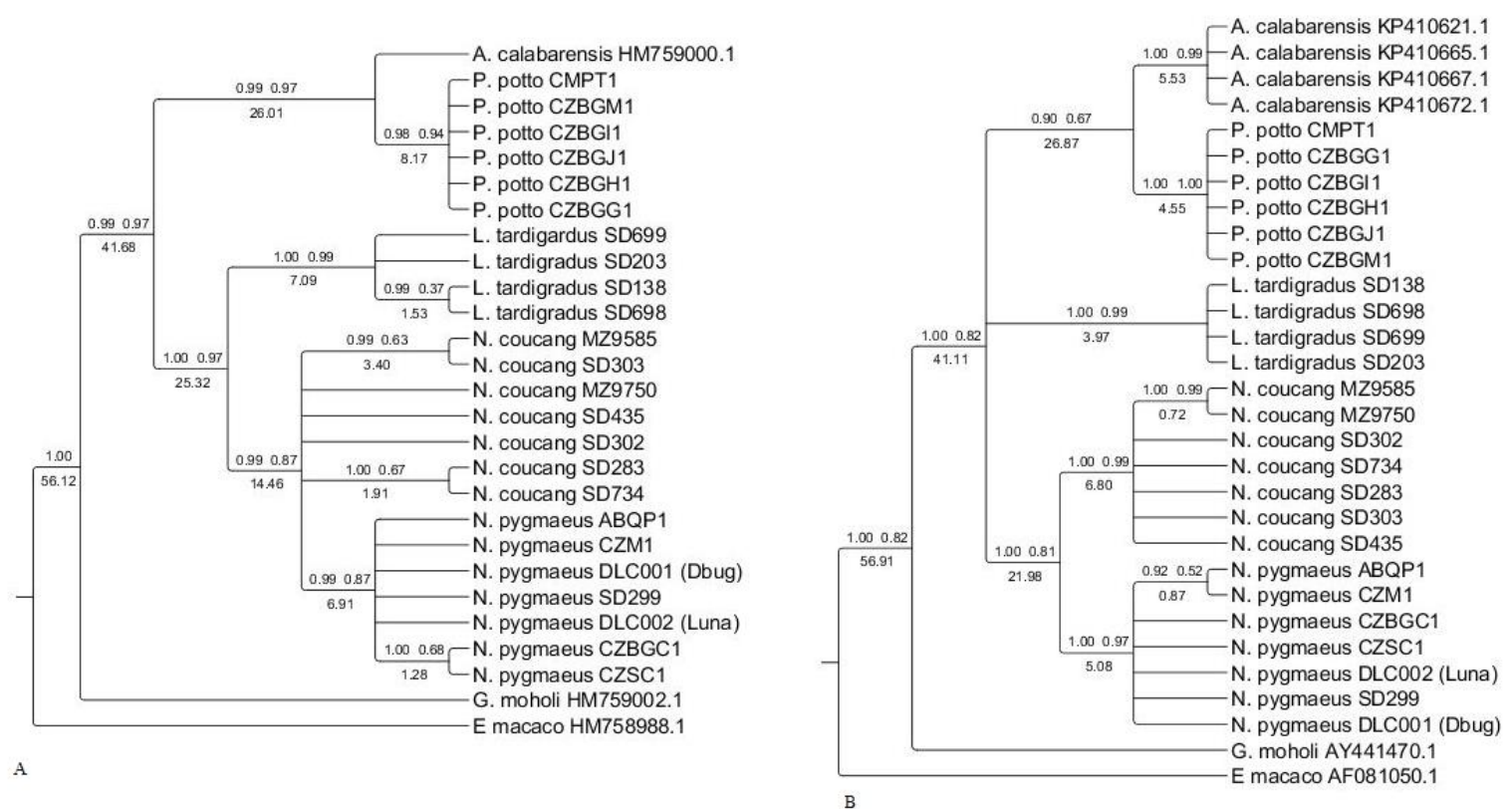

Figure 3.3: Lorisidae phylogenies from Rag2 (A) and cytochrome $b$ (B) with Arctocebus sequences. Support values on branches are the same as Figure 1. 

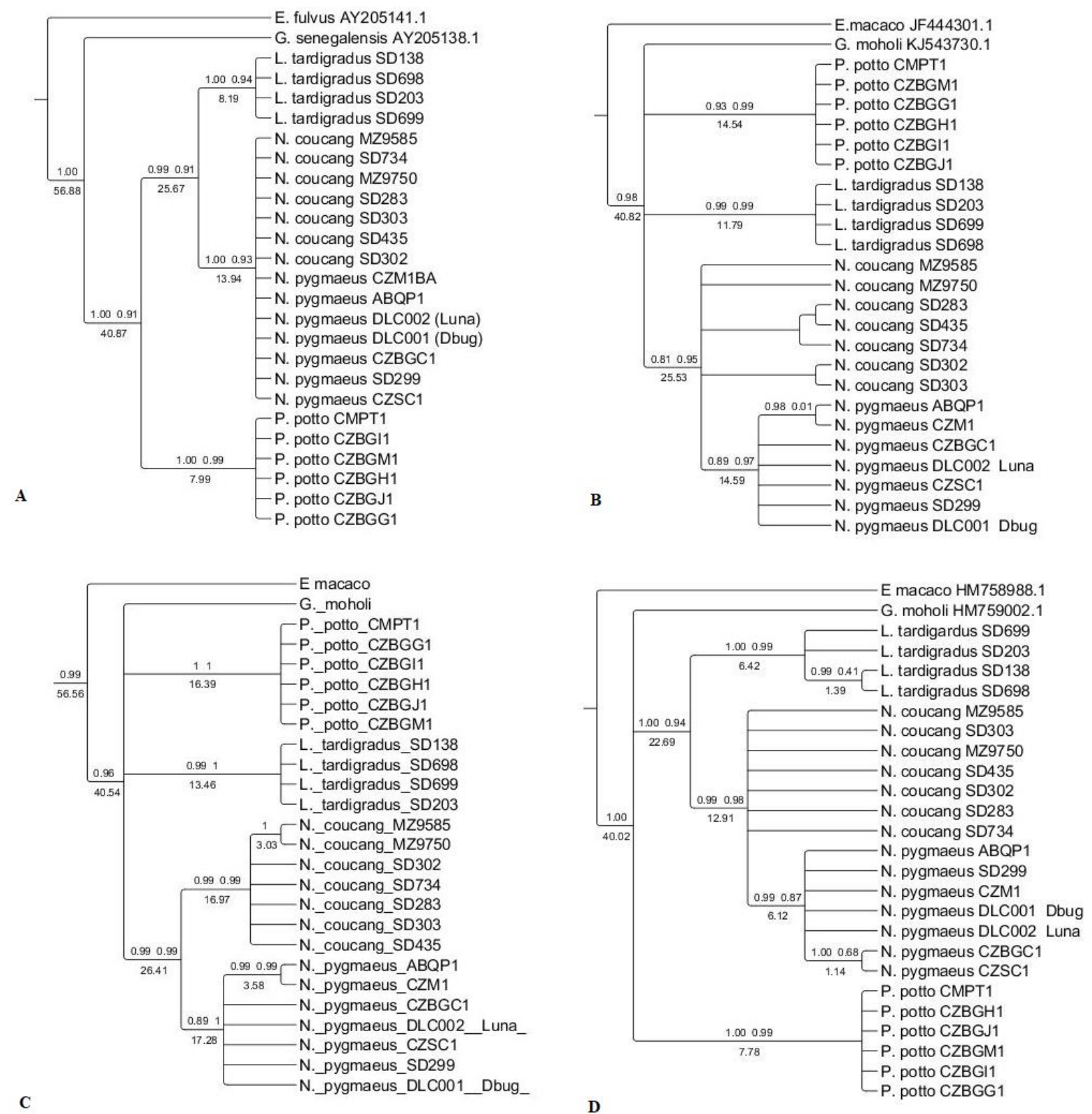

Figure 3.4: Lorisidae phylogenies from Mc1r (A), COI (B), concatenated mtDNA

\section{(C), and Rag2 without Arctocebus (D). Support values on branches are the same as}

\section{Figure 1.}




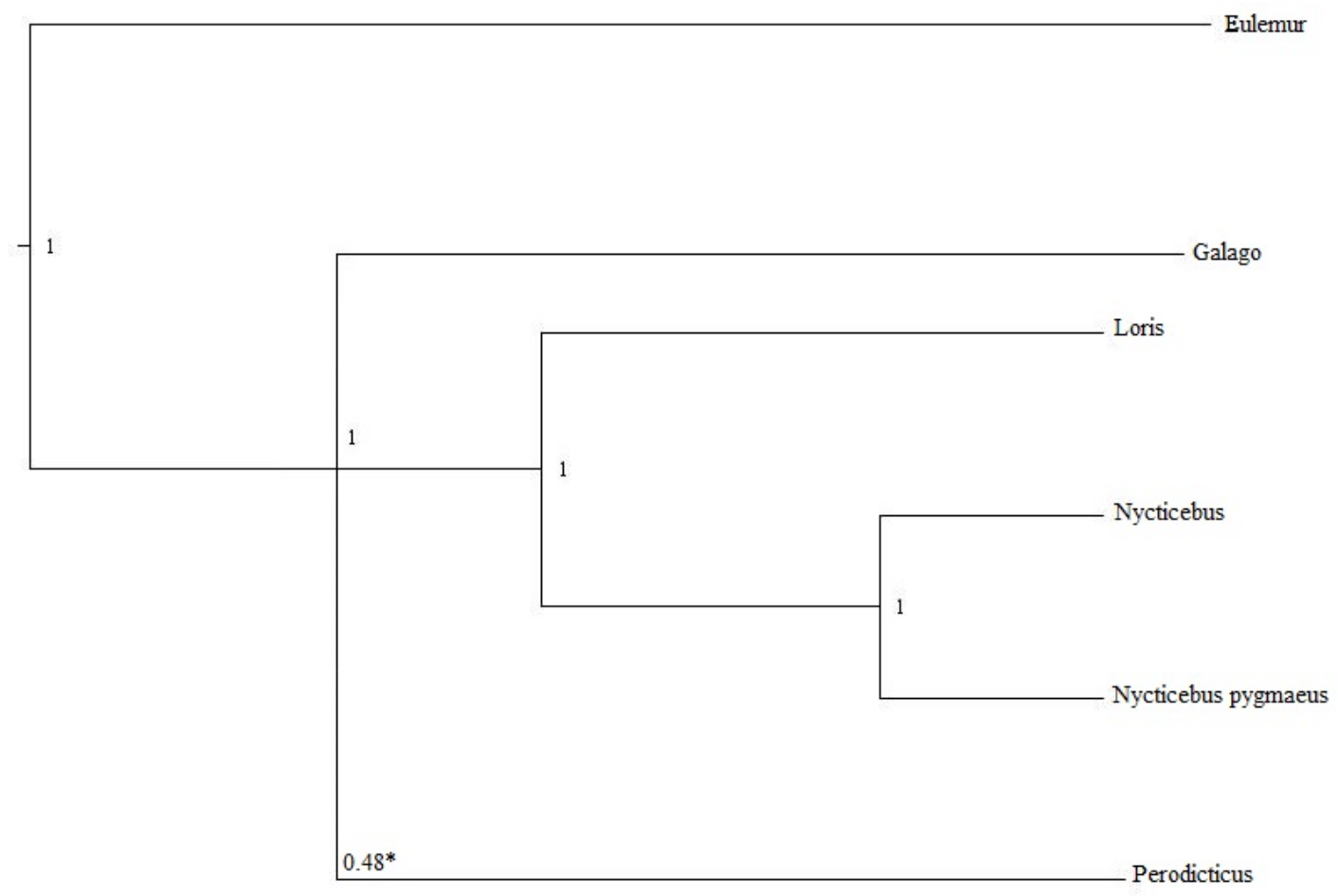

Figure 3.5: Coalescent-based species tree analyses on 900001 trees from *Beast. All four loci were used for this analysis, as well as all lorises excluding Arctocebus. Nodes show posterior probability. The $\mathbf{4 8 \%}$ probability linked to Perodicticus indicates the weak support for Lorisidae monophyly. 
Table 3.1: Loris samples acquired for this study from American Zoological Association institutions

\begin{tabular}{|c|c|c|c|}
\hline Genus/Species & $\begin{array}{l}\text { Identificatio } \\
\text { n }\end{array}$ & Specimen Facility & Sample Type \\
\hline \multirow[t]{7}{*}{ Nycticebus coucang } & SD734 & San Diego Zoo & DNA \\
\hline & SD 283 & San Diego Zoo & DNA \\
\hline & SD303 & San Diego Zoo & DNA \\
\hline & SD435 & San Diego Zoo & DNA \\
\hline & SD302 & San Diego Zoo & DNA \\
\hline & MZ9750 & Minnesota Zoo & Hair \\
\hline & MZ9585 & Minnesota Zoo & Hair \\
\hline \multirow[t]{7}{*}{ Nycticebus pygmaeus } & DLC001 & Duke Lemur Center & Tissue \\
\hline & DLC002 & Duke Lemur Center & Tissue \\
\hline & CZM1 & Capron Park Zoo & Hair \\
\hline & SD299 & San Diego Zoo & DNA \\
\hline & $\mathrm{CZSC} 1$ & Chicago Zoological Society & Hair \\
\hline & ABQP1 & ABQ Biopark & Hair \\
\hline & CZBGC1 & Cincinnati Zoo \& Botanical Garden & Hair \\
\hline \multirow[t]{4}{*}{ Loris } & SD699 & San Diego Zoo & DNA \\
\hline & SD138 & San Diego Zoo & DNA \\
\hline & SD698 & San Diego Zoo & DNA \\
\hline & SD203 & San Diego Zoo & DNA \\
\hline \multirow[t]{6}{*}{ Perodicticus } & CZBGH1 & Cincinnati Zoo \& Botanical Garden & Hair \\
\hline & CZBGM1 & Cincinnati Zoo \& Botanical Garden & Hair \\
\hline & CZBGG1 & Cincinnati Zoo \& Botanical Garden & Hair \\
\hline & CZBGJ1 & Cincinnati Zoo \& Botanical Garden & Hair \\
\hline & CZBGI1 & Cincinnati Zoo \& Botanical Garden & Hair \\
\hline & CMPT1 & Cleveland Metroparks Zoo & Hair \\
\hline
\end{tabular}


Table 3.2: GenBank sequences incorporated within the study

\begin{tabular}{lll}
\hline Genus & GenBank accession number & Genetic sequence \\
\hline Arctocebus & HM759000.1 & Rag2 \\
& KP410672.1 & Cyt $b$ \\
& KP410667.1 & Cyt $b$ \\
& KP410665.1 & Cyt $b$ \\
& KP410621.1 & Cyt $b$ \\
\hline Galago moholi & HM759002.1 & Rag2 \\
& KJ543730.1 & COI \\
\hline Galago senegalensis & AY205138.1 & Cyt $b$ \\
\hline Eulemur macaco & HM758988.1 & Mc1r \\
& JF444301.1 & Rag2 \\
& AF081050.1 & COI \\
\hline Eulemur fulvus & AY205141.1 & Cyt $b$ \\
\hline
\end{tabular}


Table 3: Primer sequences from this study

\begin{tabular}{|c|c|c|c|c|c|c|}
\hline $\begin{array}{l}\text { Locus/ } \\
\text { Basepairs } \\
\text { used }\end{array}$ & $\begin{array}{l}\text { Primer Sets } \\
\text { Forward }\end{array}$ & (5'-3') & Reverse & & $\begin{array}{l}\text { Annealing } \\
\text { Temp }\left({ }^{\circ} \mathrm{C}\right)\end{array}$ & Source \\
\hline \multirow[t]{2}{*}{$\begin{array}{l}\text { COI } \\
205\end{array}$} & $5477 \mathrm{~F}$ & AAG TTT GCT AAT CCG AGC AGA G & $5740 \mathrm{R}$ & ATG AGG CTA GGA GAA GAA GGA & $55^{\circ}$ & 5 \\
\hline & LtarCO12F & AAT TAG GCC AGCC CAG GGA CT & LtarCO12R & $\begin{array}{l}\text { AAG AAT CAG AAT AGA TGT TGA TAG } \\
\text { AGG }\end{array}$ & $55^{\circ}$ & 1 \\
\hline $\begin{array}{l}\text { Cyt. } b \\
331\end{array}$ & CB 1 & $\begin{array}{l}\text { CCA TCC AAC ATC TCA GCA TGA } \\
\text { TGA AA }\end{array}$ & CB2 & CCC TCA GAA TGA TAT TTG TCC TCA & $55^{\circ}$ & 2 \\
\hline RAG2 & RAG2F & GAT TCC TGC TAY CTY CCT CCT CT & RAG2R & CCC ATG TTG CTT CCA AAC CAT A & $55^{\circ}$ & 4 \\
\hline \multirow[t]{2}{*}{716} & RAG2F & GAT TCC TGC TAY CTY CCT CCT CT & RAG2R2 & GAT AGC CCA TCC TGA AGT TCT & $55^{\circ}$ & $2 \& 4$ \\
\hline & RAG2F2 & GTG GAT TTT GAA TTT GGG TGT & RAG2R & CCC ATG TTG CTT CCA AAC CAT A & $55^{\circ}$ & $2 \& 4$ \\
\hline MC1R & MC1R-F & AGT GCC TGG AGG TGT CTG T & MC1R-R1 & GCA CCT CCT TGA GTG TCT TG & $60^{\circ}$ & 1 \\
\hline \multirow[t]{2}{*}{731} & MC1R-F & AGT GCC TGG AGG TGT CTG T & MC1R-R1.1 & AAT GAA GAG GGT GCT GGA GA & $58^{\circ}$ & $1 \& 2$ \\
\hline & MC1R-F.2 & ATA TCA CAG CAT CGT GAC TCT & MC1R-R1 & GCA CCT CCT TGA GTG TCT TG & $55^{\circ}$ & $1 \& 2$ \\
\hline
\end{tabular}

Designed by Munds using Primer3 (Rozen \& Skaletsky, 1998)

${ }^{2}$ Kocher et al. (1989)

${ }^{3}$ Palumbi et al. (1991)

${ }^{4}$ Perelman et al. (2011)

${ }^{5}$ Mary Blair, Ph.D. (personal communication) 
Table 3.4: Node support (posterior probability (PP) \& bootstrap (BP), Divergence times in million years (MY), Divergence 95\% highest posterior density (HPD), rate 95\% HPD, and branch lengths (Bayesian PP and Maximum likelihood results from all analyses.

\begin{tabular}{|c|c|c|c|c|c|c|c|}
\hline Locus & Taxon & $\begin{array}{l}\text { Node } \\
\text { Support } \\
\text { (PP/BP) }\end{array}$ & $\begin{array}{l}\text { Date } \\
\text { (MY) }\end{array}$ & $\begin{array}{l}\text { Date 95\% } \\
\text { HPD }\end{array}$ & Rate & $\begin{array}{l}\text { Rate 95\% } \\
\text { HPD }\end{array}$ & $\begin{array}{l}\text { Branch } \\
\text { Length } \\
\text { (PP/ML) }\end{array}$ \\
\hline \multirow[t]{7}{*}{ All Genes } & Lorisidae & $0.99 / 0.89$ & 41.65 & $36.02-47.11$ & 0.001 & $0-0.001$ & $14.81 / 0.007$ \\
\hline & Perodicticus & $1 / 1$ & 3.53 & $0.42-8.11$ & 0.002 & $0.001-0.002$ & $38.12 / 0.052$ \\
\hline & Lorisinae & $1 / 0.93$ & 30.3 & $21.92-38.79$ & 0.002 & $0.001-0.004$ & $11.35 / 0.019$ \\
\hline & Loris & $1 / 0.99$ & 4.08 & $0.46-9.21$ & 0.002 & $0.001-0.003$ & $26.22 / 0.033$ \\
\hline & Nycticebus & $1 / 1$ & 18.4 & $10.244-26.95$ & 0.002 & 0.001-0.004 & $11.9 / 0.022$ \\
\hline & N. coucang & $1 / 0.99$ & 6.49 & $1.76-11.68$ & 0.002 & $0.001-0.004$ & $11.9 / 0.02$ \\
\hline & N. pygmaeus & $1 / 0.99$ & 4.87 & $0.95-9.61$ & 0.002 & 0.001-0.003 & $13.52 / 0.017$ \\
\hline Cytb & Lorisidae & $0.99 / 0.82$ & 41.11 & $35.65-46.52$ & 0.0045 & $0.0003-0.0101$ & $15.8 / 0.036$ \\
\hline \multirow[t]{8}{*}{ Arctocebus } & Perodictinae & $0.9 / 0.67$ & 26.87 & $15.78-38.14$ & 0.0045 & $0.0002-0.0107$ & $14.24 / 0.048$ \\
\hline & Arctocebus & $1 / 0.99$ & 5.53 & $1.0023-11.43$ & 0.0094 & $0.0037-0.0161$ & $21.34 / 0.159$ \\
\hline & Perodicticus & $1 / 1$ & 4.55 & $0.71-9.87$ & 0.0063 & $0.0019-0.0119$ & $22.32 / 0.114$ \\
\hline & Lorisinae & $0.63 / 0.35$ & 33.85 & $23.93-42.79$ & 0.0028 & $0.0001-0.0074$ & $7.25 / 0.021$ \\
\hline & Loris & $1 / 0.99$ & 3.97 & $0.24-9.68$ & 0.0032 & 0.0009-0.006 & $29.89 / 0.072$ \\
\hline & Nycticebus & $0.99 / 0.81$ & 21.98 & $12.49-31.71$ & 0.0074 & $0.0018-0.0143$ & $11.87 / 0.079$ \\
\hline & N. coucang & $1 / 0.99$ & 6.8 & $2.0-12.47$ & 0.0087 & $0.0028-0.0155$ & $15.18 / 0.105$ \\
\hline & N. pygmaeus & $1 / 0.97$ & 5.08 & $0.94-10.27$ & 0.005 & $0.0009-0.0105$ & $16.9 / 0.081$ \\
\hline \multirow[t]{8}{*}{ Cytb $b^{*}$} & Lorisiformes & $0.99 / .82$ & 41.25 & $35.36-46.82$ & 0.0035 & $0.0001-0.0124$ & $15.47 / 0.028$ \\
\hline & Galago split & $0.34 / \mathrm{NA}$ & 28.45 & $15.77-41.14$ & 0.0026 & $0.0001-0.0076$ & $6.21 /$ \\
\hline & Perodicticus & $1 / 1$ & 4.21 & $0.59-9.22$ & 0.0092 & $0.0032-0.0163$ & $30.84 / 0.150$ \\
\hline & Lorisinae & $0.33 / 0.55$ & 30.88 & $19.47-41.97$ & 0.0039 & $0.0001-0.0109$ & $4.75 / 0.033$ \\
\hline & Loris & $1 / 0.99$ & 3.62 & $0.21-8.76$ & 0.0045 & $0.0011-0.0091$ & $32.88 / 0.072$ \\
\hline & Nycticebus & $0.99 / 0.80$ & 21.97 & $11.33-33.49$ & 0.0079 & $0.001-0.0163$ & $14.42 / 0.076$ \\
\hline & N. coucang & $1 / 0.99$ & 6.3 & $1.71-11.82$ & 0.01 & $0.0031-0.0181$ & $15.79 / 0.105$ \\
\hline & N. pygmaeus & $1 / 0.99$ & 4.79 & $0.91-10.01$ & 0.0057 & $0.008-0.021$ & $17.29 / 0.08$ \\
\hline \multirow[t]{4}{*}{$\mathrm{COI}^{*}$} & Lorisiformes & $0.98 /$ & 40.82 & $35.14-46.6$ & 0.0085 & $0-0.0385$ & $16.01 / \mathrm{NA}$ \\
\hline & Loris/Africa & $0.33 / 0.48$ & 31.44 & $17.95-43.15$ & 0.0051 & $0-0.0263$ & $9.38 / 0.139$ \\
\hline & Galago split & $0.37 / 0.28$ & 23.53 & $9.04-38.35$ & 0.0108 & $0-0.0487$ & $7.91 / 0.120$ \\
\hline & Perodicticus & $0.93 / 0.99$ & 14.54 & $2.8-28.52$ & 0.0367 & $0-0.1104$ & $8.99 / 0.471$ \\
\hline
\end{tabular}




\begin{tabular}{|c|c|c|c|c|c|c|c|}
\hline & Loris & $0.99 / 0.99$ & 11.79 & $0.75-25.88$ & 0.0392 & $0.0023-0.1187$ & $19.65 / 0.594$ \\
\hline & Nycticebus & $0.81 / 0.95$ & 25.53 & $12.91-38.28$ & 0.0337 & $0-0.0977$ & $15.29 / 0.051$ \\
\hline & N. coucang & $0.46 / 0.95$ & 17.19 & $1.7-25.31$ & 0.004 & $0-0.0205$ & $8.34 / 0.351$ \\
\hline & N. pygmaeus & $0.89 / 0.97$ & 14.59 & $4.17-26.05$ & 0.0251 & $0-0.0747$ & $10.94 / 0.167$ \\
\hline Rag2* & Lorisidae & $0.99 / 0.97$ & 41.68 & $36.07-47.3$ & 0.0002 & $0-0.0005$ & $14.44 / 0.013$ \\
\hline \multirow[t]{7}{*}{ Arctocebus } & Perodictinae & $0.99 / 0.97$ & 26.01 & $13.45-38.24$ & 0.0004 & $0.0001-0.0007$ & $15.67 / 0.006$ \\
\hline & Perodicticus & $0.98 / 0.94$ & 8.17 & $1.5-17.21$ & 0.0003 & $0-0.0007$ & $17.83 / 0.005$ \\
\hline & Lorisinae & $1 / 0.97$ & 25.32 & $15.01-36.14$ & 0.0005 & $0.0001-0.0012$ & $16.36 / 0.01$ \\
\hline & Loris & $1 / 0.98$ & 7.09 & $1.09-15.73$ & 0.0005 & $0.0001-0.0009$ & $18.23 / 0.01$ \\
\hline & Nycticebus & $0.99 / 0.87$ & 14.46 & $6.03-24.93$ & 0.0004 & $0-0.0008$ & $10.86 / 0.004$ \\
\hline & N. coucang & $0.39 / 0.97$ & 10.49 & $3.58-19.37$ & 0.0003 & $0-0.0005$ & $3.97 / 0.004$ \\
\hline & N. pygmaeus & $0.99 / 0.87$ & 6.91 & $1.72-14.01$ & 0.0004 & $0-0.0008$ & $7.55 / 0.003$ \\
\hline \multirow[t]{7}{*}{ Rag2 } & Lorisidae & $0.36 / 0.72$ & 38.18 & $25.48-43.43$ & 0.0003 & $0-0.0006$ & $1.84 / 0.002$ \\
\hline & Perodicticus & $1 / 0.99$ & 7.78 & $1.15-17.9$ & 0.0004 & $0.0001-0.0008$ & $30.4 / 0.011$ \\
\hline & Lorisinae & $0.99 / 0.94$ & 22.69 & $12.5-33.91$ & 0.0006 & $0-0.0012$ & $15.49 / 0.010$ \\
\hline & Loris & $1 / 0.99$ & 6.42 & $0.9-14.68$ & 0.0005 & $0.0001-0.001$ & $16.28 / 0.009$ \\
\hline & Nycticebus & $0.99 / 0.98$ & 12.91 & $4.79-22.94$ & 0.0004 & $0-0.0009$ & $9.79 / 0.004$ \\
\hline & N. coucang & $0.39 / 0.98$ & 11.52 & $2.65-17.57$ & 0.0003 & $0-0.0006$ & $1.39 / 0.001$ \\
\hline & N. pygmaeus & $0.99 / 0.87$ & 6.12 & $1.4-12.88$ & 0.0004 & $0-0.0009$ & $6.79 / 0.003$ \\
\hline \multirow[t]{8}{*}{ mtDNA $^{*}$} & Lorisiformes & $0.96 / \mathrm{NA}$ & 40.54 & $34.84-46.39$ & 0.0165 & $0-0.573$ & $16.02 / \mathrm{NA}$ \\
\hline & Loris/Africa & $0.33 / 0.63$ & 30.02 & $15.13-42.52$ & 0.0036 & $0-0.0128$ & $10.51 / 0.021$ \\
\hline & Galago split & $0.33 / \mathrm{NA}$ & 23.61 & $8.72-39.27$ & 0.0041 & $0-0.0114$ & $6.41 / \mathrm{NA}$ \\
\hline & Perodicticus & $1 / 1$ & 16.39 & $3.49-31.42$ & 0.0672 & $0.0043-0.1843$ & $7.22 / 0.153$ \\
\hline & Loris & $0.99 / 1$ & 13.46 & $1.18-28.78$ & 0.052 & $0.0025-0.1584$ & $16.57 / 0.111$ \\
\hline & Nycticebus & $0.99 / 0.99$ & 26.41 & $13.13-39.66$ & 0.064 & $0-0.1976$ & $14.12 / 0.086$ \\
\hline & N. coucang & $0.99 / 0.99$ & 16.97 & $5.04-30.27$ & 0.0482 & $0-0.1577$ & $9.45 / 0.072$ \\
\hline & N. pygmaeus & $0.89 / 1$ & 17.28 & $5.09-30.57$ & 0.0266 & $0-0.0716$ & $9.13 / 0.071$ \\
\hline \multirow[t]{5}{*}{ Mc1r ${ }^{*}$} & Lorisidae & $0.99 / 0.91$ & 40.87 & $35.16-46.58$ & 0.0003 & $0-0.0007$ & $16.01 / 0.04$ \\
\hline & Perodicticus & $1 / 0.99$ & 7.99 & $1.43-16.78$ & 0.0009 & $0.0004-0.0015$ & $32.87 / 0.024$ \\
\hline & Lorisinae & $0.99 / 0.91$ & 25.67 & $14.9-36.73$ & 0.0008 & $0.0001-0.0017$ & $15.19 / 0.013$ \\
\hline & Loris & $1 / 0.94$ & 8.19 & $1.31-16.86$ & 0.0005 & $0.0001-0.0011$ & 17.49/0.009 \\
\hline & Nycticebus & $0.99 / 0.93$ & 13.94 & $5.91-23.11$ & 0.0006 & $0.0001-0.0014$ & $11.73 / 0.007$ \\
\hline
\end{tabular}




\section{Literature Cited}

Ali, JR., Aitchison, J.C., 2008. Gondwana to Asia: Plate tectonics, paleogeography and the biological connectivity of the Indian sub-continent from the Middle Jurassic through latest Eocene (166-35Ma). Earth-Sci. Rev. 88(3): 145-166.

Animal Behavioral Society. 2008. Guidelines for the treatment of animals in behavioral research and teaching. Animal Behavior Society Handbook.

Arnason, U., Gullberg, A., Janke, A., 1999. The mitochondrial DNA molecule of the aardvark, Orycteropus afer, and the position of the Tubulidentata in the eutherian tree. Proc. R. Soc. Lond. B. Biol. Sci. 266: 339-345.

Bailey, N.W., Macias Garcia, C., Ritchie, M.G., 2007. Beyond the point of no return? A comparison of genetic diversity in captive and wild populations of two nearly extinct species of Goodeid fish reveals that one is inbred in the wild. Heredity 98: 360-367.

Barsh, G.S., 1996. The genetics of pigmentation: from fancy genes to complex traits. Trends in Genetics 12(8):299-305.

Bearder, S.K., 1999. Physical and social diversity among nocturnal primates: a new view based on long term research. Primates 40(1): 267-282.

Bensasson, D., Zhang, D., Hartl, D.L., Hewitt, G.M., 2001. Mitochondrial pseudogenes: evolution's misplaced witnesses. TRENDS Ecol. Evolut. 16(6): 314-321.

Bickford, D., Lohman, D.J., Sodhi, N.S., Ng, P.K.L., Meier, R., Winker, K., Ingram, K.K., Das, I., 2006. Cryptic species as a window on diversity and conservation. TRENDS Ecol. Evolut. 22(3):148-155. 
Bradley, B.J., Mundy, N.I., 2008. The primate palette: The evolution of primate coloration. Evol. Anthr. 17:97-111.

Cartmill, M., 1975. Strepsirhine basicranial structures and the affinities of the Cheirogaledae. In: Phylogeny of the Primates. USA: Spring Press, 313-354.

Charles-Dominque, P., 1977. Ecology and behavior of nocturnal primates: prosimians of equatorial West Africa. New York: Columbia University Press, 1977.

Chatterjee, S., Scotese, C.R., 1999. The breakup of Gondwana and the evolution and biogeography of the Indian plate. Proc.-Indian Natl. Sci. Acad. Part A. 65(3): 397-426.

Chen, Z., Zhang, Y., Shi, L., Liu, R., Wang, Y., 1993. Studies on the chromosomes of genus Nycticebus. Primates 34(1): 47-53.

de Boer, L.E.M., 1973. Cytotaxonomy of the Lorisoidea (Primates: Prosimii). Genetica 44(3): 330-367.

de Wit, M.J., 2003. Madagascar: Heads it's a continent, tails it's an island. Annu. Rev. Earth Planet. Sci. 31(1): 213-248.

Douday, C.J., Delsuc, F., Boucher, Y., Doolittle, W.F., Douzery, E.J., 2003. Comparison of Bayesian and maximum likelihood bootstrap measures of phylogenetic reliability. Mol. Biol. Evol. 20(2): 248-254.

Drummond, A.J., Suchard, M.A., Xie, D., Rambaut, A., 2012. Bayesian phylogenetics with BEAUti and the BEAST 1.7. Mol. Biol. Evol. 29(8):1969-1973

Eggert, L.S., Maldonado, J.E., Fleischer, R.C., 2005. Nucleic acid isolation from ecological samples: animal scat and other associated materials. Mol. Evol.: Producing the Biochemical Data, Part B. Methods in Enzymol. 6: 73-80. 
Fleagle, J.G., Primate Adaptation and Evolution. New York, Academic Press.

Fletcher, W., Yang, Z., 2010. The effect of insertions, deletions, and alignment errors on the branch-site test of positive selection. Mol. Biol. Evol. 27(10): 2257-2267.

Goodman, M., Porter, C.A., Czeulusnia, J., Page, S.L., Schneider, H., Shoshani, J., Gunnell, G., Groves, C.P., 1998. Toward a phylogenetic classification of primates based on DNA evidence complemented by fossil evidence. Mol. Phylogenet. Evol. 9(3): 585598.

Groves, C.P., 1971. Systematics of the genus Nycticebus. In: Biegert J, Leutenegger W, editors. Taxonomy, anatomy, reproduction. Proc. of the $3^{\text {rd }}$ Intl. Congress of Primatol. 1:44-53.

Hajibabaei, M., Singer, G.A., Hebert, P.D., Hickey, D.A., 2007. DNA barcoding: how it complements taxonomy, molecular phylogenetics and population genetics. TRENDS Genet. 23(4): 167-172.

Harrison, T., 2010. Later tertiary Lorisformes. In: Werdelin L, Sanders W (eds). Cenozoic mammals of Africa. Berkely: University of California Press, 333-349.

Hazkani-Covo, E., Zeller, R.M., Martin, W., 2010. Molecular poltergeists:

Mitochondrial DNA copies (numts) in sequenced nuclear genomes. PLoS Genetics. 6(2): $1-11$.

Heath, T.A., Hedtke, S.M., Hillis, D.M., 2008. Taxon sampling and the accuracy of phylogenetic analyses. J. Syst. Evol. 46(3): 239-257.

Hebert, P.D.N., Cywinska, A., Ball, S.L., 2003. Biological identifications through DNA barcodes. Proc. R. Soc. Lond. B. Biol. Sci. 270(1512): 313-321. 
Hedtke, S.M., Townsend, T.M., Hillis, D.M., 2006. Resolution of phylogenetic conflict in large data sets by increased taxon sampling. Syst. Biol. 55(3): 522-529.

Heled, J., Drummond, A.J., 2009. Bayesian inference of species trees from multilocus data. Mol. Biol. Evol. 27(3): 570-580.

Hillis, D.M., Pollock, D.D., McGuire, J.A., Zwickl, D.J., 2003. Is sparse taxon sampling a problem for phylogenetic inference? Syst. Biol. 52(1): 124-126.

Hoekstra, H.E., 2006. Genetics, development and evolution of adaptive pigmentation in vertebrates. Heredity. 97(3): 222

Kubatko, L.S., 2007. Inconsistency of phylogenetic estimates from concatenated data under coalescence. Syst. Biol. 56(1): 17-24.

Kullnig-Gradinger, C.M., Szakacs, G., Kubicek, C.P., 2002. Phylogeny and evolution of the genus Trichoderma: a multigene approach. Mycological Research. 106(7): 757-767.

Lacy, R.C., 1987. Loss of genetic diversity from managed populations: Interacting effects of drift, mutation, immigration, selection, and population subdivision. Conserv. Biol. 1(2): 143-158.

Larget, B.R., Kotha, S.K., Dewey, C.N., Ane, C., 2010. BUCKy: Gene tree/ species tree reconciliation with Bayesian concordance analysis. Bioinfo. 26(22): 2910-2911.

Lavergne, A., Douzery, E., Stichler, T., Catzeflis, F.M., Springer, M.S., 1996.

Interordinal mammalian relationships: evidence for paenungulate monophyly is provided by complete mitochondrial 12S rRNA sequences. Mol. Phylogenet. Evol. 6: 245-258.

Liu, L., Edwards, S.V., 2009. Phylogenetic analysis in the anomaly zone. Syst. Biol. 58(41): 452-460. 
Loytynoja, A., Goldman, N., 2008. Phylogeny-aware gap placement prevents errors in sequence alignment and evolutionary analysis. Science 320: 1632-1635.

Mason, V.C., Li, G., Helgen, K.M., Murphy, W.J., 2011. Efficient cross-species capture hybridization and next-generation sequencing of mitochondrial genomes from noninvasively sampled museum specimens. Genome Res. 21(10): 1695-1704.

Masters, J.C., Anthony, N.M., De Wit, M.J., Mitchell, A., 2005. Reconstructing the evolutionary history of the Lorisidae using morphological, molecular, and geological data. Am. J. Phys. Anthropol. 127(4):465-480.

Masters, J.C., Boniotto, M., Crovela, S., Roos, C., Pozzi, L., Delpero, M., 2007. Phylogenetic relationships among the Lorisoidea as indicated by craniodental morphology and mitochondrial sequence data. Am. J. Primatol. 69:6-15.

Munds, R.A., Nekaris, K.A.I., Ford, S.M., Taxonomy of the Bornean loris with new species Nycticebus kayan (Primates, Lorisidae). Am. J. Primatol. 75(1):46-56.

Nash, L., Bearder, S., Olson, T., 1989. Synopsis of galago species characteristics. Int. J. Primatol. 10: 57-80.

Nekaris, K.A.I., Bearder, S.K., 2007. The Lorisiform primates of Asia and mainaland Africa: Diversity shrouded in darkness. In: Campbell C, Fuentes A, MacKinnon K, Panger M, Bearder SK (eds) Primates in Perspective. Oxford University Press, Oxford, UK p 24-45

Nekaris, K.A.I., Munds, R., 2010. Using facial markings to unmask diversity: The slow lorises (Primates: Lorisidae: Nycticebus) of Indonesia. In: Gursky S, Supriatna J, editors. The Primates of Indonesia New York: Springer p 383-396. 
Pamilo, P., Nei, M., 1988. Relationships between gene trees and species trees. Mol. Biol. Evol. 54(5): 568-583.

Pastorini, J., Sauther, M.L., Sussman, B.W., Gould, L., Cuozzo, F.P., Fernando, P., Nievergelt, C.M., Mundy, N.I., 2015. Comparison of the genetic variation of captive ring-tailed lemurs with a wild population in Madagascar. Zoo Biol. 34: 463-472.

Perelmann, P., Johnson, W.E., Roos, C., Seuanez, H.N., Horvath, J.E., Moreira, M.A.M., Kessing, B., Pontius, J., Roelke, M., Rumpler, Y., Schneider, M.P.C., Silva, A., O’Brien, S.J., Pecon-Slattery, J., 2011. A molecular phylogeny of living primates. PLoS Genet. $7(3): 1-17$.

Petter, J.J., Petter Rousseaux, A., 1979. Classification of the prosimians. In: Doyle, G.A., Martin, R., (eds) The Study of Prosimian Behavior. Academic Press, New York p 1-44.

Phillips, E.M., Walker, A., 2002. Fossil lorisoids. In: Hartwig, W.C., editor. The Primate Fossil Record. Cambridge, Cambridge University Press p 83-95.

Pickford, M., 2012. Lorisine primate from the Late Miocene of Kenya. J. Biologic. Res.Bollenttino della Societa Italiana di Biologia Sperimentale 85(1).

Pollock, D.D., Zwickl, D.J., Mcguire, J.A., Hillis, D.M., 2002. Increased taxon sampling is advantageous for phylogenetic inference. Syst. Biol. 51(4): 664-671.

Porter, C.A., Goodman, M., Stanhope, M.J., 1996. Evidence on mammalian phylogeny from sequences of exon 28 of the von Willebrand factor gene. Mol. Phylogenet. Evol. 5: 89-101.

Pozzi, L., Disotell, T.R., Masters, J.C., 2014. A multilocus phylogeny reveals deep lineages within African galagids (Primates: Galagidae). BMC Evol. Biol. 14:72. 
Pozzi, L., Nekaris, K.A.I., Perkin, A., Bearder, S.K., Pimley, E.R., Schulze, H., Streicher, U., Nadler, T., Kitchener, A., Zischler, H., Zinner, D., Roos, C., 2015. Remarkable ancient divergences amongst neglected lorisiform primates. Zool. J. Linnean Soc. 175: 661-674.

Puslednik, L., Serb, J.M., 2008. Molecular phylogenetics of the Pectinidae (Mollusca: Bivalvia) and effects of increased taxon sampling and outgroup selection on tree topology. Mol. Phylogenet. Evol. 48: 1178-1188.

Rasmussen, A., Janke, A., Arnason, U., 1998. The mitochondrial DNA molecule of the hagfish (Myxine glutinosa) and vertebrate phylogeny. J. Mol. Evol. 46: 382-388.

Rasmussen, D.T., Nekaris, K.A.I., 1998. Evolutionary history of lorisiform primates. Folia Primatol. 69(Suppl. 1):250-285.

Rokas, A., Williams, B.L., King, N., Carroll, S.B., 2003. Genome-scale approaches to resolving incongruence in molecular phylogenies. Nature. 425(6960): 798.

Roos, C., Schmitz, J., Zischler, H., 2004. Primate jumping genes elucidate strepsirrhine phylogeny. Proc. Natl. Acad. Sci. USA. 101:10650-10654.

Sanderson, M.J., Shaffer, H.B., 2002. Troubleshooting molecular phylogenetic analyses. Annu. Rev. Ecol. Evol. 33:49-72.

Schwartz, J.H., \& Tattersall, I., 1985. Evolutionary relationships of living lemurs and lorises (Mammalia, Primates) and their potential affinities with European Adapidae. Anthropological Papers of the American Museum of Natural History. 60:1-100.

Seiffert, E.R., Simons, E.L., Attia, Y., 2003. Fossil evidence for an ancient divergence of lorises and galagos. Nature. 422: 421-424. 
Seiffert, E.R., 2007. Early evolution and biogeography of lorisiform strepsirrhines. Am. J. Primatol. 69: 27-35.

Seiffert, E.R., 2012. Early primate evolution in Afro-Arabia. Evol. Anthropol. 21(6): 239-253.

Song, H., Buhay, J.E., Whiting, M.F., Crandall, K.A., 2008. Many species in one: DNA barcoding overestimates the number of species when nuclear mitochondrial pseudogenes are coamplified. Proc. Natl. Acad. Sci. 105(36): 13486-13491.

Sorenson, M.D., Quinn, T.W., 1998. Numts: A challenge for Avian systematics and population biology. The Auk. 115(1): 214-221.

Springer, M.S., DeBry, R.W., Douday, C., Amrine, H.M., Madsen, O., de Jong, W.W., Stanhope, M.J., 2001. Mitochondrial versus nuclear gene sequences in deep-level mammalian phylogeny reconstruction. Mol. Biol. Evol. 18(2): 132-143.

Stover, B.C., Muller, K.F. 2010. TreeGraph 2: Combining and visualizing evidence from different phylogenetic analyses. BMC BioInfo. 11(7): 1-9.

Susko, E., 2008. On the distributions of bootstrap support and posterior distributions for a star tree. Syst. Biol. 57(4):602-612.

Svensson, M.S., Bersacola, E., Mills, M.S.L., Munds, R.A., Nijman, V., Perkin, A., Masters, J.C., Couette, S., Nekaris, K.A.I., Bearder, S.K., 2017. A giant among dwarfs: a new species of galago (Primates: Galagidae) from Angola. Am. J. Phys. Anthropol. 163(1): 30-43.

Thalmann, O., Hebler, J., Poinar, H.N., Paabo, S., Vigilant, L., 2004. Unreliable mtDNA data due to nuclear insertions: a cautionary tale from analysis of humans and other great apes. Mol. Ecol. 13: 321-335. 
Waugh, J., 2007. DNA barcoding in animal species: Progress, potential and pitfalls. BioEssays 29(2): 188-197.

Wiens, F., 2002. Behavior and ecology of wild slow lorises (Nycticebus coucang): Social organization, infant care system, and diet. Doctoral Dissertation University of Bayreuth. Xia, X., 2017. DAMBE6: New tools for microbal genomics, phylogenetics and molecular evolution. J. Heredity. 108(4): 431-437.

Yoder, A.D., 1994. Relative position of the Cheirogaleidae in strepsirrhine phylogeny: A comparison of morphological and molecular methods and results. Am. J. Phys. Anthropol. 94(1): 25-46.

Yoder, A.D., Rasoloarison, R.M., Goodman, S.M., Irwin, J.A., Atsalis, S., Ravosa, M.J., Ganzhorn, J.U., 2000. Remarkable species diversity in Malagasy mouse lemurs (Primates, Microcebus). Proc. Natl. Acad. Sci. 97(21):11325-11330.

Yoder, A.D., Yang, Z., 2000. Estimation of primate speciation dates using local molecular clocks. Mol. Biol. Evol. 17(7): 1081-1090.

Yoder, A.D., Irwin, J.A., Payseur, B.A., 2001. Failure of the ILD to determine data combinability for slow loris phylogeny. Syst. Biol. 50(3): 408-424.

Zardoya, R., Meyer, A., 1996. Phylogenetic performance of mitochondrial protein-coding genes in resolving relationships among vertebrates. Mol. Biol. Evol. 13: 933-942.

Zwickl, D.J., Hillis, D.M., 2002. Increased taxon sampling greatly reduces phylogenetic error. Syst. Biol. 51(4): 588-598. 


\title{
CHAPTER 4:
}

\section{MOLECULAR EVOLUTION OF THE MELANOCORTIN 1 RECEPTOR (MC1R) IN LORISES (ORDER PRIMATES: FAMILY LORISIDAE)}

\author{
Rachel A. Munds ${ }^{1,2}$, Chelsea L. Titus ${ }^{3}$, Lori S. Eggert ${ }^{3}, \&$ Gregory E. Blomquist ${ }^{1}$ \\ ${ }^{1}$ Department of Anthropology, University of Missouri, Columbia, MO 65211 \\ ${ }^{2}$ Nocturnal Primate Research Group, Oxford Brookes University, Oxford OX3 0BP, UK \\ ${ }^{3}$ Division of Biological Sciences, University of Missouri, Columbia, MO 65211
}

\begin{abstract}
The melanocortin 1 receptor (Mc1r) gene is highly responsible for variation in coat and skin color, particularly black/brown and dark skin phenotypes and red/yellow light skin phenotypes. These studies have indicated that variation in Mc1r is influenced by the effects of selection, as changes in coloration and patterning can strongly impact the ability of organisms to attract mates, blend with the environment, or act as a warning signal to potential predators of their potency. The effects of Mc1r on humans is well known and studies have demonstrated the effects of Mc1r on an intraspecific level, but studies examining the impacts of this locus on non-human primates are lacking. By investigating the effects of this gene on an interspecific level in primates, we shed light on how primate coat color has evolved within a lineage. The primate family Lorisidae present a great opportunity to explore Mc1r variation on an interspecific level, as it has four genera: two of which are all brown and are found in Africa (Arctocebus and Perodicticus), while the other two are colorful and patterned and are found in Asia (Loris and Nycticebus). Here, we explore the evolution of Mc1r in Lorisidae to examine its influence on primate coat color. We used the mitochondrial cytochrome $b$ gene and an
\end{abstract}


intron in the nuclear Rag2 gene to infer a phylogeny for the Lorisidae onto which we mapped the evolution of Mc1r. Overall, our results indicate Mc1r is undergoing purifying selection in Lorisidae $(\mathrm{dN} / \mathrm{dS}=0.144)$, with 61 variable sites, only 14 of which were nonsynonymous. Along the evolutionary branches, we found most nonsynonymous substitutions to be on the African loris branch, with a total of 5. Past research has found that maintaining a dark phenotype or the interactions from other melanin influencing genes contribute to the high number of nonsynonymous substitutions in some organisms, which would explain our results along the African loris branch, but more studies are needed for confirmation.

Key words: Melanocortin 1 receptor, Lorisidae, Perodicticus, purifying selection, aposematic, trait evolution

\section{Introduction}

Several loci have been identified that influence coat color and pattern variation in numerous organisms, with the most well-studied locus being the melanocortin 1 receptor (Mc1r). The Mc1r is responsible for melanin production, specifically the production of two common pigments: eumelanin (brown and black) and pheomelanin (yellow and red) (Barsh, 1996; (Hoekstra \& Nachman, 2003). Amino acid changes in the Mc1r have been associated with color changes in insects, birds, mice, domesticated animals, and other mammals (Theron et al., 2001; Hoekstra \& Nachman, 2003; Mundy, 2005). Based on the significant amino acid substitutions in Mc1r, these studies were able to examine the possible mechanisms underlying the genetic changes influencing the observable 
phenotypic changes. For example, (Nachman et al., 2003) found four charge-changing amino acid polymorphisms in the Mc1r of rock pocket mice (Chaetodipus intermediusi) in Arizona. These mice are typically light in color, and live on light-colored rocks, but in some regions dark-colored mice are found that live on dark-colored rocks. By examining these Mc1r changes, researchers found they were associated with the two coat color morphs (dark and light), and furthermore, these changes were linked to aiding the mice in blending with their environment (Nachman et al., 2003). This study was even extended to explore if similar phenotypic variation found in other geographic areas had similar evolutionary trajectories; they did not. In fact, Hoekstra and Nachman (2003) concluded that for a New Mexico population Mc1r was not responsible for the phenotypic changes observed. Other studies have explored if and how Mc1r has changed over an evolutionary phylogeny. Corso et al. (2016) examined variation in Mc1r sequences in toucans (Ramphastidae). By comparing the synonymous (dS) and non-synonymous (dN) substitutions in Mc1r and relating them to the observed phenotypic changes they were able to demonstrate genetic-phenotypic evolution. For toucans, they suggested that darker plumage resulted from positive selection or a relaxation of selection on Mc1r (Corso et al., 2016). These past studies on mice, toucans, and other organisms have found Mc1r amino acid changes correspond to phenotypic changes along a known evolutionary lineage.

Changes in Mc1r are linked to color variation in humans, which have led to a better understanding of how hair and skin color are correlated with evolutionary events. Lighter skin pigmentation, red/yellow hair color, freckles, and sensitivity to UV are the result of more than 30 non-synonymous mutations in the Mc1r gene (Sulem et al., 2007). 
The changes in hair color production are due to a relationship between $\mathrm{Mc} 1 \mathrm{r}$ and the melanocyte-stimulating hormone (MSH) or the Agouti Signaling Protein (ASIP). Mc1r regulates the amount of eumelanin and pheomelanin produced during hair growth as well as influencing skin coloration and tanning responses; the latter effect being well documented (Valverde et al., 1995; Moro et al., 1999; Harding et al., 2000; Mundy \& Kelly, 2003; Hoekstra, 2006; Mundy \& Kelly, 2006; Beaumont et al., 2007; Nasti \& Timares, 2015). A loss of function of Mc1r results in pheomelanin production which is characterized by a red/yellow phenotype with fair skin. The production of eumelanin results in organisms with a brown/black phenotype and a dark complexion (Valverde $e t$ al., 1995; Jackson, 1997; Mundy \& Kelly, 2003; Hoekstra, 2006; Nasti \& Timares, 2015). In humans a transition to pheomelanin (red/yellow) is considered to be derived, whereas the eumelanin (brown/black) phenotype is ancestral (Jackson, 1997; Sturm et al., 2003; Sulem et al., 2007; Han et al., 2008). Although other genes such as ASIP, KIT, TYRP, TYR, OCA2 have been identified to influence hair and skin pigmentation in humans (Sturm, 2009) and other mammals (Eizirik et al., 2003; Majerus \& Mundy, 2003; Hokestra, 2006), Mc1r is the most well studied. Past studies emphasize the importance of Mc1r as a candidate gene for understanding the variation and evolution of coloration in vertebrates (Majerus \& Mundy, 2003; Hokestra, 2006; Gompel \& Prud'homme, 2009; Nunes et al., 2011).

The role of Mc1r in non-human primates has not been well studied, even though many non-human primates exhibit flamboyant colors, such as reds, yellows and even blue, and have striking coat patterns with facemasks and dorsal stripes (Bradley \& Mundy, 2008). One of the most comprehensive studies of Mc1r in non-human primates 
found that nonsynonymous mutations were not well-correlated to phenotypic changes, specifically coat color, and instead appeared to more strongly correlated with phylogenetic associations (Mundy and Kelley 2003). This study also found that purifying selection is the primary mode of evolution for the Mc1r gene in non-human primate lineages. There were a few exceptions, especially with respect to Leontopithecus rosalia (golden-lion tamarin), where results indicated a higher than expected $\mathrm{dN} / \mathrm{dS}$ ratio (0.91) that was not significantly different from 1 , and several substitutions and deletions at functionally important sites. Their finding suggests the red hair phenotype observed in Leontopithecus could be due to a loss of function in Mc1r, like in humans, but more research is needed (Mundy \& Kelly, 2003). Although their study is one of the most comprehensive studies of Mc1r evolution in non-human primates, Mundy \& Kelly (2003) focused on select species, and mainly on monkeys and apes. Furthermore, not every species of a genus or family were studied, which complicates the ability to infer functional changes of Mc1r within a taxon (Makova \& Norton, 2005). Finally, few strepsirrhines were studied, and some, such as Loris species (slender lorises) were treated as outgroups. Mundy \& Kelly's (2003) study has improved our understanding of Mc1r evolution in non-human primates, but a narrower focus on a single primate family could reveal important functional sites in Mc1r that correspond to pigmentation variation (Makov \& Norton, 2005).

Variations in non-human primate coat colors and patterns have been noted as possible adaptations for camouflage, sexual selection, species recognition, thermal strategies, and even as anti-predator strategies (Ford, 1994; Bearder, 1999; Bradley \& Mundy, 2008; Kamilar \& Bradley, 2011; Nekaris et al., 2013), in stark contrast to studies 
on human hair and skin pigmentation which correlates to UV exposure, vitamin D synthesis, and climatic adaptations (Valverde et al., 1995; Sturm et al., 2003; Jablonski, 2004; Yuen \& Jablonski, 2010; Jablonski, 2012; Nasti \& Timares, 2015). Studies on non-human primate variation are often based on behavioral ecology and taxonomy, as few have explored the genetics of coat colors in primates (c.f. Bradley \& Mundy, 2008). Striking coat colors are predominantly found in diurnal haplorhines (tarsiers, monkeys, and apes), whereas the nocturnal strepsirrhines (lemurs and lorises) appear to possess more subdued coat colors. Yet, in the strepsirrhines we observe highly contrasting coat patterns, where dark spots pop out due to white outlines. This type of countershading results in face masks and dorsal stripes that have been used to distinguish species (Ford, 1994 ; Bearder, 1999; Nekaris \& Munds, 2010; Munds et al., 2013; Svensson et al., 2017).

Furthermore, countershading has been postulated to be a mate-recognition or species recognition cue (Ford, 1994; Bearder, 1999). The contrasting light and dark coloration stand out at night, making it easy for conspecifics to identify each other. The dark spot coloration can vary from black/brown to red/yellow in some species, and result in different contrasting values, which would further reinforce species diversification (Ford, 1994; Munds et al.,2013). Yet, some have proposed that these coats are adaptive signals for either mimicry or aposematism. For example, slow lorises (Nycticebus) are the only toxic primate. These colorful primates possess glands in their armpits that secrete a toxin. When this toxin is mixed with their saliva it produces a noxious bite that inflicts necrosis wounds or even anaphylactic shock to its victims (Nekaris et al.,2013). Their toxic bite has led some to speculate that their coat patterns are warning signals to 
potential predators (Nekaris et al., 2013). But Nycticebus is not the only colorful primate in the family Lorisidae; slender lorises (Loris) also possess striking coat colors and patterns. Slender lorises are not toxic, but they could be possible mimics of either slow lorises (partially sympatric) or cobras (sympatric).

The Lorisidae family presents a unique opportunity to examine the evolution of coat patterns and color within a small clade. There are two distinct subfamilies separated by geography and coat colors and patterns. The Perodictinae of Africa has two genera: the potto (Perodicticus) and the angwantibo (Arctocebus), both of which are monochromatic brown and lack any distinct facemask or dorsal stripe. Conversely, the Asian Lorisinae (slender lorises (Loris) and slow lorises (Nycticebus)) have distinct facemasks and dorsal stripes and are found in various colors such as yellow, red, grey, and black (Fig. 4.1).

We argue that Perodictinae, more specifically Perodicticus, retain the ancestral form of Lorisidae coloration, and that countershading is an evolutionary mechanism for species recognition or nocturnal camouflage. This hypothesis agrees with past studies that have found darker phenotypes to be indicative of an ancestral form (Valverde et al.,1995; Hoekstra \& Nachmann, 2003; Majerus \& Mundy, 2003; Hoekstra, 2006; Sulem et al.,2007; Nunes et al., 2011). To date, most studies on coat color variation in Lorisidae are based on phenotypic analyses, using such variation as a way to demarcate species (Nekaris \& Nijman, 2007; Nekaris \& Munds, 2010; Munds et al.,2013) rather than as a way to explore their coat color and pigment evolution (c.f. Nekaris et al.,2013). By examining the evolution of Mc1r in Lorisidae and comparing it to phenotype variation, we aim to better understand the evolution of Lorisidae coat color and pigmentation. We 
expect the overall nonsynonomous to synonomous substitution ratio (dN/dS) of Mc1r to indicate purifying selection, as has been found with numerous other studies (Mundy \& Kelly, 2003; Majerus \& Mundy, 2003; Makov \& Norton, 2005; Nunes et al.,2011). Such a finding does not suggest Mc1r lacks a functional role in coat or skin morphology in Lorisidae, but instead would indicate it is highly conserved in Lorisidae, as an Mc1r loss of function has been noted as deleterious in other organisms (Valverde et al., 1995; Moro et al.,1999; Harding et al.,2000; Makov \& Norton, 2005; Hoekstra, 2006; Beaumont et al.,2007; Nasti \& Timares, 2015). Finally, from this study, we predict that there are more nonsynonymous mutations along the Lorisinae (Loris \& Nycticebus) branches than along the Perodictinae branches (Arctocebus \& Perodicticus). We argue this because Lorisinae have been evolving independently from pottos for at least 30my (Pozzi et al., 2015; Munds et al.,2018), and possess red/yellow phenotypes that are different from Galagidae, the outgroup of this study. Alternatively, pottos maintain a monochromatic, dark phenotype that is more comparable to galagos, which is why we predict less nonsynonymous mutations will be found along their branch.

\section{Material and Methods}

\section{Tissue collection and sequencing}

Lorisidae samples (DNA, hair, tissue) were acquired from American Zoological Association institutions, with the majority of samples being hair follicles. Tissues samples were only collected from Loris, Nycticebus and Perodicticus as Arctocebus is not found in captivity. The collection protocol adhered to the humane animal handling 
guidelines (The Animal Behavior Society, 2003), and samples were collected were done by trained personnel at each institution. To reduce the risk of contamination, handlers were instructed to wear sterile gloves and to use a piece of tape to remove the $\sim 20$ hair and follicles from the individual lorises. Once collected each sample was stored separately and stored in a clean, dry coin envelope. Additionally, the Duke Lemur Center provided samples from two deceased N. pygmaeus individuals, and from the Frozen Zoo ${ }^{\circledR}$ collection at the San Diego Institute for Conservation Research.

DNA hair follicle extraction followed the Instagene protocol from (Eggert et al., 2005). We extracted tissue sample DNA using the DNeasy Blood and Tissue kit (Qiagen, Valencia, CA) with the manufacturer's protocols. Samples from the Frozen $Z_{0 o}{ }^{\circledR}$ were received as extracted DNA, thus we determined the DNA concentrations of these samples using a Nano-drop spectrophotometer (Thermo Fisher Scientific, Waltham, M.A.) and diluted to a $15 \mathrm{ng} / \mu \mathrm{L}$ concentration for amplification using the polymerase chain reaction (PCR).

We sequenced fragments from the mitochondrial (mtDNA) cytochrome $b$ (cytb) gene, an intron from the nuclear recombinant activation gene 2 (Rag2), and the nuclear melanocortin 1 receptor (Mc1r) gene (Table 1). Our Mc1r primers were designed from Mundy \& Kelly’s (2003) slender loris (Loris) sequence (GenBank Accession: AY205137.1) and amplify a region of Mc1r known to contribute to melanin production. The PCR was performed in $25 \mu \mathrm{L}$ volumes containing $1 \mathrm{X}$ PCR Gold Buffer $(50 \mathrm{mM}$ KCL, $8 \mathrm{mM}$ Tris-HCL), $0.2 \mathrm{mM}$ dNTPs, $0.4 \mu \mathrm{M}$ each forward and reverse primers, 2 $\mathrm{mM} \mathrm{MgCl} 2$, 1 X BSA, $0.5 \mathrm{U}$ Amplitaq Gold DNA Polymerase (Thermo Fisher Scientific, Waltham, MA), and $1 \mu \mathrm{L}(\sim 15 \mathrm{ng})$ of DNA template. Amplifications were performed 
under the following conditions for all genes: pre-denaturation at $95^{\circ}$ for 10 minutes; 40 45 cycles of denaturation at $95^{\circ} \mathrm{C}$ for 1 minute, primer annealing for 1 minute at locus specific temperatures (Table 4.1), and primer extension at $72^{\circ}$ for 1 minute; and a final elongation step at $72^{\circ} \mathrm{C}$ for 10 minutes. Amplification products were visualized in a $2 \%$ agarose gel and prepared for sequencing with a Qiaquick PCR Purification Kit (Qiagen, Valencia, CA), in which we followed the standard protocol except we incubated the elution step for 5 minutes and eluted in a $20 \mu \mathrm{L}$ volume. We also prepared some of our sequences using the EXO-AP protocol, in which Exo-AP Clean-up was run in $23.5 \mu \mathrm{L}$ volume reactions containing $2.75 \mu \mathrm{L}$ of 10x FastAP buffer (Thermo Fisher Scientific, Waltham, M. A.), $0.50 \mu \mathrm{L}$ of $1 \mathrm{U} / \mu \mathrm{L}$ FastAP (Thermo Fisher Scientific, Waltham, M. A.), $0.25 \mu \mathrm{L}$ of $20 \mathrm{U} / \mu \mathrm{L}$ Exonuclease I (New England Biolabs Inc., Ipswich, M. A.), and $20 \mu \mathrm{L}$ of PCR product. The incubation profile included enzyme activation at $37^{\circ} \mathrm{C}$ for 15 minutes and inactivation at $80^{\circ} \mathrm{C}$ for 10 minutes. Amplification products were sequenced in both directions at the University of Missouri DNA Core Facility in a 3730x1 96capillary DNA Analyzer with Applied Biosystems Big Dye Terminator cycle sequencing chemistry (Thermo Fisher Scientific, Waltham, MA).

\section{Phylogenetic reconstruction \& test of selection}

The software GENEIOUS v. 8.0.5 (Biomatters, Ltd.) was used to align and edit forward and reverse sequences, remove primers and test for the presence of pseudogenes by translating sequences. We acquired outgroup sequences of Galago from GenBank (accession: AY205138.1(Mc1r), HM759002.1 (Rag2), AY441470.1 (cytb)) and aligned them to our Lorisidae sequences before importing them into MEGA (Kumar et al., 2008) 
in FASTA format. For further analyses, Mc1r was translated into protein sequences using MEGA. All aligned DNA sequences (cyt $b$, Rag2, and Mc1r) and protein sequences (Mc1r) were exported from MEGA. Analyses did not include Arctocebus as they are not found in captivity so tissue samples were not acquired.

We used a Bayesian partitioned analysis for phylogenetic reconstruction using cyt $b$ and Rag2 genes with program BEAST ver.2.4.5 (Drummond et al., 2012). Rag2 and cyt $b$ sequences were individually uploaded to jModeltest ver. 2.1.7. to determine the optimal model of nucleotide substitution under the AICc criterion, which is preferred for small datasets. Based on our results from jModeltest we used a GTR+G substitution model with gamma distribution fixed to 0.295 for cyt $b$, and an HKY+I substitution model with proportion of invariable sites fixed to 0.681 and a kappa of 4.8769 for Rag2. Program BEAST permits the user to analyze different gene sequences together, while maintaining the optimal substitution models for each gene (Drummond et al.,2012). Both genes used the uncorrelated lognormal relaxed-clock model. We used a Yule process of speciation on the tree prior, with birth rate as a gamma distribution $(\alpha=0.001, \beta=1000)$. Gamma shape was exponential with a mean of 1. Calibration points for divergence time was a mean of 58 million years ago (MYA) with a standard deviation of 3.0 for the time to most recent common ancestor (TMRCA) for Lemuriformes and Lorisiformes, and a TMRCA of 40 MYA with a standard deviation of 3.0 was used for the Galagidae and Lorisidae split. Dates used are based on well-supported phylogenetic studies and the fossil record (Yoder et al., 2001; Seiffert, 2007; Perelman et al., 2011). 
Four independent Markov chain Monte Carlo (MCMC) runs with 40 million generations with an initial 50000 burn-in (where we sampled every 1000) were done for both $\log$ and tree files. Tracer ver. 1.4.1 was used to read log files and see if the estimated sample size (ESS) met the minimum criteria of exceeding 200 for all parameters; our sampling was more than sufficient. TreeAnnotater ver 2.4 .5 was used to prepare each tree file for examination. Parameters for TreeAnnotater files were: $25 \%$ burn-in, with Maximum clade credibility, and mean node heights. The four tree files were combined using LogCombiner ver 1.5.3. The final combined tree file was viewed with FigTree ver 1.3.1. The minimum displayed node support was $75 \%$ posterior probability (PP). For this study we found it best to use the Bayesian trees instead of a species tree. The advantage of a species tree is that unlike concatenated trees, species trees allow each gene tree to influence each other, whereas with concatenated trees a single gene can impact the entire phylogeny (Heled \& Drummond, 2009; Liu \& Edwards, 2009). But past studies on Lorisidae have demonstrated inconsistencies with the phylogenies resulting from a species-tree analysis, and found the concatenated tree to be more reliable (Pozzi et al., 2014; Munds et al., 2018)

A maximum-likelihood estimate of the rate of nonsynonymous substitutions per nonsynonymous site to synonymous substitutions per synonymous site $(\omega=d N / d S)$ under a codon-based substitution model (codeML) using PAML v.4 (Yang, 2007) was used to test for the effects of natural selection on Mc1r. The cyt $b$ and Rag2 Bayesian partitioned analysis tree from BEAST was used as the input tree for the analysis (Fig. 4.2). The phylogeny from the cyt $b / \operatorname{Rag} 2$ tree agrees with past studies that found Lorisidae to represent a monophyletic family, which is currently the most accepted phylogeny for this 
family (Roos et al., 2004; Perelman et al., 2011; Pozzi et al., 2014; Pozzi et al., 2015; Munds et al., 2018). The aligned Mc1r codon FASTA file was used for the sequence file. A typical codon model of M0 (one-ratio of dN/dS) was selected to measure $\omega$ (Yang, 2007). Although there are known color differences among the clades of Lorisidae (Nekaris \& Bearder, 2007) detailed phenotypic analyses were not incorporated in this study and therefore we did not run clade or branch model analyses. A clade model analysis is used to compare/contrast a selected clade and compare it to the other clades based on known nonsynonymous changes. Branch model analyses are similarly used to select a particular branch that leads from a clade of interest to the other clades in order to infer nonsynonymous changes (Yang, 2007; Corso et al., 2016). So far, no study has investigated possible nonsynonymous changes within Lorisidae, therefore a clade or branch model seemed inappropriate for our study. A 729-bp alignment of Mc1r was used for the three analyzed genera of Lorisidae (Loris, Perodicticus, Nycticebus). The $N$. coucang and N. pygmaeus were analyzed separately, giving a total of four separate analyzed groups: the minimum suggested number of groups for these analyses (Yang, 2007). The fourth Lorisidae genus, Arctocebus, is not found in captivity and is not included in this study. The Mc1r substitutions were mapped onto the cyt $b / \operatorname{Rag} 2$ phylogenetic tree using FigTree ver. 1.3.1. 


\section{Results}

The resulting cyt $b /$ Rag 2 phylogenetic tree agrees with previous studies that found Lorisidae to be a monophyletic family with Galagidae (galago) as a close sister taxon (Perlemann et al., 2011; Pozzi et al., 2014; Pozzi et al., 2015; Munds et al., 2018) (Fig. 4.2.A). Similarly, the Mc1r phylogeny found Lorisidae to be monophyletic (Fig. 4.2.B), but unlike the cyt $b / \operatorname{Rag} 2$ phylogeny the Mc1r phylogeny did not distinctly separate Nycticebus coucang from N. pygmaeus. Both trees showed a long, independent evolution of Perodicticus potto from the other Lorisidae (cyt b/Rag 2: 38my, Mc1r: 33my), but the age of the Perodicticus genus is relatively young (cyt $b / \operatorname{Rag} 2: 4 m y$, Mc1r: $8 m y)$. In comparison, the Lorisinae clade (Nycticebus, Loris) arose 26-30mya, with Loris being 4 (cytb/Rag2)-8 (Mc1r) myo, and Nycticebus being much older at 14 (Mc1r) -19 (cytb/Rag2) myo. Only Nycticebus has a younger age of diversification with Mc1r than with the cyt $b / \operatorname{Rag} 2$ phylogeny.

The overall $d N / d S$ ratios for Mc1r in the Lorisidae phylogeny was 0.144 , indicating purifying selection. Within Lorisiformes there were 61 variable sites, with a total of 14 nonsynonymous and 47 synonymous substitutions associated with specific branches and codons. There were 4 nonsynonymous and 16 synonymous substitutions that led from Galagidae to the Lorisidae (Fig. 4.3). Within Lorisidae, most codon changes occurred with the separation of Lorisinae from TMRCA of Lorisidae (Branch 3: 2 nonsynonymous, 8 synonymous) and Perodicticus from TMRCA of Lorisidae (Branch 37: 5 nonsynonymous, 12 synonymous). There was 1 nonsynonymous and 4 synonymous substitutions on branch 12 which is where Loris and Nycticebus split, and one unique Nycticebus had a nonsynonymous substitution (Branch 19). 
Nonsynonymous substitutions were further explored to see if amino acid changes involved changes in charge. Of the 14 nonsynonymous changes, 7 resulted in charge changes, with all five of the Perodicticus substitutions resulting in charge changes (Table 4.2). The other charge changes were from one of the Galagidae and the unique Nycticebus. All Perodicticus charge changes were from either a non-polar to polar or vice versa.

\section{Discussion}

Evolutionarily, the Lorisidae melanocortin 1 receptor (Mc1r) closely resembles the phylogeny derived from a nuclear intron (Rag2) and a mitochondrial gene (cytb) (Fig 4.2). Both phylogenies found Lorisidae to be a monophyletic family with Galago as an outgroup, as has been reported in past studies (Perelman et al., 2011; Pozzi et al., 2014; Munds et al., 2018). As expected, the African pottos (Perodicticus) had the longest branch length with Mc1r at 33 million years, followed by the Asian slender lorises (Loris) at $18 \mathrm{my}$. Both these genera are relatively young, arising around 8 mya. Slow lorises (Nycticebus) were the only genus to have an evolutionary history of Mc1r that differed from Rag2/cytb phylogeny. In the concatenated cyt b/Rag2 results Nycticebus breaks off into two reciprocally monophyletic clades, with a clear pygmy loris $(N$. pygmaeus) clade that separates from the other slow lorises (N. coucang). Yet, our Mc1r results found a less defined separation between these two species, with the Mc1r phylogeny having more internal branching of individuals, and no clear divide between $N$. coucang and N. pygmaeus. The results from Mc1r for Nycticebus suggest that there may be minor distinctions between individuals within species and these differences might be 
from color differences either pertaining to coat or skin color, as has been seen in other vertebrates as well as other primates, such as humans (Valverde et al., 1995; Rana et al., 1999; Mundy \& Kelly, 2003; Majerus \& Mundy, 2003; Hoekstra, 2006; Sulem et al., 2007; Bradley \& Mundy, 2008; Nasti \& Timares, 2015).

Our prediction that the more vibrantly colored Lorisinae (Loris and Nycticebus) would have more nonsynonymous mutations on its branches than the monochromatic Perodicticus was not supported (Figure 4.3). Overall, our dN/dS ratio was 0.144 , indicating purifying or negative selection, which was expected given the plethora of previous studies that had similar results (Mundy \& Kelly, 2003; Majerus \& Mundy, 2003; Pointer \& Mundy, 2008; Shimada et al., 2009; Nunes et al., 2011). One explanation as to why purifying selection is common with Mc1r studies is that single nonsynonymous substitutions in Mc1r can cause large phenotypic changes (Theron et al., 2001; Mundy \& Kelly, 2003; Hoekstra, 2006; Nunes et al., 2011). We found a total of 61 variable sites, with the majority being synonymous substitutions; only 14 sites were nonsynonymous. Only four nonsynonymous mutations occurred on the more colorful Lorisinae branches, with one resulting in a charge change (Ala5Asp). The majority of nonsynonymous charge changes were found on the Perodicticus branch. In fact, all five nonsynonymous substitutions found on the Perodicticus resulted in charge changes, with most resulting from a non-polar to polar (Ala8Thr; Ala121Thr; Ala137Thr) or vice versa (Ser115Phe; Thr117Iso). It is difficult to infer why pottos would have more nonsynonymous substitutions on their branch in comparison to the other Lorisidae primates, but past studies on the genetics of pigmentation on other organisms can aid in understanding Mc1r evolution in Lorisidae. 
The long divergence time that separates pottos and Lorisinae could be one explanation as to the why pottos have more nonsynonymous amino acid substitutions. Similar to our study, a study on European ocellated lizards (Lacerta lepdia spp.) found Mc1r variation and divergence time to strongly correspond. The more diverged L.l. nevadensis (9.4 million years old) was distinct from the other L. lepdia spp. in the number of Mc1r nonsynonymous mutations it had, as well as having a darker brown/black phenotype with no green coloration. Such findings suggest a form of divergent evolution leading to possible speciation of L.l. nevadensis from other L.lepdia spp. (Nunes et al., 2011). Similarly, Perodictinae separated from Lorisinae $~ 33$ mya, providing a long duration of independent evolution. Divergence between the Lorisinae genera (Loris \& Nycticebus) is younger, at 18my. Although long enough to result in different genera, different selective pressures might impact the limited Mc1r variation observed between these two genera in comparison to pottos, but more studies on these primates' behavioral ecology are needed to infer differences.

Although the eumelanin/dark phenotype is generally considered ancestral, and several past studies have found significant amino acid changes associated with organisms presenting a pheomelanin phenotype (Valverde et al., 1995; Theron et al., 2001; Mundy \& Kelly, 2003; Hoekstra, 2006; Nasti \& Timares, 2015), some studies have found significant amino acid substitutions associated with darker phenotypes too. In a study on toucans (family: Ramphastidae), Corso et al., (2016) were able to link Mc1r evolution to phenotype evolution, with the darker Ramphastos clade having more Mc1r nonsynonymous substitutions than the other genera within Ramphastidae. In fact, all significant amino acid changes occurred only with Ramphastos. Their study, along with 
several others, found that the evolution or possession of a darker phenotype results in multiple nonsynonymous Mc1r mutations (Nachman et al., 2003; Nunes et al., 2011; Janssen \& Mundy, 2013), instead of just one or two which is seen with lighter phenotypes (Rana et al., 1999; Theron et al., 2001; Mundy \& Kelly, 2003; Rosenblum et al., 2004; Hoekstra, 2006). It could be that the maintenance or evolution of a darker phenotype requires or allows more nonsynonymous mutations, which is what we found with the darker pottos. Another interesting finding, which correlates with the many Mc1r variation studies on bird plumage, is that the more monochromatic taxon of interest (pottos) had more Mc1r amino acid changes than the more patterned taxon (Lorisinae) (Theron et al., 2001; Mundy, 2005; Pointer \& Mundy, 2011; Bourgeois et al., 2012; Corso et al., 2016). Such a finding suggests that other pigment inducing genes may be responsible for the striking coat variations found in Lorisinae.

As stated, some studies have higher $\mathrm{dN} / \mathrm{dS}$ ratios for Mc1r associated with organisms that have transitioned from eumelanin (black/brown hair, dark complexion) production to a loss-of-function variant of Mc1r which causes the production of pheomelanin (red/yellow hair, fair complexion) Mc1r (Valverde et al., 1995; Rana et al., 1999; Harding et al., 2000; Mundy \& Kelly, 2003; Hoekstra, 2006; Wolf Horrell et al., 2016). This loss-of-function results in a fairer complexion and red hair which is considered deleterious as it increases UV sensitivity; the more eumelanin present, the more protected the organism is from UV damage (Wolf-Horrell et al., 2016). These findings are why we predicted more amino acid charge changes along the Lorisinae branch, as Lorisinae possess red/yellow haired species, whereas pottos are darker. One thing to note is that although pottos have darker fur color, their skin is fairer in 
comparison to many Lorisinae. Thus, some of the noted amino acid changes could be influencing the maintenance of fairer skin for pottos. Studies on humans, mice, and a few other organisms have indicated that although the loss-of-function Mc1r variants are deleterious due to increased UV sensitivity, such an adaptation can be useful as it helps to increase UV absorption which induces vitamin D synthesis (Bodmer \& Cavalli-Sforza, 1976; Wolf Horrell et al., 2016). As nocturnal primates, it could be advantageous to have such a mutation occur in pottos, but it does not explain why pottos would have this mutation and not Lorisinae too.

More behavioral ecology studies on Lorisidae, particularly potto, will help better understand the ecological or behavioral factors that may have resulted in pottos being monochromatic in comparison to Lorisinae and many other nocturnal primates. It is believed the vivid colors and facemasks seen in Lorisinae and other nocturnal primates are used as mate recognition cues, countershading, and possibly, in the case of slow lorises, as signals for aposematism (Ford, 1994; Bearder, 1999; Caro, 2005; Bradley \& Mundy, 2008; Kamilar \& Bradley, 2011; Nekaris et al., 2013). Why pottos would lack the facemasks and coloration so commonly seen in other nocturnal primates is difficult to explain, due to the dearth of behavioral ecology and even taxonomic studies on them (c.f. Charles-Dominque, 1977; Pimley et al., 2005; Butynski \& de Jong, 2017). Past studies have found them to be quite secretive, and seemingly more reliant on olfactory cues than visual or auditory cues, in comparison to other nocturnal primates (Cowgill, 1974; Manley, 1974; Charles-Dominque, 1977; Oates, 1984; Pimley et al., 2005). This preference for olfactory signaling might be a useful explanation for their subdued coat color and patterns, but more research is needed to confirm such a hypothesis. Another 
explanation for the selection of a dark phenotype is protection from overexposure to UV radiation, which is particularly true in humans, and species that live in open areas or on the edge of forests (Valverde et al., 1995; Jablonski, 2012; Nasti \& Timares, 2015; Corso et al., 2016). To our knowledge, pottos prefer dense vegetation and are nocturnal, so the effects of UV exposure would be minimal (Charles-Dominque, 1977; Pimley et al., 2005); in fact, as stated previously, we expect they would evolve a phenotype to help in getting more UV exposure to increase vitamin D synthesis.

Finally, pertaining to their phenotype, a probable explanation for the higher amino acid changes on the Perodicticus branch could be the influence of another gene that interacts with Mc1r: the Agouti Signaling Protein (ASIP). ASIP acts as an antagonist/reverse agonist to Mc1r (Jackson, 1997; Mundy \& Kelly, 2006). Several phenotypes are observed from the regulation of ASIP, most notably is a pale ventral area, and hairs throughout the body are pale but band against a dark background otherwise referred to as agouti hairs (Mundy \& Kelly, 2006). Pottos possess agouti hairs and a pale area, and although Lorisinae do have pale ventral surface many of them appear to lack agouti hairs. Along with ASIP, other genes like KIT, TYRP1, and Tabby which influence coat patterns (Eizirik et al., 2001; Fontanesi et al., 2010; Hauswirth et al., 2013) could be influencing the lack of Mc1r variation in Lorisinae, as has been noted in past studies on many domestic animals (Marklund et al., 1996; Rieder et al., 2001; Fontanesi et al., 2011; Hanna et al., 2014) and mice (Steiner et al., 2007). As is the case with most of these explanations, more research is needed to explore the impacts of other pigment genes and how they influence primate coat and color variation. 


\section{Conclusion}

As an order, primates present an opportunity to explore the evolution of coat colors and patterns through genetics. Primates are colorful. Primates have a wide-variety of coat patterns. Some species are dichromatic whether for sexual selection or another purpose. Yet, we know very little about the possible selective advantages of these coat colors and patterns. Our study does not just highlight the dearth of information on Lorisidae and their coat color evolution, but also our limited knowledge regarding non-human primate pigment variation. This study is not the first to explore primate color evolution through Mc1r (c.f. Mundy \& Kelly, 2003; Mundy \& Kelly, 2006) or the first study to call attention to the need for more research exploring the genetic basis of coat evolution in non-human primates (Bradley \& Mundy, 2008), but it is one of the first to examine Mc1r evolution associated with a single primate family. Our research attempts to provide a stepping-stone for future work to explore the possible mechanistic reasonings for variation within family. We acknowledge that it is a small-scaled study, and that more detailed analyses of not only their genetics, but also their phenotypes could elicit better explanations for our findings and for the evolution of coat colors and patterns in the Lorisidae. What has been found was that the brown, monochromatic potto has more nonsynonymous Mc1r mutations which could correspond to its darker phenotype and longer, independent evolution from the other Lorisidae. 


\section{Acknowledgements}

We thank the American Zoological Association for their assistance with this project, and the participatory zoos and institutions. Dr. Helena Fitch-Snyder for her advice, information on the AZA captive lorises, and her time. Drs Elena Less and Mike Dulaney for studbook information. Finally, we thank financial support from Sigma Xi. Also, we thank two anonymous reviewers who greatly improved the quality of this manuscript. 


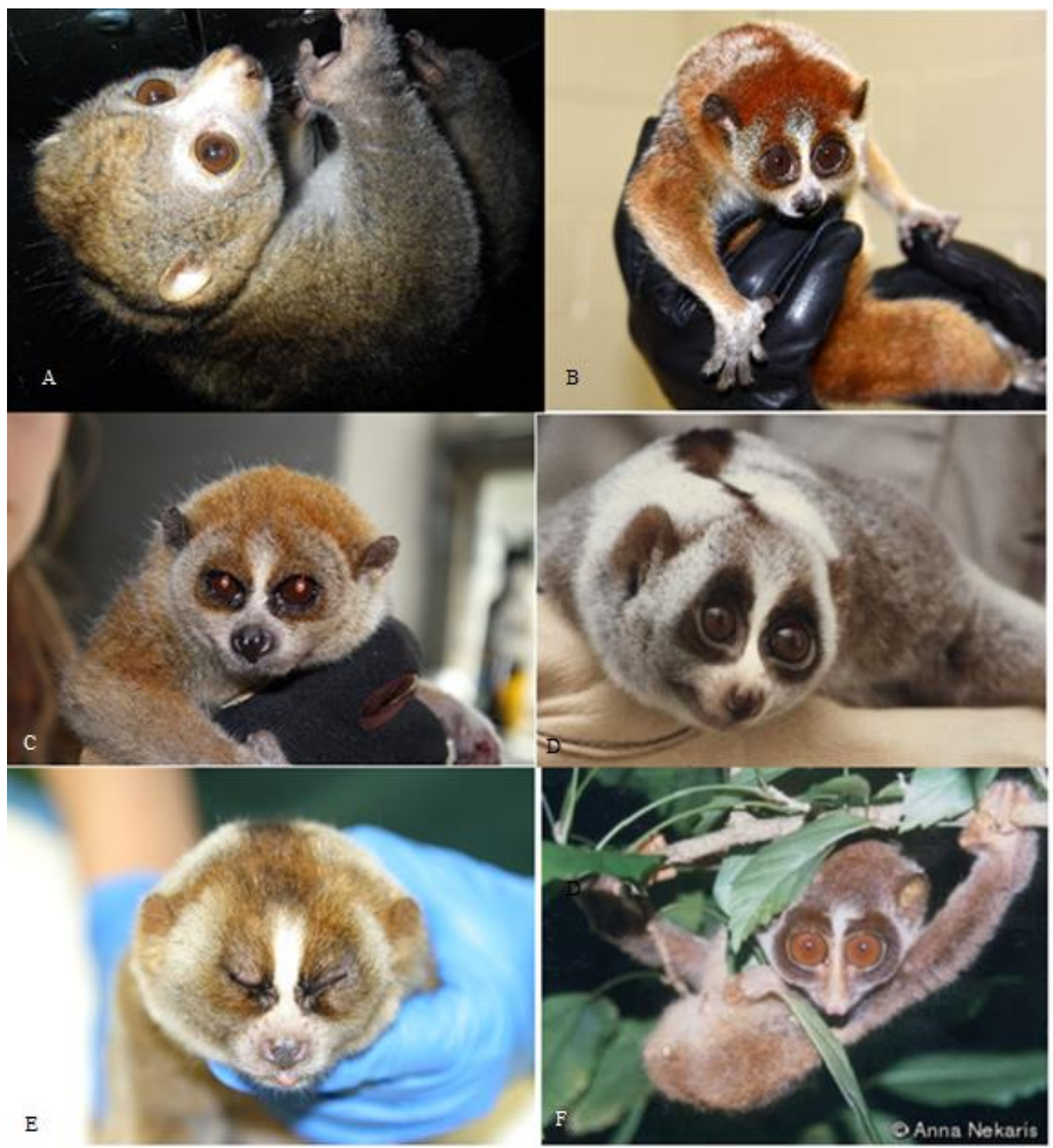

Figure 4.1: Coat colors and patterns of examined Lorisidae species: A) Perodicticus potto (Cincinnati Zoo), B) Nycticebus pygmaeus (Brookfield Zoo, Chicago), C) $N$. pygmaeus (Capron Zoo), D) N. coucang (possible N. bengalensis) (San Diego Zoo/ courtesy Dr. Helena Fitch-Snyder), E) N. coucang (Minnesota Zoo), F) Loris tardigradus (image copyright Dr. K.A.I. Nekaris) 

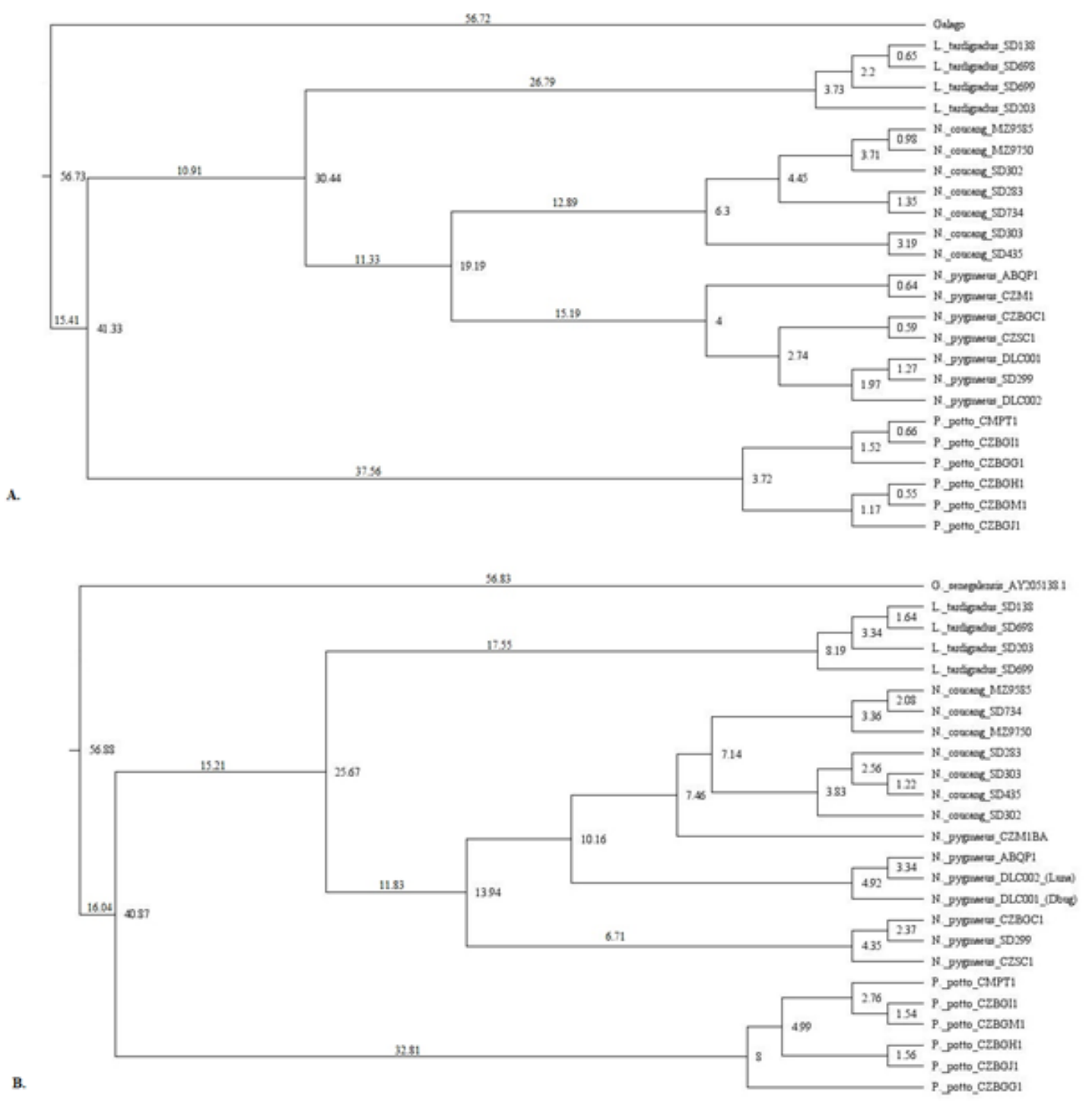

Figure 4.2: Bayesian cytochrome $b$ and Rag2 phylogenetic tree (A) and Mc1r (B). Node labels are ages in millions of years, branch lengths are the length in millions of years. 


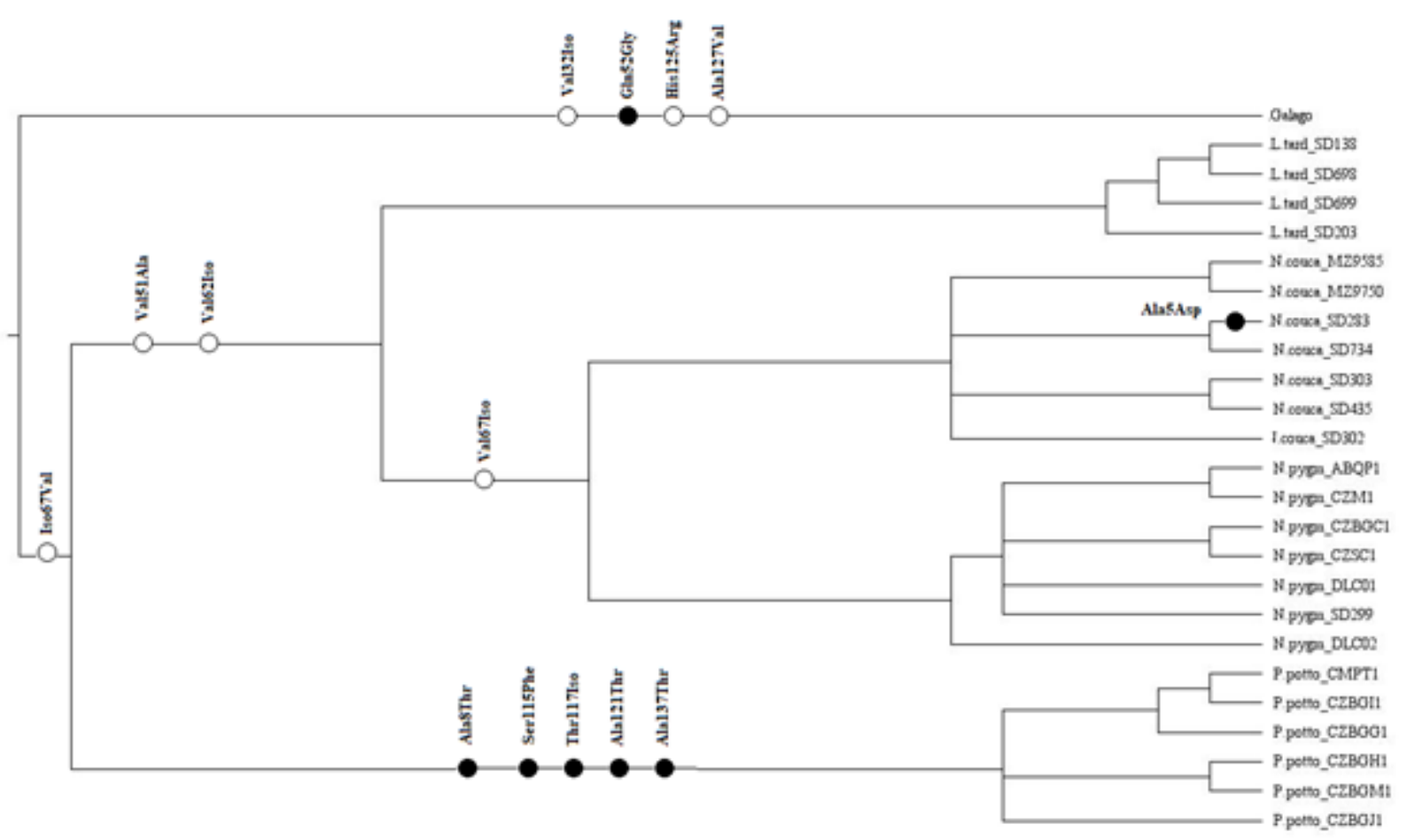

Figure 4.3: Bayesian phylogenetic tree of Lorisidae using Rag2/cytb with Mc1r nonsynonymous mutations mapped onto branches. Non-filled circles indicate amino acid substitutions that did not result in a charge change. Filled circles are chargechange amino acid substitutions. Site numbers correspond to specific sites found within this study's Mc1r sequence. 
Table 4.1: Primer sequences used for this study

\begin{tabular}{|c|c|c|c|c|}
\hline $\begin{array}{l}\text { Sequence/ } \\
\text { basepairs } \\
\end{array}$ & Forward Primer & "Reverse Primer & $\begin{array}{l}\text { Annealing } \\
\text { Temp }\end{array}$ & Source \\
\hline Cyt b / 331 & CCA TCC AAC ATC TCA GCA TGA TGA AA & CCC TCA GAA TGA TAT TTG TCC TCA & $55^{\circ}$ & 2 \\
\hline Rag2 / 716 & $\begin{array}{l}\text { GAT TCC TGC TAY CTY CCT CCT CT } \\
\text { GAT TCC TGC TAY CTY CCT CCT CT } \\
\text { GTG GAT TTT GAA TTT GGG TGT }\end{array}$ & $\begin{array}{l}\text { CCC ATG TTG CTT CCA AAC CAT A } \\
\text { GAT AGC CCA TCC TGA AGT TCT } \\
\text { CCC ATG TTG CTT CCA AAC CAT A }\end{array}$ & $\begin{array}{l}55^{\circ} \\
55^{\circ} \\
55^{\circ}\end{array}$ & $\begin{array}{l}3 \\
2 \& 3 \\
2 \& 3\end{array}$ \\
\hline Mc1r / 729 & $\begin{array}{l}\text { AGT GCC TGG AGG TGT CTG T } \\
\text { AGT GCC TGG AGG TGT CTG T } \\
\text { ATA TCA CAG CAT CGT GAC TCT }\end{array}$ & $\begin{array}{l}\text { GCA CCT CCT TGA GTG TCT TG } \\
\text { AAT GAA GAG GGT GCT GGA GA } \\
\text { GCA CCT CCT TGA GTG TCT TG }\end{array}$ & $\begin{array}{l}60^{\circ} \\
58^{\circ} \\
55^{\circ}\end{array}$ & $\begin{array}{l}1 \\
1 \\
1\end{array}$ \\
\hline
\end{tabular}

${ }^{1}$ Designed by Munds using Primer3 (Rozen \& Skaletsky, 1998)

${ }^{2}$ Kocher et al. (1989)

${ }^{3}$ Perelman et al. (2011) 
Table 4.2: Nonsynonymous substitutions detected in the Lorisidae. Highlighted rows indicate charge changes. Site number is pertaining to location in sequences used and not the specific location on Mc1r. Sequence (SEQ) sets are listed and how they change, resulting in the specific amino acid (AA) changes.

\begin{tabular}{|l|l|l|l|l|l|l|l|l|}
\hline SITE & SEQ 1 & AA 1 & Type AA & SEQ 2 & AA 2 & Type AA & Branch & TAXON \\
\hline 5 & GCT & Alanine & Nonpolar & GAT & Aspartic acid & Acidic & 19 & \#9 \\
\hline 8 & GCC & Alanine & Nonpolar & ACC & Threonine & Polar & 37 & POTTO \\
\hline 32 & GTG & Valine & Nonpolar & ATC & Isoleucine & Nonpolar & 1 & GAL \\
\hline 51 & GTG & Valine & Nonpolar & GCG & Alanine & Nonpolar & 3 & DAE/NAE \\
\hline 52 & CAG & Glutamine & Polar & GGG & Glycine & Nonpolar & 1 & GAL \\
\hline 62 & GTC & Valine & Nonpolar & ATC & Isoleucine & Nonpolar & 3 & DAE/NAE \\
\hline 67 & ATC & Isoleucine & Nonpolar & GTC & Valine & Nonpolar & 2 & FORM/DAE \\
\hline 67 & GTC & Valine & Nonpolar & ATC & Isoleucine & Nonpolar & 12 & NYC \\
\hline 115 & TCC & Serine & Polar & TTC & Phenylalanine & Nonpolar & 37 & POTTO \\
\hline 117 & ACC & Threonine & Polar & ATC & Isoleucine & Nonpolar & 37 & POTTO \\
\hline 121 & GCC & Alanine & Nonpolar & ACC & Threonine & Polar & 37 & POTTO \\
\hline 125 & CAC & Histidine & Basic & CGC & Arginine & Basic & 1 & GAL \\
\hline 127 & GCT & Alanine & Nonpolar & GTT & Valine & Nonpolar & 1 & GAL \\
\hline 137 & GCC & Alanine & Nonpolar & ACC & Threonine & Polar & 37 & POTTO \\
\hline
\end{tabular}




\section{Literature Cited}

Barsh, G.S. 1996. The genetics of pigmentation: from fancy genes to complex traits. Trends Genet. 12: 299-305.

Bearder, S.K. 1999. Physical and social diversity among nocturnal primates: A new view based on long term research. Primates 40: 267-282.

Beaumont, K.A., Shekar, S.N., Shekar, S.L., Newton, R.A., James, M.R., Stow, J.L., et al. 2007. Receptor function, dominant negative activity and phenotype correlations for MC1R variant alleles. Hum. Mol. Genet. 16: 2249-2260.

Bodmer, W.F. \& Cavalli-Sforza, L.L. 1976. Genetics, Evolution, and Man. W H Freeman \& Company.

Butyniski, T.M. \& de Jong, Y.A. 2017. The Mount Kenya potto is a subspecies of the Eastern Potto Perodicticus ibeanus. Primate Cons. 31: 49-52.

Bradley, B.J. \& Mundy, N.I. 2008. The primate palette: The evolution of primate coloration. Evolutionary Anthropology: Issues, News, and Reviews 17: 97-111.

Caro, T. 2005. The adaptive significance of coloration in mammals. BioSci. 55: 125 136.

Charles-Dominque, P. 1977. Ecology and Behavior of Nocturnal Primates.

Corso, J., Mundy, N.I., Fagundes, N.J.R. \& de Freitas, T.R.O. 2016. Evolution of dark colour in toucans (Ramphastidae): a case of molecular adaptation? J. Evol.

Biol. 29: 2530-2538.

Cowgill, U.M. 1974. Co-operative behaviour in Perodicticus. In: Prosimian Biology, pp. 261-272.

Drummond, A.J., Suchard, M.A., Xie, D. \& Rambaut, A. 2012. Bayesian phylogenetics with BEAUti and the BEAST 1.7. Mol. Biol. Evol. 29: 1969-1973. 
Eggert, L.S., Maldonado, J.E. \& Fleischer, R.C. 2005. Nucleic Acid Isolation from Ecological Samples-Animal Scat and Other Associated Materials. In: Methods in Enzymology, pp. 73-82.

Eizirik, E., Yuhki, N., Johnson, W.E., Menotti-Raymond, M., Hannah, S.S. \& O'Brien, S.J. 2003. Molecular Genetics and Evolution of Melanism in the Cat Family. Curr. Biol. 13: 448-453.

Fontanesi, L., Dall'Olio, S., Beretti, F., Portolano, B. \& Russo, V. 2011. Coat colours in the Massese sheep breed are associated with mutations in the agouti signalling protein (ASIP) and melanocortin 1 receptor (MC1R) genes. Animal 5: 817.

Fontanesi, L., Forestier, L., Allain, D., Scotti, E., Beretti, F., Deretz-Picoulet, S., et al. 2010. Characterization of the rabbit agouti signaling protein (ASIP) gene: transcripts and phylogenetic analyses and identification of the causative mutation of the nonagouti black coat colour. Genomics 95: 166-175.

Ford, S.M. 1994. Taxonomy and Distribution of the Owl Monkey. In: Aotus: the Owl Monkey, pp. 1-57.

Gompel, N. \& Prud'homme, B. 2009. The causes of repeated genetic evolution. Dev. Biol. 332: 36-47.

Han, J., Kraft, P., Nan, H., Guo, Q., Chen, C., Qureshi, A., et al. 2008. A genomewide association study identifies novel alleles associated with hair color and skin pigmentation. PLoS Genet. 4: e1000074.

Hanna, L.L.H., Sanders, J.O., Riley, D.G., Abbey, C.A. \& Gill, C.A. 2014. Identification of a major locus interacting with MC1R and modifying black coat color in an $\mathrm{F}_{2}$ Nellore-Angus population. Genet. Sel. Evol. 46: 4.

Harding, R.M., Healy, E., Ray, A.J., Ellis, N.S., Flanagan, N., Todd, C., et al. 2000. Evidence for variable selective pressures at MC1R. Am. J. Hum. Genet. 66: 13511361. 
Hauswirth, R., Jude, R., Haase, B., Bellone, R.R., Archer, S., Holl, H., et al. 2013. Novel variants in theKITandPAX3genes in horses with white-spotted coat colour phenotypes. Anim. Genet. 44: 763-765.

Hoekstra, H.E. 2006. Genetics, development and evolution of adaptive pigmentation in vertebrates. Heredity 97: 222-234.

Hoekstra, H.E. \& Nachman, M.W. 2003. Different genes underlie adaptive melanism in different populations of rock pocket mice. Mol. Ecol. 12: 1185-1194.

Jablonski, N.G. 2012. Human skin pigmentation as an example of adaptive evolution. Proc. Am. Philos. Soc. 156: 45-57.

Jablonski, N.G. 2004. The Evolution of Human Skin and Skin Color. Annu. Rev. Anthropol. 33: 585-623.

Jackson, I.J. 1997. Homologous pigmentation mutations in human, mouse and other model organisms. Hum. Mol. Genet. 6: 1613-1624.

Janssen, K. \& Mundy, N.I. 2013. Molecular population genetics of the melanic plumage polymorphism in Arctic skuas (Stercorarius parasiticus): evidence for divergent selection on plumage colour. Mol. Ecol. 22: 4634-4643.

Kamilar, J.M. \& Bradley, B.J. 2011. Interspecific variation in primate coat colour supports Gloger's rule. J. Biogeogr. 38: 2270-2277.

Kumar, S., Nei, M., Dudley, J. \& Tamura, K. 2008. MEGA: A biologist-centric software for evolutionary analysis of DNA and protein sequences. Brief. Bioinform. 9: 299-306.

Majerus, M.E.N. \& Mundy, N.I. 2003. Mammalian melanism: natural selection in black and white. Trends Genet. 19: 585-588.

Makova, K. \& Norton, H. 2005. Worldwide polymorphism at the MC1R locus and normal pigmentation variation in humans. Peptides 26: 1901-1908. 
Manley, G.H. 1974. Function of the external genetical glands of Perodicticus and Arctocebus. In: Prosimian Biology pp. 313-330.

Marklund, L., Moller, M.J., Sandberg, K. \& Andersson, L. 1996. A missense mutation in the gene for melanocyte-stimulating hormone receptor (MC1R) is associated with the chestnut coat color in horses. Mamm. Genome 7: 895-899.

Moro, O., Ideta, R. \& Ifuku, O. 1999. Characterization of the promoter region of the human melanocortin-1 receptor (MC1R) gene. Biochem. Biophys. Res. Commun. 262: $452-460$.

Munds, R.A., Nekaris, K.A.I. \& Ford, S.M. 2013. Taxonomy of the Bornean Slow Loris, With New Species Nycticebus kayan (Primates, Lorisidae). Am. J. Primatol. 75: $46-56$.

Munds, R.A., Titus, C.L., Eggert, L.S. \& Blomquist, G.E. 2018. Using a multi-gene approach to infer the complicated phylogeny and evolutionary history of lorises (Order Primates: Family Lorisidae). Mol. Phylogenet. Evol., doi: 10.1016/j.ympev.2018.05.025.

Mundy, N.I. 2005. A window on the genetics of evolution: MC1R and plumage colouration in birds. Proc. Biol. Sci. 272: 1633-1640.

Mundy, N.I. \& Kelly, J. 2003. Evolution of a pigmentation gene, the melanocortin-1 receptor, in primates. Am. J. Phys. Anthropol. 121: 67-80.

Mundy, N.I. \& Kelly, J. 2006. Investigation of the role of the agouti signaling protein gene (ASIP) in coat color evolution in primates. Mamm. Genome 17: 12051213.

Nachman, M.W., Hoekstra, H.E. \& D’Agostino, S.L. 2003. The genetic basis of adaptive melanism in pocket mice. Proc. Natl. Acad. Sci. U. S. A. 100: 5268-5273.

Nasti, T.H. \& Timares, L. 2015. MC1R, eumelanin and pheomelanin: their role in determining the susceptibility to skin cancer. Photochem. Photobiol. 91: 188-200. 
Nekaris, K.A.I., \& Bearder, S.K. 2007. The Lorisiform primates of Asia and mainland Africa; Diversity shrouded in darkness. In: Campbell, C., Fuentes A., MacKinnon, K., Panger, M., Bearder, S.K. (Eds.), Primates in Perspective, Oxford University Press, Oxford, UK pp. 24-45.

Nekaris, K.A.I., Moore, R.S., Rode, E.J. \& Fry, B.G. 2013. Mad, bad and dangerous to know: the biochemistry, ecology and evolution of slow loris venom. J. Venom. Anim. Toxins Incl. Trop. Dis. 19: 21.

Nekaris, K.A.I. \& Munds, R. 2010. Using Facial Markings to Unmask Diversity: The Slow Lorises (Primates: Lorisidae: Nycticebus spp.) of Indonesia. In: Indonesian Primates, pp. 383-396.

Nekaris, K.A.I. \& Nijman, V. 2007. CITES Proposal Highlights Rarity of Asian Nocturnal Primates (Lorisidae: Nycticebus). Folia Primatol. 78: 211-214.

Nunes, V.L., Miraldo, A., Beaumont, M.A., Butlin, R.K. \& Paulo, O.S. 2011. Association of Mc1r variants with ecologically relevant phenotypes in the European ocellated lizard, Lacerta lepida. J. Evol. Biol. 24: 2289-2298.

Oates, J.F. 1984. The niche of the potto, Perodicticus potto. Int. J. Primatol. 5: 5162.

Perelman, P., Johnson, W.E., Roos, C., Seuánez, H.N., Horvath, J.E., Moreira, M.A.M., et al. 2011. A molecular phylogeny of living primates. PLoS Genet. 7: e1001342.

Pimley, E.R., Bearder, S.K., Dixson, A.F. 2005. Social organization of the MilneEdward's potto. Am. J. Primatol. 66: 317-330.

Pointer, M.A. \& Mundy, N.I. 2008. Carotenoid genetics: chicken skin sheds light on carotenoid genetics. Heredity 101: 393-394.

Pozzi, L., Disotell, T.R. \& Masters, J.C. 2014. A multilocus phylogeny reveals deep lineages within African galagids (Primates: Galagidae). BMC Evol. Biol. 14: 72. 
Pozzi, L., Nekaris, K.A.-I., Perkin, A., Bearder, S.K., Pimley, E.R., Schulze, H., et al. 2015. Remarkable ancient divergences amongst neglected lorisiform primates. Zool. J. Linn. Soc. 175: 661-674.

Rieder, S., Taourit, S., Mariat, D., Langlois, B. \& Guérin, G. 2001. Mutations in the agouti (ASIP), the extension (MC1R), and the brown (TYRP1) loci and their association to coat color phenotypes in horses (Equus caballus). Mamm. Genome 12: $450-455$.

Roos, C., Schmitz, J. \& Zischler, H. 2004. Primate jumping genes elucidate strepsirrhine phylogeny. Proc. Natl. Acad. Sci. U. S. A. 101: 10650-10654.

Rosenblum, E.B., Hoekstra, H.E. \& Nachman, M.W. 2004. Adaptive reptile color variation and the evolution of the Mc1r gene. Evolution 58: 1794-1808.

Seiffert, E.R. 2007. Early evolution and biogeography of lorisiform strepsirrhines. Am. J. Primatol. 69: 27-35.

Steiner, C.C., Weber, J.N. \& Hoekstra, H.E. 2007. Adaptive variation in beach mice produced by two interacting pigmentation genes. PLoS Biol. 5: e219.

Sturm, R.A. 2009. Molecular genetics of human pigmenation diversity. Human Mol. Gen. 81: 9-17.

Sturm, R.A., Duffy, D.L., Box, N.F., Newton, R.A., Shepherd, A.G., Chen, W., et al. 2003. Genetic association and cellular function of MC1R variant alleles in human pigmentation. Ann. N. Y. Acad. Sci. 994: 348-358.

Sulem, P., Gudbjartsson, D.F., Stacey, S.N., Helgason, A., Rafnar, T., Magnusson, K.P., et al. 2007. Genetic determinants of hair, eye and skin pigmentation in Europeans. Nat. Genet. 39: 1443-1452.

Svensson, M.S., Bersacola, E., Mills, M.S.L., Munds, R.A., Nijman, V., Perkin, A., et al. 2017. A giant among dwarfs: a new species of galago (Primates: Galagidae) from Angola. Am. J. Phys. Anthropol. 163: 30-43. 
The Animal Behavior Society \& The Animal Behavior Society. 2003. Guidelines for the Treatment of Animals in Behavioural Research and Teaching. In: Exploring Animal Behavior in Laboratory and Field, pp. 399-409.

Theron, E., Hawkins, K., Bermingham, E., Ricklefs, R.E. \& Mundy, N.I. 2001. The molecular basis of an avian plumage polymorphism in the wild: a melanocortin-1receptor point mutation is perfectly associated with the melanic plumage morph of the bananaquit, Coereba flaveola. Curr. Biol. 11: 550-557.

Valverde, P., Healy, E., Jackson, I., Rees, J.L. \& Thody, A.J. 1995. Variants of the melanocyte-stimulating hormone receptor gene are associated with red hair and fair skin in humans. Nat. Genet. 11: 328-330.

Wolf Horrell, E.M., Boulanger, M.C. \& D’Orazio, J.A. 2016. Melanocortin 1

Receptor: Structure, Function, and Regulation. Front. Genet. 7: 95.

Yang, Z. 2007. PAML 4: phylogenetic analysis by maximum likelihood. Mol. Biol. Evol. 24: 1586-1591.

Yoder, A.D., Irwin, J.A. \& Payseur, B.A. 2001. Failure of the ILD to determine data combinability for slow loris phylogeny. Syst. Biol. 50: 408-424.

Yuen, A.W.C. \& Jablonski, N.G. 2010. Vitamin D: In the evolution of human skin colour. Med. Hypotheses 74: 39-44. 


\section{CHAPTER 5: CONCLUSION}

This dissertation demonstrates that by incorporating genetic and allometric methods we can improve our understanding of cryptic, nocturnal primate diversity and evolution. Although allometry is not a new tool, it is an excellent way to explore size and shape variation among phenotypically similar species. Furthermore, multivariate allometry is useful to discern how specific features of an organism has changed as it has changed in size, which can aid in interpreting evolutionary processes and history (Klingenberg and Zimmermann, 1992; Klingenberg, 1998, 2016). Since its advent, the use of genetics has been beneficial in improving our understanding of the evolutionary history of an organism. As the cost of genetic work has decreased, more refined techniques have been developed, including a multi-gene approach to infer phylogenetic evolution (Springer et al., 2001; Rokas et al., 2003). Different genes evolve at different rates, and thus concatenating several genes together is useful when trying to infer the relatedness and evolutionary time of a deeply rooted family, like Lorisidae. One gene approaches are not wrong, but they do not provide a clear evolutionary picture. Alternatively, a candidate gene approach, which focuses on one gene that is known to impact a specific phenotype, can be useful in understanding how a gene impacts a phenotype or fitness of an organism. Candidate genes can shed light on our understanding of the evolution of a phenotype of interest, if that phenotype/gene has undergone selective pressures, and how has this trait evolved along a phylogeny (Hoekstra and Nachman, 2003; Cunninghame Graham and Vyse, 2004; Hoekstra et al., 2004). As I have demonstrated, these methods can be applied to better understand cryptic species, such as tarsiers and lorises. 
Evolutionary allometry, the study of size and shape variation across taxa, is useful in identifying subtle differences among species, particularly cryptic species. This type of analysis was applied to tarsiers to infer if there are three distinct groups based on body size differences, as (Groves and Shekelle, 2010) proposed. In their study they found tarsiers to form three size-based morphs: small (Sulawesi species), medium (Philippine species) and large (Bornean species). Their descriptions were not quantified but based on a rough categorization. Our multivariate craniodental allometry analyses did detect two tarsier groups: a Sulawesi clade and a Philippine/Bornean clade, with the larger-bodied group having shorter skulls and smaller orbits in comparison to the Sulawesi species. But overall, we found that tarsier skulls, across taxa, generally stay the same shape as they increase in size. We speculate this is a result of their evolution towards shared extreme adaptations, such as hypertrophic eyes to aid in nocturnal vision, their large tarsal bone for vertical clinging and leaping, and faunivorous diet. Such extreme adaptations influence the limited size and cranial differences among tarsiers, which explains the lack of variation we see across taxa as well as even compared to ancestral tarsiers from the Miocene. Applying such methods to other cryptic species might help to determine what features of the crania are changing as species deviate in size, which in turn could assist in detecting subtle differences that could be used for species differences.

Yet, sometimes we have a poor understanding of the evolutionary history of an organism, which complicates interpreting its phenotypic evolution or relatedness among species and genera. By incorporating a multi-gene approach and sampling from the majority of the taxa in the primate family Lorisidae, we were able to establish the phylogenetic relationship among the four genera. Past studies on this family were 
inconsistent, with some studies finding them to be monophyletic, paraphyletic, or an unresolvable trichotomy with their sister family Galagidae. Such variation in results were because these studies relied on only one gene, or just one type of gene, or morphology, and thus failed to incorporate the use of several different types (mitochondrial (mtDNA), nuclear intron, nuclear exon) genes for interpreting Lorisidae phylogeny. Our research aim was to resolve the complicated evolutionary history of Lorisidae by using a multiapproach (2 mtDNA, one nuclear intron, and one nuclear exon). We found that by concatenating all genes, Lorisidae compose an ancient ( 40mya), monophyletic family with two subfamilies and four genera (Perodictinae from Africa (Arctocebus and Perodicticus) and Lorisinae from Asia (Loris and Nycticebus)). Furthermore, our single gene analyses highlighted the problems of depending on one gene to infer phylogenies, as we found discordance between topologies with some single-genes resolving the family as paraphyletic or a trichotomy with Galagidae. In the future, increasing the number of individuals and genes sampled will improve our evolutionary understanding of Lorisidae.

Finally, a candidate gene approach was used to understand the evolution of coat color in Lorisidae. The melanocortin 1 receptor (Mc1r) gene influences the production of eumelanin (brown/black or dark phenotypes) and pheomelanin (yellow/red or light phenotypes). Past studies have indicated that changes in this gene's sequence to be associated with color changes in a variety of organisms and impacted by selective events. Lorisidae presented a great opportunity to explore the evolution of this gene and how it is affiliated to phenotype, as these primates have two distinct morphs: the subdued, brown Perodictinae (Perodicticus) and the colorful Lorisinae (Loris and Nycticebus). By focusing on Mc1r we were able to demonstrate this gene is under purifying selection. In 
addition, results found a higher rate of charge-changing amino acid substitutions along the darker morphed Perodicticus, which we did not expect. We anticipated finding more amino acid substitutions as color variation increased, which is affiliated with Lorisinae. Past studies on other species suggest that our findings might indicate it takes more mutations to retain or evolve a darker phenotype than it does for a lighter phenotype. Mc1r is influenced by other genes, therefore studies on the genetics of these primates focusing on genes such as KIT or ASIP, will help in understanding the evolution of coat color and pattern in these primates.

Often, when attempting to understand human evolution, the living primates that most closely resemble the base of the phylogeny of Primates are overlooked. Yet, we cannot build a strong foundation of interpreting human evolution if our base is weak. More research is needed on cryptic primates, such as tarsiers and lorises, not only to improve our understanding of them, but also to improve our understanding of primate evolution in general. Expanding research on a larger scale will help in better understanding their evolution and phylogenies. Increasing the number of genes used may better explain the muddled evolutionary history of Lorisidae. We found them to be monophyletic, but using SNPS, or a genome-wide approach will only further enhance our understanding. In addition, getting samples from wild-caught species will shed light on the hidden diversity of these primates. The Asian Lorisinae have received a lot of attention regarding their diversity, due to their striking coat colors and patterns, but little attention has been given to the African Perodictinae. The Perodictinae may all look alike, and therefore lack species variation, but further work is needed to investigate if these primates are more diverse than assumed. 
Other avenues of research should explore the evolution of candidate genes on Lorisidae, and other primates, particularly genes that do impact coat variation such as KIT or ASIP. These studies will help us understand the possible adaptive importance of coat color and variation we see in so many non-human primates. Also, it may explain how complexion (fair, dark) varies among taxa and the selective pressures that such variation undergoes. We know this is under selection in humans and other organisms, but few studies have explored this in non-human primates. Future studies should explore if such variation faces selection and how and why.

Finally, although allometry is not a new method, the application of it to explore differences in subtle, cryptic species is powerful. Incorporating such analyses on other organisms, like Lorisiade or small-bodied cryptic primates will be essential in explaining how these primates have changed as they have increased or decreased in size. Our research has demonstrated how useful it can be in quantifying size and shape differences among quite similar species. This same methodology could be applied to other species that lack clear distinguishing phenotypes, like pottos, to assess variation within. It can also help us interpret the variation observed and what might be the evolutionary mechanisms constraining diversity.

Cryptic species are getting more attention, and much of this is because of the incorporation of genetics and application of new tools of analyses. Improving our understanding of these species is not only beneficial to understanding evolutionary processes, but also it is vital to conserve species. The world is facing a sixth extinction crisis (Leakey, 1996; Ceballos et al., 2015, 2017; Estrada et al., 2018), and if we are unable to recognize the diversity in the world then is is plausible we will lose species that 
were never recognized. By applying tools to understand phylogenetic relations, detect subtle differences among taxa, and eventually determine what impacts the fitness of an organism, we will be able to better conserve species. 


\section{Literature Cited}

Ceballos G, Ehrlich PR, Barnosky AD, García A, Pringle RM, Palmer TM. 2015. Accelerated modern human-induced species losses: Entering the sixth mass extinction. Sci Adv 1:e1400253.

Ceballos G, Ehrlich PR, Dirzo R. 2017. Biological annihilation via the ongoing sixth mass extinction signaled by vertebrate population losses and declines. Proc Natl Acad Sci U S A 114:E6089-E6096.

Cunninghame Graham DS, Vyse TJ. 2004. The candidate gene approach: have murine models informed the study of human SLE? Clinical \& Experimental Immunology $137: 1-7$.

Estrada A, Garber PA, Mittermeier RA, Wich S, Gouveia S, Dobrovolski R, Nekaris KAI, Nijman V, Rylands AB, Maisels F, Williamson EA, Bicca-Marques J, Fuentes A, Jerusalinsky L, Johnson S, de Melo FR, Oliveira L, Schwitzer C, Roos C, Cheyne SM, Kierulff MCM, Raharivololona B, Talebi M, Ratsimbazafy J, Supriatna J, Boonratana R, Wedana M, Setiawan A. 2018. Primates in peril: the significance of Brazil, Madagascar, Indonesia and the Democratic Republic of the Congo for global primate conservation. PeerJ 6:e4869.

Groves C, Shekelle M. 2010. The Genera and Species of Tarsiidae. Int J Primatol 31:1071-1082. 
Hoekstra HE, Drumm KE, Nachman MW. 2004. Ecological genetics of adaptive color polymorphism in pocket mice: geographic variation in selected and neutral genes. Evolution 58:1329-1341.

Hoekstra HE, Nachman MW. 2003. Different genes underlie adaptive melanism in different populations of rock pocket mice. Mol Ecol 12:1185-1194.

Klingenberg CP. 1998. Heterochrony and allometry: the analysis of evolutionary change in ontogeny. Biol Rev Camb Philos Soc 73:79-123.

Klingenberg CP. 2016. Size, shape, and form: concepts of allometry in geometric morphometrics. Dev Genes Evol 226:113-137.

Klingenberg CP, Zimmermann M. 1992. Static, Ontogenetic, and Evolutionary Allometry: A Multivariate Comparison in Nine Species of Water Striders. Am Nat 140:601-620.

Leakey RE. 1996. The Sixth Extinction: Patterns of Life and the Future of Humankind. Anchor.

Rokas A, King N, Finnerty J, Carroll SB. 2003. Conflicting phylogenetic signals at the base of the metazoan tree. Evolution and Development 5:346-359.

Springer MS, DeBry RW, Douady C, Amrine HM, Madsen O, de Jong WW, Stanhope MJ. 2001. Mitochondrial versus nuclear gene sequences in deep-level mammalian phylogeny reconstruction. Mol Biol Evol 18:132-143. 


\section{Appendix 1-Supplemental Figures for Chapter 3}

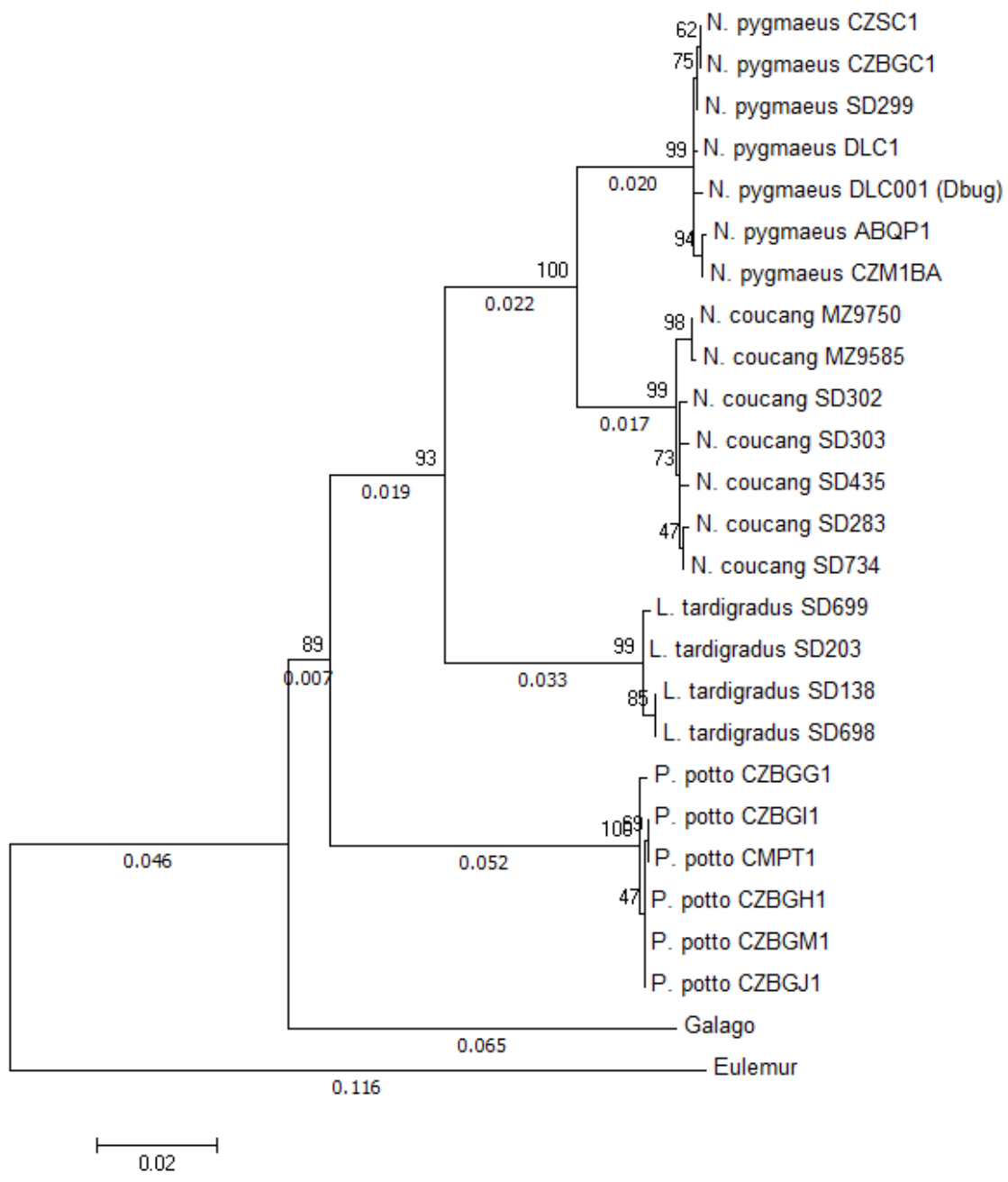

Figure A3.1: Concatenated maximum likelihood tree of all genes with branch lengths proportional to the estimated branch lengths. Node supports are showing on top of branches, by the clade. Branch lengths are shown below the branches. 


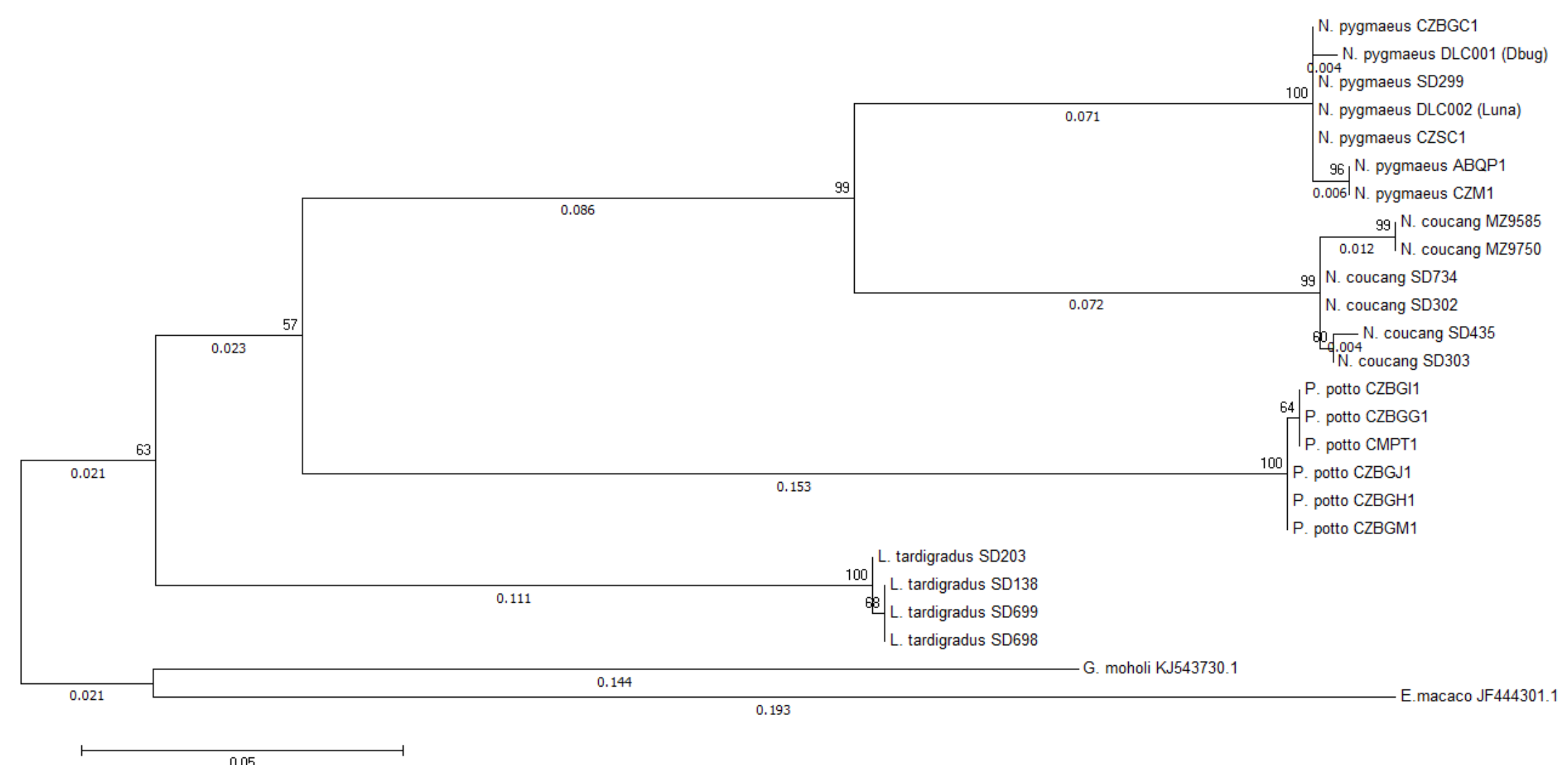

Figure A3.2: Concatenated Cytochrome c oxidase subunit 1 and cytochrome $b$ maximum likelihood tree with branch lengths proportional to the estimated branch lengths. Node supports are showing on top of branches, by the clade. Branch lengths are shown below the branches. 


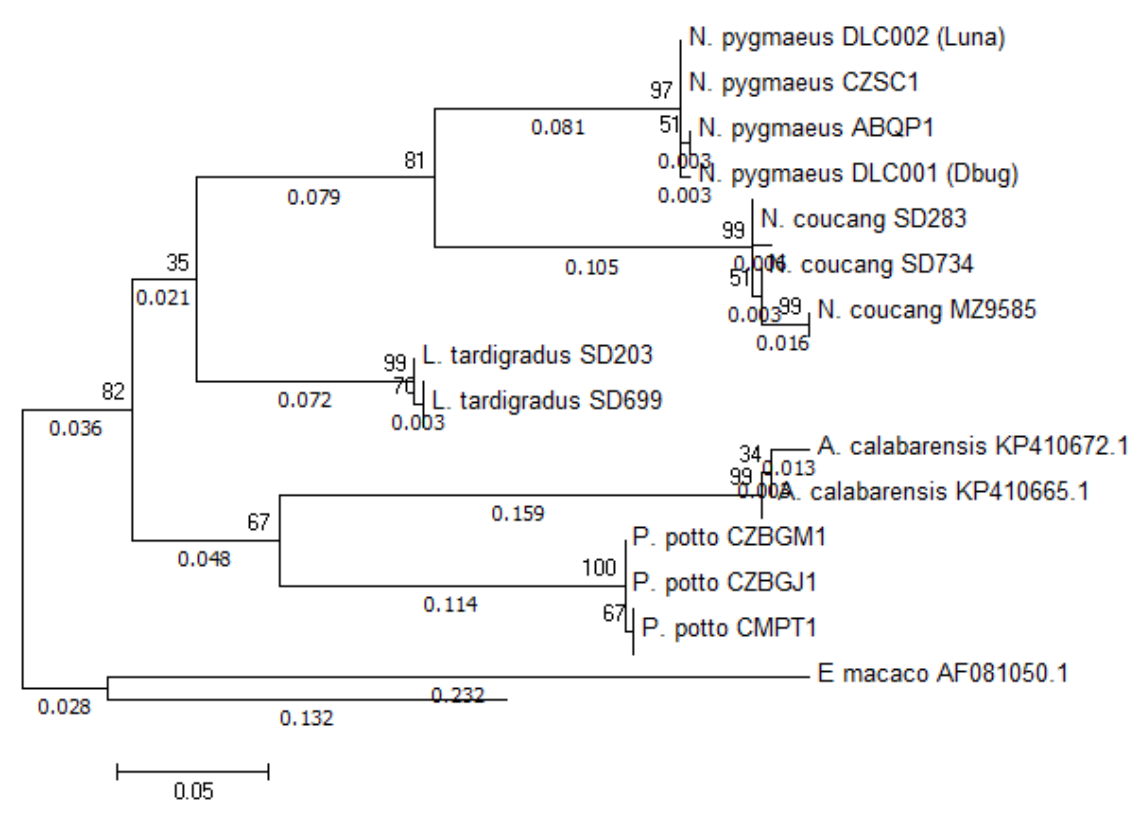

A.

Figure A3.3: Cytochrome b maximum likelihood trees with Arctocebus (A) and without Arctocebus (B). Branch lengths are proportional to the estimated branch lengths. Node supports are showing on top of branches, by the clade. Branch lengths are shown below the branches.

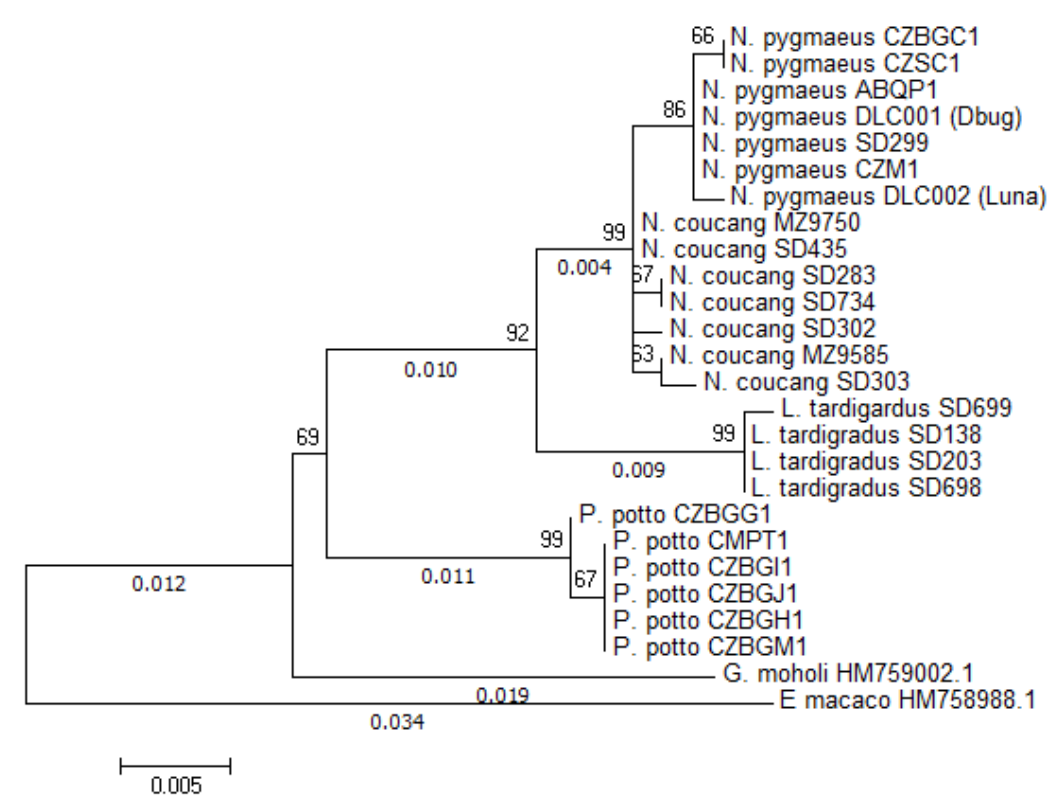

B. 


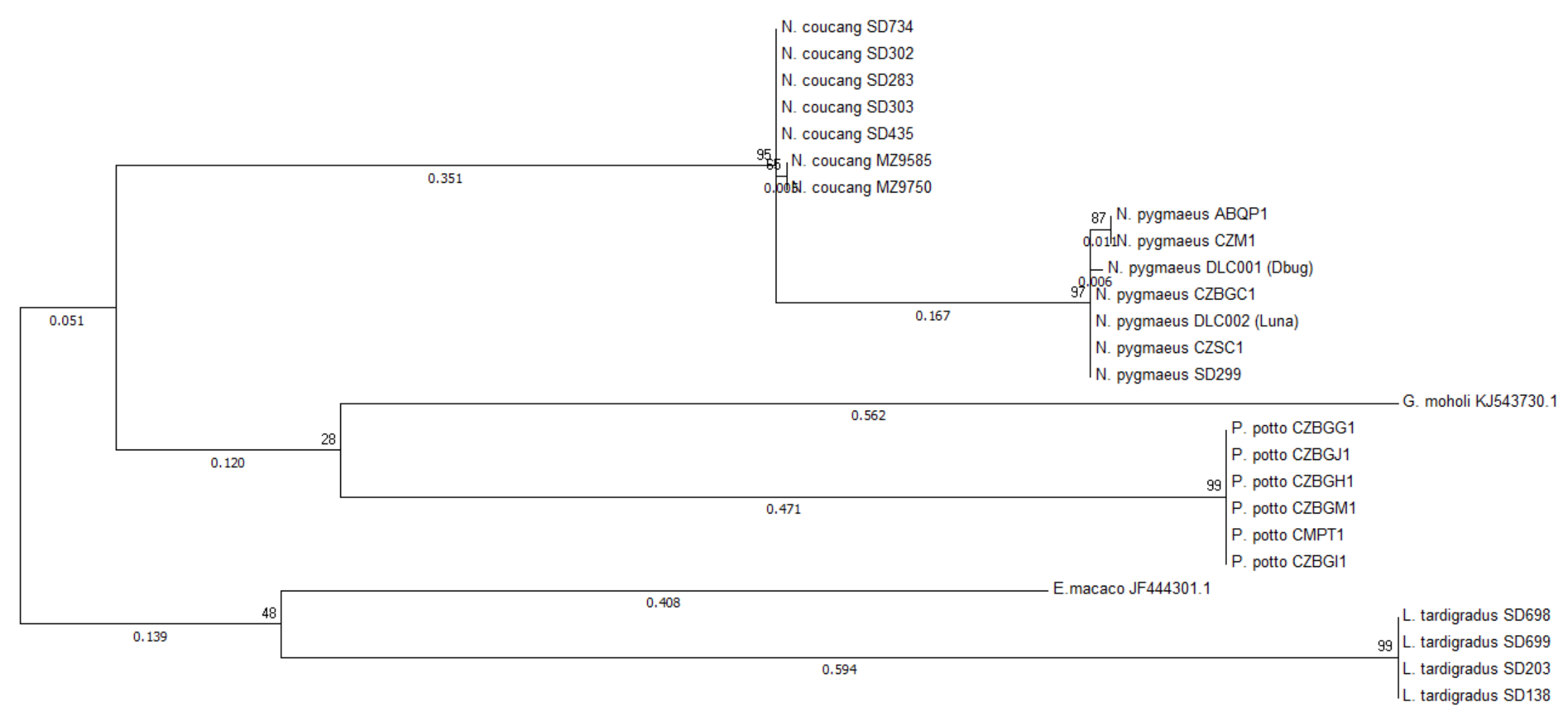

0.1

Figure A3.4: Cytochrome c oxidase subunit 1 maximum likelihood tree with branch lengths proportional to the estimated branch length. Node supports are showing on top of branches, by the clade. Branch lengths are shown below the branches. 


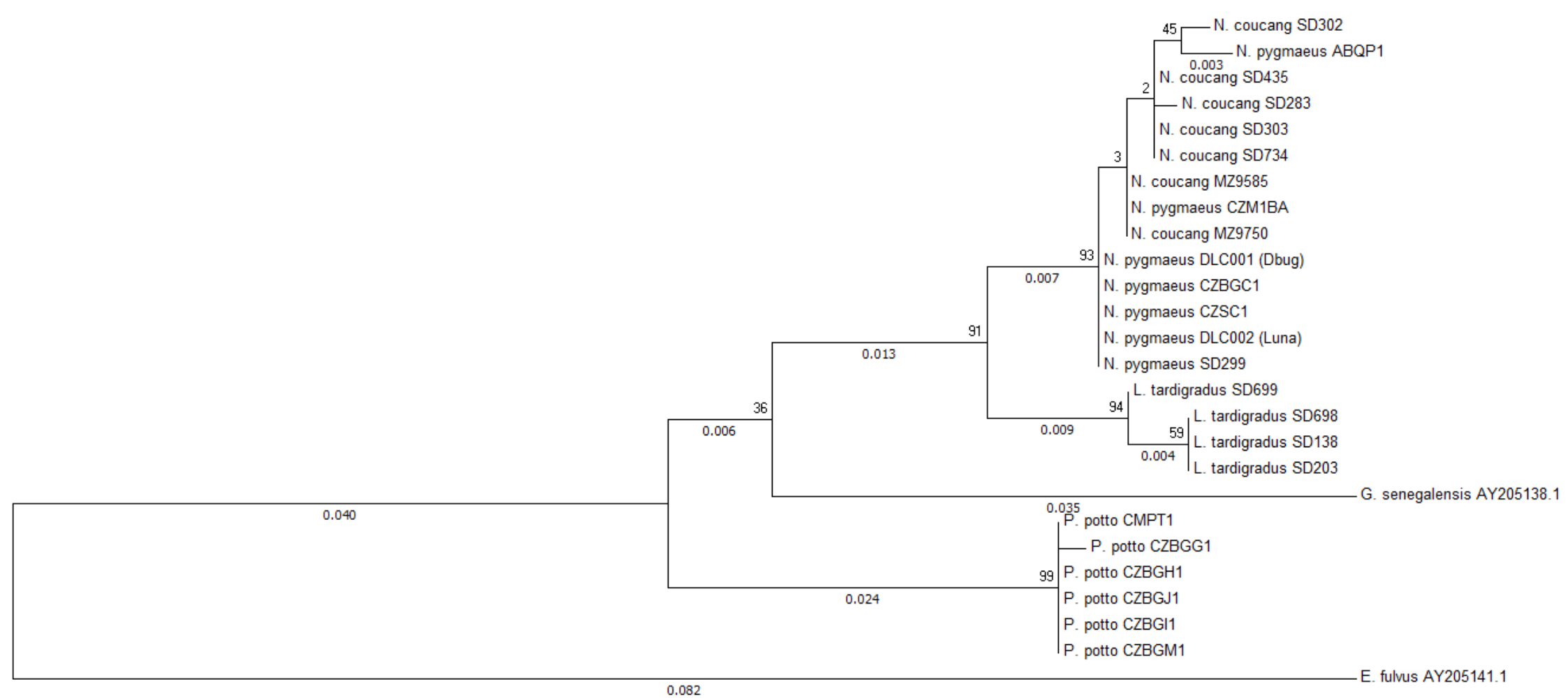

0.082

Figure A3.5: The melanocortin 1 receptor maximum likelihood tree with branch lengths proportional to estimated branch lengths. Node supports are showing on top of branches, by the clade. Branch lengths are shown below the branches. 

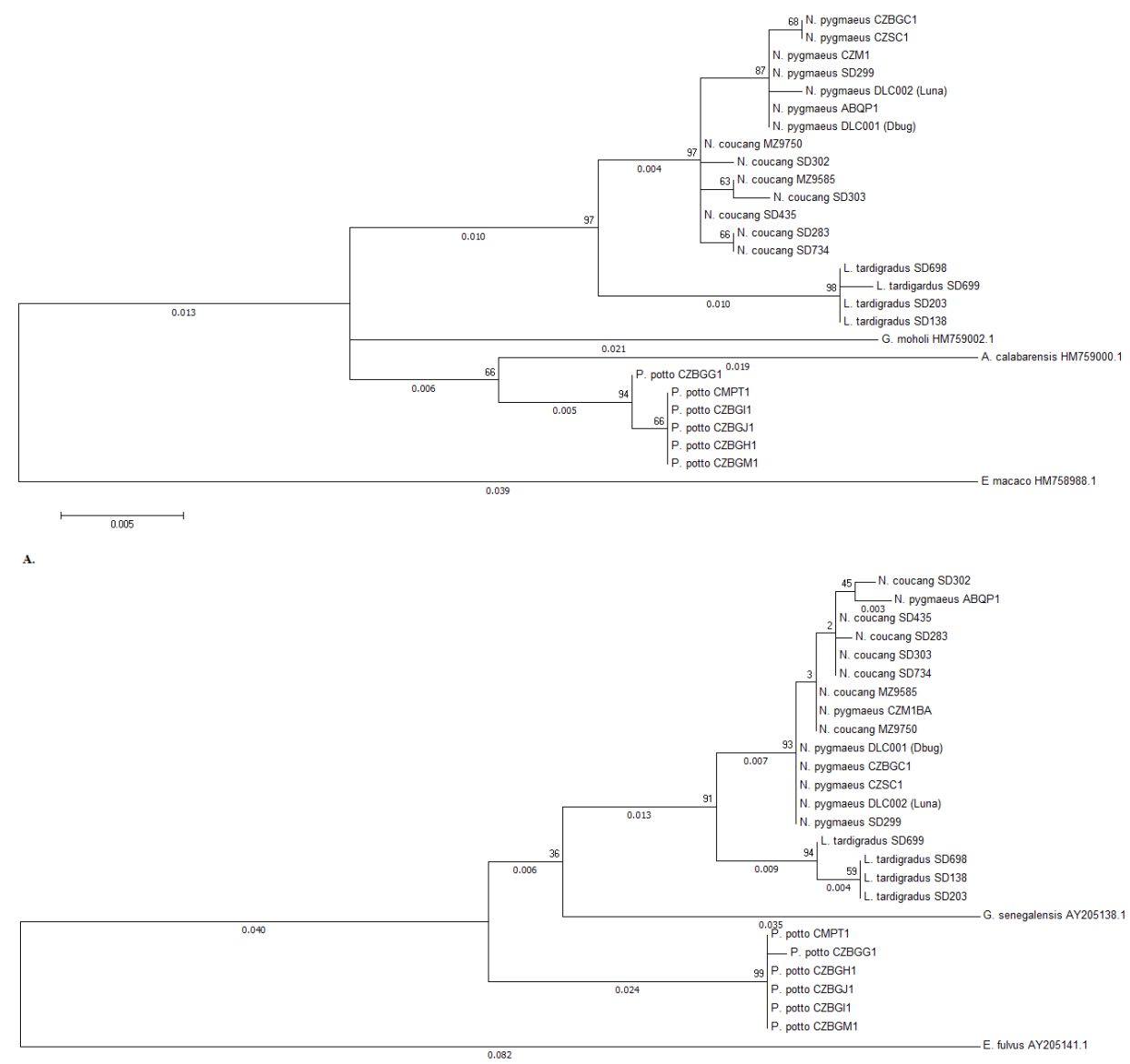

Figure A3.6: Recombination activating gene 2 maximum likelihood trees with Arctocebus (A) and without Arctocebus (B). Branch lengths are proportional to the estimated branch lengths. Node supports are showing on top of branches, by the clade. Branch lengths are shown below the branches. 


\section{VITA}

Rachel A. Munds grew up in rural Illinois. She attended Southern Illinois University, Carbondale where we obtained a BA in Anthropology. She earned an M.Phil. in Primate Conservation from Oxford Brookes University. Her research focused on the diversity, abundance and niche partitioning of Borneo's two nocturnal primates (Nycticebus menagensis and Tarsius bancanus). Her research took her to the rainforests of Malaysia and involved visits to several USA museums where she examined the pelage variation of slow lorises (Nycticebus). Three new species of slow lorises were recognized based on the results of her analyse which resulted in international recognition for her and her coauthors' (Drs. Nekaris \& Ford) work. This path led her to the University of Missouri for her $\mathrm{PhD}$ where she learned how to analyze and conduct genetic research under the guidance of her PhD advisor Dr. Gregory Blomquist and committee member Dr. Lori Eggert. Rachel graduated in 2018 and wants to continue exploring the mechanisms that influence diversity in primates and how they affect selection. 